University of Louisville

ThinkIR: The University of Louisville's Institutional Repository

Electronic Theses and Dissertations

8-2017

\title{
Targeting Fas pathway as an effective means of inducing tolerance to pancreatic islets.
}

Kyle Blake Woodward

University of Louisville

Follow this and additional works at: https://ir.library.louisville.edu/etd

Part of the Other Immunology and Infectious Disease Commons

\section{Recommended Citation}

Woodward, Kyle Blake, "Targeting Fas pathway as an effective means of inducing tolerance to pancreatic islets." (2017). Electronic Theses and Dissertations. Paper 2759.

https://doi.org/10.18297/etd/2759

This Doctoral Dissertation is brought to you for free and open access by ThinkIR: The University of Louisville's Institutional Repository. It has been accepted for inclusion in Electronic Theses and Dissertations by an authorized administrator of ThinkIR: The University of Louisville's Institutional Repository. This title appears here courtesy of the author, who has retained all other copyrights. For more information, please contact thinkir@louisville.edu. 


\title{
TARGETING FAS PATHWAY AS AN EFFECTIVE MEANS OF INDUCING TOLERANCE TO PANCREATIC ISLETS
}

\author{
By \\ Kyle Blake Woodward \\ B.S., Brigham Young University 2009 \\ M.S., University of Louisville 2012

\begin{abstract}
A Dissertation
Submitted to the Faculty of the

School of Medicine at the University of Louisville

in Partial Fulfillment of the Requirements

for the Degree of
\end{abstract} \\ Doctor of Philosophy \\ In Microbiology and Immunology \\ Department of Microbiology and Immunology \\ University of Louisville \\ Louisville, Kentucky
}

August, 2017 
Copyright 2017 by Kyle Woodward

All rights reserved 

TARGETING FAS PATHWAY AS AN EFFECTIVE MEANS OF INDUCING TOLERANCE TO PANCREATIC ISLETS

\author{
By \\ Kyle Woodward \\ B.S., Brigham Young University, 2009 \\ M.S., University of Louisville, 2012 \\ A Dissertation Approved on
}

August 3, 2017

by the following Dissertation Committee:

Dissertation Director: Haval Shirwan, Ph.D.

Dissertation Co-Director: Esma Yolcu, Ph.D.

Committee Member: Haribabu Bodduluri, Ph.D.

Committee Member: Michele Kosiewicz, Ph.D.

Committee Member: Mariusz Ratajczak, M.D., Ph.D., D.Sci. 


\section{DEDICATION}

To my daughter Lily, whose love of learning inspires me.

To my son Ewan, who convinced me to shave off my beard.

To my daughter Ruby, who will always be a baby in my arms, no matter how big she gets.

To my wife Emily, who is the best mom in America and has helped me become a better father. 


\section{ACKNOWLEDGMENTS}

I would like to thank my mentor Dr. Haval Shirwan for his infectious passion for science, his guidance, and his dedication to helping me become a scientist. I would also like to thank my co-mentor, Dr. Esma Yolcu for her detailed teaching and training, and for standing up for my ideas and concerns. I would like to thank m committee members Dr. Haribabu Bodduluri, Dr. Michele Kosiewicz, Dr. Mariusz Ratajczak, and Dr. Paula Chilton for their support and input and for the time they put in to help me. I would like to thank my wife Emily for all of her support and for willingly moving across the country to achieve my dreams. I would like to thank my parents David and Pauline for always pushing me to reach higher. I would like to thank my lab members Hong Zhao, Feng Wang, Pradeep Shrestha, Laura Bandura-Morgan, Gunes Dinc, Hampartsoum Barsoumian, Orlando Grimany, William Bowen, Chris Williams, Helen Min Tan, and Lalit Batra. I would also like to thank the many collaborators who worked with us: Nadir Askenasy, Devon Headen, Jessica Weaver, Christopher Johnson, Lonnie Shea, Andres Garcia, Michael Skoumal, and Ryan Pearson. Finally, I would like to thank the department of Microbiology and Immunology and the Institute of Cellular Therapeutics for providing great mentors, friends, and facilities. 


\title{
ABSTRACT
}

\section{TARGETING FAS PATHWAY AS AN EFFECTIVE MEANS OF INDUCING TOLERANCE TO PANCREATIC ISLETS}

\author{
Kyle Woodward
}

August 8, 2017

Signaling through Fas/FasL is critical to immune homeostasis and tolerance to self-antigens. SA-FasL is a chimeric protein of FasL and streptavidin. SA-FasL exists as oligomers with potent apoptotic function on Fas expressing immune cells and tightly binds to biotinylated surfaces. Islet grafts engineered to transiently display SA-FasL on their surface established tolerance in allogeneic recipients with a short course of rapamycin.

We hypothesized that SA-FasL on the islet allograft will induce apoptosis in alloreactive T effector (Teff) cells and phagocytes clearing apoptotic bodies will produce tolerogenic molecules, such as TGF- $\beta$, that will lead to the generation and/or expansion of Treg cells at the induction phase. Treg cells will then home to allografts in response to inflammatory cues and will be maintained in the graft by alloantigens for long-term graft protection. In support of this hypothesis, we demonstrated reduced alloreactive T cells in the draining lymph nodes of SAFasL-engineered grafts as compared to controls. Depletion of phagocytes or blocking TGF- $\beta$ peri- and immediate post-transplantation of allogeneic SA-FasLislet grafts abrogated tolerance as the grafts were rejected acutely. 
Systemic nature of the tolerance at the induction phase was shown by demonstrating that both un-engineered as well as SA-FasL-engineered islet grafts simultaneously transplanted under the contralateral kidney capsules survived indefinitely. SA-FasL-islets had characteristics of immune privilege as chemical destruction of the long-term graft followed by the transplantation of an un-engineered graft at the same location 4 days later resulted in the protection of the second set graft.

We also tested whether tolerance to allografts requires physical presence of SA-FasL on the graft. To investigate this, we engineered biotinylated poly ethylene glycol (PEG) hydrogel or poly(lactic-co-glycolide) (PLGA) scaffolds with SA-FasL and co-transplanted with unmanipulated allogeneic islets under the kidney capsule or epididymal fat pad, respectively, resulted in indefinite ( $>200$ days) islet survival. Flow cytometry revealed increased amounts of Tregs in the graft and draining lymph nodes in the PEG model. Mice rejected these grafts when Tregs were depleted. Taken together, the studies presented herein elucidate the mechanistic basis of SA-FasL-mediated tolerance and show that SA-FasL-engineered biomaterials are also effective in inducing tolerance. 
TABLE OF CONTENTS

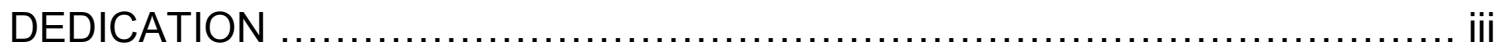

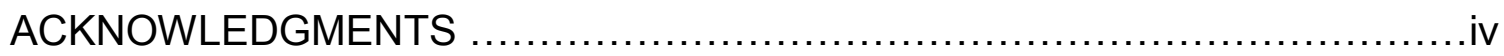

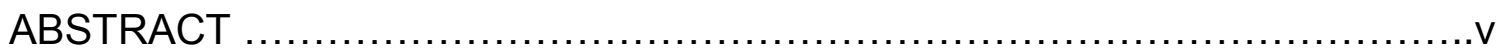

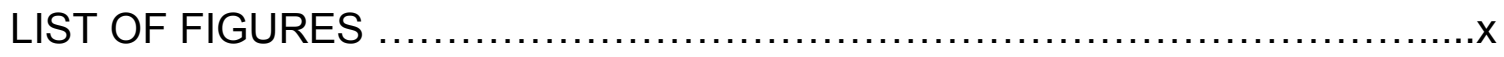

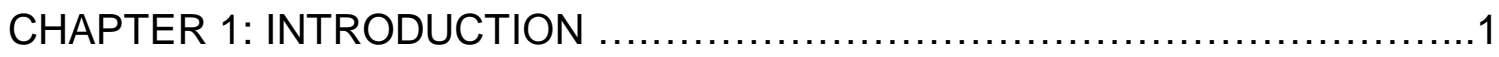

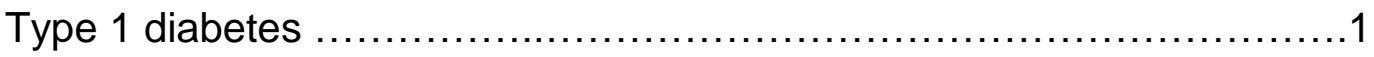

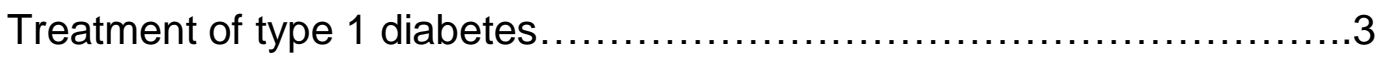

Immune regulation as an approach to induce allotolerance ................. 7

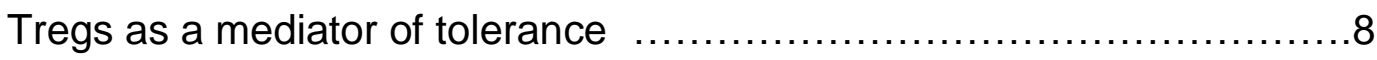

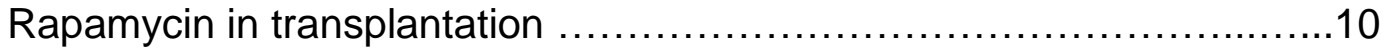

Fas-mediated activation induced cell death (AICD) as a means of

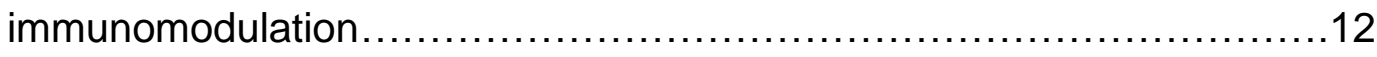

SA-FasL as a novel form of FasL.....................................14

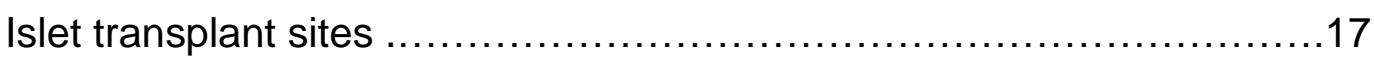

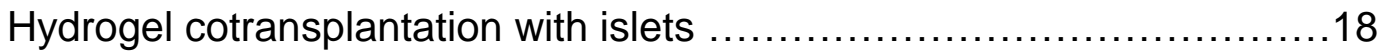

Utilizing scaffolds for alternative transplant sites........................19

CHAPTER 2: SA-FASL-ENGINEERED ISLETS INDUCE A BIPHASIC SPATIOTEMPORAL ALLOTOLERANCE REQUIRING A PHAGOCYTE/TGF-

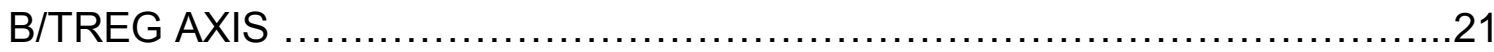


Introduction

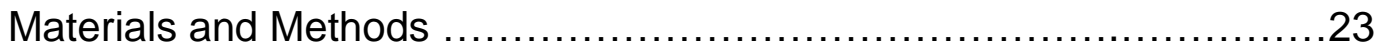

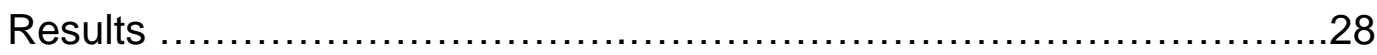

Reduced frequency of proliferating alloreactive T cells in lymph nodes draining FasL-engineered islet grafts 28

Systemic donor-reactive responses persist despite long-term islet graft acceptance 31

Phagocytes are required for tolerance induction 32

TGF- $\beta$ is required for the induction, but not the maintenance of tolerance 36

Tolerance is systemic at the induction phase and shows both donor and tissue specificity

SA-FasL-engineered islets establish a donor-specific immune privilege site that requires the graft for maintenance 42 Immune privilege cannot be extended to a second set of unmanipulated islet grafts transplanted to a distant site under the cover of rapamycin 45

\section{CHAPTER 3: LOCAL IMMUNOMODULATION WITH SA-FASL-ENGINEERED} BIOMATERIALS ACHIEVES ALLOGENEIC ISLET GRAFT ACCEPTANCE ....47 Introduction

Materials and Methods

Results 52 
SA-FasL-engineered microgels induce apoptosis.

Long-term islet allograft survival induced by SA-FasL-engineered

microgels

Tregs required for long-term survival of islets in mice treated with

SA-FasL-engineered microgels.................................55

Transplantation of SA-FasL modified islets on microporous

scaffolds

FasL scaffolds support allogeneic graft function without sustained immunosuppression 66

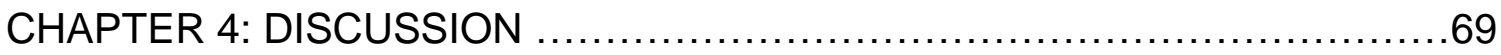

Summary, implications, and future directions...................76

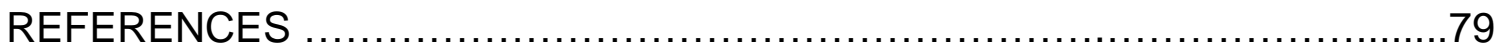

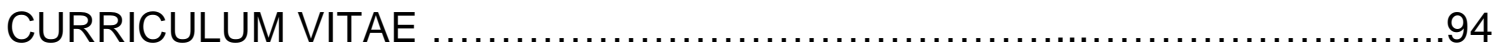




\section{LIST OF FIGURES}

FIGURE

PAGE

1. Schematic diagram of events leading to type 1 diabetes................... 4

2. Schematic diagram of fas/fasl pathway of apoptosis ......................15

3. Engineering cell membranes with SA-FasL ..............................16

4. Graft milieu-localized modulation of alloreactive $T$ cell responses as the prominent feature of tolerance established by SA-FasL-engineered allogeneic islets

5. Liposome encapsulated clodronate depletes both macrophages and immature dendritic cells in mice

6. Depletion of phagocytes or blockade of TGF- $\beta$ at the induction phase of SA-FasL-mediated tolerance results in prompt islet graft rejection

7. Tolerance to SA-FasL-engineered islet grafts is donor-specific and systemic at the induction phase

8. Treg depletion in long-term islet-graft recipients

9. Tolerance induced by SA-FasL-engineered islet grafts evolves into donorspecific immune privilege at the maintenance phase sustained by the presence of graft and Treg cells

10. Microgels for controlled presentation of immunomodulatory proteins 
11. Survival of allogeneic islet grafts co-transplanted with SA-FasL-presenting

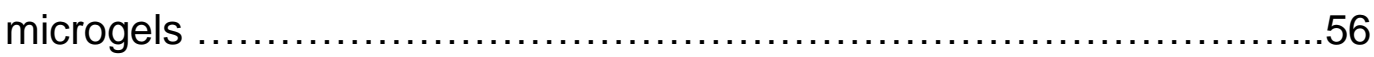

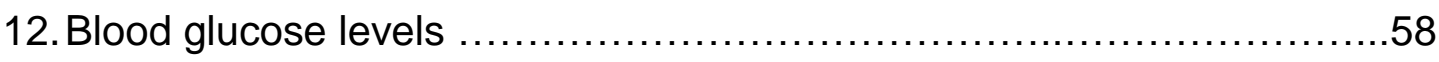

13. Immune monitoring and the role of CD4+CD25+FoxP3+ Treg cells in islet

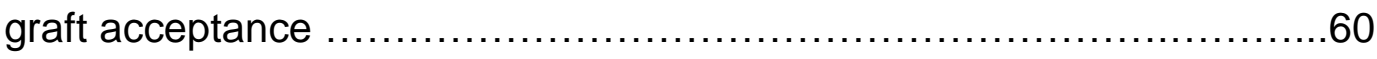

14. SA-FasL engineered islets establish allogeneic tolerance when transplanted on PLGA scaffolds ......................................63

15. Islets on scaffolds conjugated with SA-FasL demonstrate robust long-term

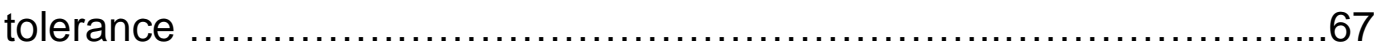




\section{CHAPTER 1: INTRODUCTION}

\section{Type 1 diabetes}

Diabetes affects a rapidly increasing number of people each year. In 2014 , 29 million people in the United States alone suffered from diabetes ${ }^{1}$. It contributes to 200,000 deaths and is estimated to cost $\$ 245$ billion in the US per year ${ }^{1}$. A significant portion (5-10\%) of those with diabetes in the US are afflicted with the autoimmune form known as type 1 diabetes. Diabetes is characterized by hyperglycemia and can contribute to hypertension, blindness, kidney disease, and the need for limb amputations.

Type 1 diabetes is caused by the loss of insulin producing $\beta$ cells in the islets of Langerhans, located in the pancreas. Genetics play a large role in the onset of type 1 diabetes, as several genes have been linked to increased susceptibility. Among the strongest correlations with the disease are MHC genes $^{2,3}$. Further adding to the evidence for the genetic basis of diabetes, in studies examining monozygotic twins where one has type 1 diabetes the second twin was diabetic in approximately $50 \%$ of the pairs of twins in the study $y^{4,5}$.

However, as the concordance rate of type 1 diabetes among monozygotic twins is only around $50 \%$, environmental factors are implicated as another 
contributor to the development of disease. Although the nature and diversity of the environmental factors yet to be fully investigated, viruses are considered one of the main suspects. Coxsackie virus may initiate inflammation and $\beta$ cell antigen shedding leading to type 1 diabetes, as it has been shown to infect human $\beta$ cells in vitro and infection was inhibited by type I and type II interferons $^{6}$. Viral infections can then increase the MHC I expression on the surface of $\beta$ cells, and also lead to the production of inflammatory cytokines, which lead T cells and other leukocytes to attack infected $\beta$ cells and possibly uninfected $\beta$ cells as well ${ }^{7}$. As Non-obese diabetic (NOD) mice spontaneously become diabetic, these mice have been used to study many facets of autoimmune diabetes, which may have parallels to T1D in humans. NOD mice with suppressor of cytokine signaling 1 knocked out (SOCS-1-Tg NOD) become diabetic after infection with Coxsackie virus, further implicating it as a possible trigger for the cascade of events which ultimately leads to $\mathrm{T}^{\mathrm{D}} \mathrm{D}^{6}$.

Later events in that cascade are more studied, as early signs of diabetes can be detected once $\beta$ cell loss is significant enough. In recently deceased human patients suffering from T1D, $\mathrm{CD}^{+}$and $\mathrm{CD} 4^{+} \mathrm{T}$ cells, macrophages, and $\mathrm{CD} 20^{+} \mathrm{B}$ cells are found infiltrating islets in higher levels when compared to nondiabetics $^{8}$. On top of that, $\mathrm{T}$ cells are suspected to play a large role due to genetic screening revealing that HLA genes show the strongest link to T1D in humans, with DR3/4-DQ8 comprising almost $50 \%$ of children with anti-islet autoimmunity by the age of $5^{3}$, implying that $\mathrm{CD} 4^{+} \mathrm{T}$ cells in these patients may play a key role in the destruction of $\beta$ cells. In NOD mice, $C D 4^{+} \mathrm{T}$ cell depletion 
reverses new onset diabetes, further adding weight to the idea that they are a crucial cell type in the development of $\mathrm{T}^{1} \mathrm{D}^{9}$. Furthermore, proinsulin and insulin are major targets of $\mathrm{CD}^{+} \mathrm{T}$ cells and mice transgenic for proinsulin that was modified to eliminate a dominant $\mathrm{CD}^{+} \mathrm{T}$ cell epitope do not develop $\mathrm{T}^{1} \mathrm{D}^{10}$. $\mathrm{CD}^{+} \mathrm{T}$ cells may have a huge part in $\beta$ cell destruction as well, as evidenced by a study showing HLA-A2 $2^{+}$patients have circulating $C D 8^{+} T$ cells that kill $\beta$ cells in vitro by targeting a pre-proinsulin peptide chain ${ }^{2}$. This observation is also supported by mouse studies, as $\mathrm{CD} 8^{+} \mathrm{T}$ cells in NOD mice have been discovered which recognize the insulin $\beta$ chain, and can therefore target $\beta$ cells ${ }^{11}$. See Figure 1 for a schematic diagram of the events leading to islet destruction.

\section{Treatment of type 1 diabetes}

One of the miracles of modern medicine is the availability of insulin to treat diabetes. However, even with insulin administration blood glucose is often difficult to regulate, and thus the severe of long-term effects such as kidney disease and arterial damage leading to limb amputation may still occur with such treatment.

Another option being explored is the prevention of diabetes through early screening and immunosuppression. Genetically at risk children can be positively screened for insulin autoantibodies and islet cell antibodies long before beta cell

destruction is complete $^{12}$. Additionally, when type 1 diabetes is initially diagnosed, there is often a honeymoon period in which administration of insulin 


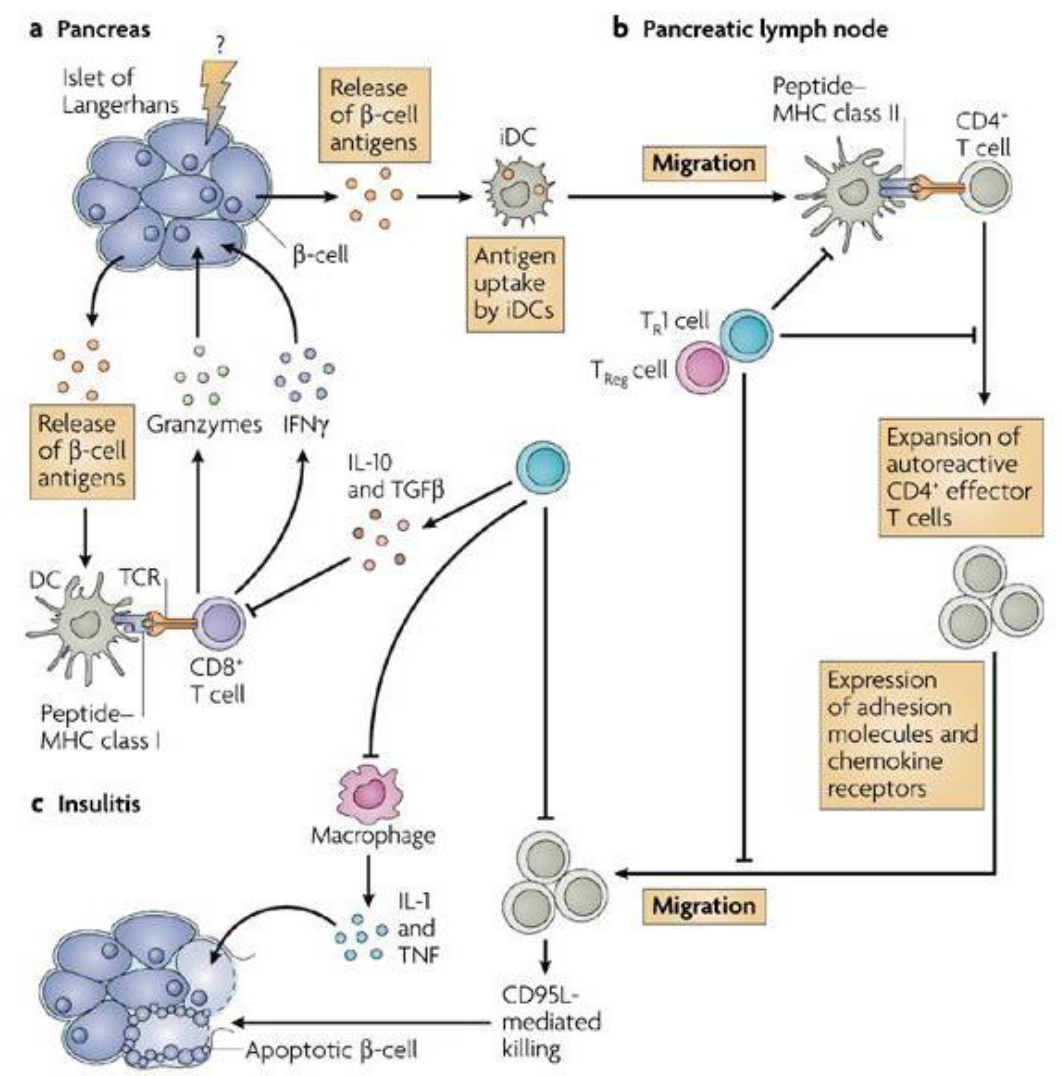

Nature Reviews | Immunology

Figure 1: Schematic diagram of events leading to type 1 diabetes. (A) Islet antigens are released and taken up by DCs, which present to $C D 8^{+} T$ cells which then release destructive granzymes and IFN- $\gamma$. (B) iDCs with the antigens migrate to draining lymph nodes and present to $\mathrm{CD} 4^{+} \mathrm{T}$ cells which expand and prime effector cells. The T cells upregulate adhesion molecules allowing migration into the pancreas. (C) Activated $\mathrm{CD} 4^{+} \mathrm{T}$ cells activate and recruit inflammatory cells to the pancreas. Damage is caused by inflammatory cytokines and direct killing by FasL (CD95L) on $\mathrm{CD}^{+} \mathrm{T}$ cells. Tregs can regulate at any stage, either directly or indirectly through APCs. (Roncarolo et al. Nat Rev Immunol 2007;7:585-598.) 
eases the burden of the few remaining beta cells allowing them to produce insulin. If the autoimmune aspects of type 1 diabetes were regulated at these points, possibly through $\mathrm{T}$ cell suppression, diabetes could theoretically be reversed when the patients recover beta cells and therefore regain sufficient control of blood glucose levels. However, genetic and antibody screening of all children is not yet practical, and no studies have sufficiently prevented diabetes as of yet. For instance, studies with vaccination soon after diagnosis using alum and glutamic acid decarboxylase, a critical protein in autoimmune diabetes, found no significant reduction in insulin production loss among other factors, in direct contrast to animal models which show vaccination to a target antigen to be tolerizing $^{13,14}$. Therefore, I do not see this as an alternative to transplantation, but rather a potential treatment option.

A fourth option for treatment of type 1 diabetes is transplanting of beta cell containing islets from healthy donor pancreas. Successful transplantation of islets is an effective cure of T1D, and working out protocols which allow the patient to retain the transplant are therefore currently a focus in T1D research. The current leading clinical protocol, the Edmonton Protocol, is able to restore control of blood glucose through intraportal transplant of islets ${ }^{15}$. Despite the great success of the Edmonton Protocol, it is still far from an ultimate solution to type 1 diabetes. Upon following the patients, only $31 \%$ retained insulin independence after two years, and $10 \%$ after five years ${ }^{15,16}$.

Islet transplants under this protocol are done by injecting islet cells directly into the portal vein. This is very convenient, bypassing the need for surgery, and 
as islets are in contact with the blood stream they may easily detect blood glucose levels and secrete insulin into the blood in response. However, such direct injection into the portal vein leads to the instant blood mediated inflammatory reaction, in which a large amount of islets are swiftly destroyed ${ }^{17,18}$. This is characterized by platelets binding the islets, coagulation, infiltration of

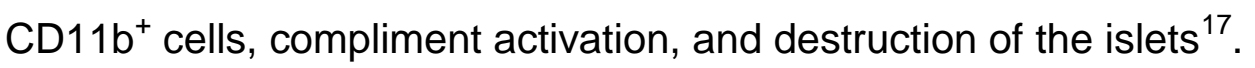

In order to compensate for the islets to this instant blood mediated inflammatory reaction, more islets must be transplanted in the beginning. This may require up to four donors to have islets pooled together in order to gain successful insulin independence ${ }^{19}$. This may be somewhat obviated by transplanting islets in another location, however, no suitable replacements for intraportal transplantation have been sufficiently researched for clinical islet transplants as of yet.

In addition to the immediate loss of islets due to instant blood mediated inflammatory reaction, there is a slower loss due to the immune response. Under the Edmonton Protocol, multiple donors are required for a single transplant, giving a large chance that one or more of the sets of donated islets will not be HLA matched. As with many mismatched transplants, effector T cells can soon destroy the graft without proper immunosuppressive drugs. Those used in this protocol are daclizumab, rapamycin, and tacrolimus. Daclizumab is an IL-2 receptor monoclonal antibody which inhibits IL-2 uptake in effector T cells, blocking proliferation and growth. This also blocks IL-2R on regulatory Tregs, and therefore may have conflicting effects. Rapamycin, also known as sirolimus, 
works through inhibition of mTOR, which in turn inhibits effector T cells and is known to induce regulatory $\mathrm{T}$ cells in vitro. Tacrolimus is a calcineurin inhibitor that blocks IL-2 production in T cells. Altogether, these drugs are effective at stopping much of the $\mathrm{T}$ cell response that would quickly eliminate transplanted islets. However, increasing evidence shows that long-term use of tacrolimus and rapamycin as per the Edmonton Protocol causes damage to kidneys and islets, suggesting that these drugs may be counterproductive ${ }^{20,21}$. In addition, such immunosuppression weakens the body's natural defense against tumors and infections.

\section{Immune regulation as an approach to induce allotolerance}

Despite their toxic effects, these drugs must be used under the current protocol in order to keep T cell mediated rejection under control. In addition, autoreactive $\mathrm{CD}^{+}$and $\mathrm{CD}^{+} \mathrm{T}$ cells have already established $\beta$-cell autoimmunity in T1D patients. As such, how can effector T cells be kept in check? There are several methods already existing in the immune system to stop or control rogue $\mathrm{T}$ cells, including the deletion of $\mathrm{T}$ cells in the thymus, known as central tolerance. This is brought about by APCs such as medullary thymic epithelial cells or dendritic cells in the thymus presenting antigen to T cells in the thymus $^{22}$. T cells that tightly bind to self-antigens presented by MHC class I or class II are deleted before being allowed to escape to the periphery and cause damage. 
While this system has been extensively studied as a preemptory mechanism to control autoimmunity, its validity has also been shown in transplant settings. In a rat allogeneic islet transplant model, Posselt et al. showed that allogeneic islets transplanted into the thymus survived indefinitely through deletion of alloreactive $\mathrm{T}$ cells ${ }^{23}$. This central tolerance translated into systemic tolerance, as a second set of donor-matched islets transplanted under the kidney capsule of the thymically manipulated rats also survived without further immune intervention.

Relevant to the context of this thesis are studies with bone marrow mixed chimerism to induce tolerance. Mixed chimeras were shown to be tolerant to both the donor and recipient antigens established by thymic deletion of responding $\mathrm{T}$ cell clones $^{24}$. The presence of a functional Fas ligand protein (FasL, CD95L) on the surface of donor bone marrow cells was shown to be requisite for the induced tolerance ${ }^{25,26}$.

\section{Tregs as a mediator of tolerance}

Immune tolerance to self-antigens is maintained not only by central tolerance through the deletion of autoreactive $T$ cells in the thymus, but also by several peripheral mechanisms. $\mathrm{CD} 4^{+} \mathrm{CD} 25^{+} \mathrm{Foxp}^{+}$regulatory cells (Tregs) are critical to peripheral tolerance mechanisms ${ }^{27}$ as the lack of these cells or defects in their function results in massive autoimmunity in humans and rodents ${ }^{28,} 29$. Tregs are either developed in the thymus (tTregs) or induced in the periphery 
(pTreg). Tregs express several markers which aid in their suppressive function, including CTLA-4, ICOS, and LAG-3 ${ }^{30}$ and suppress not only T effector cells, but various other immune effector cells, such as NK cells, B cells. Tregs suppress target cells through cell-to-cell contact as well as various immunosuppressive cytokines, such as IL-10 and TGF- $\beta$, or through competition for IL-2, a cytokine required for the generation, expansion, and function of Tregs ${ }^{31}$.

Importantly, Tregs have been shown to suppress autoimmune diabetes in the BDC2.5/NOD mouse model ${ }^{32}$. These mice are genetically modified to contain a CD4 ${ }^{+} \mathrm{T}$ cell population which is specific for $\beta$ cell antigen, however they are kept in check by regulatory cells, blocking the onset of diabetes in young BDC2.5/NOD mice. When Tregs in 5-week-old BDC2.5/NOD mice are depleted through diphtheria toxin receptor expressed under the control of FOXP3 promotor, and therefore, Treg specific, they acquired overt diabetes in 3-5 days 32. Humans with recent onset of T1D were shown to have normal frequency of Treg cells, yet they have a reduced ability to suppress effector $\mathrm{T}$ cell proliferation in vitro ${ }^{33}$. Ex vivo expanded Treg cells were shown to prevent and reverse TD in NOD and the expanded cells have been tested in various clinical trials to prevent treat T1D as well as prevent allograft rejection with reported clinical benefits ${ }^{34,35}$.

Important in the context of this dissertation are our published observations that $\mathrm{CD} 4^{+} \mathrm{CD} 25^{+} \mathrm{Foxp}^{+}$regulatory cells are critical to tolerance established by pancreatic islets engineered with SA-FasL ${ }^{27}$. Confocal microscopy revealed an increased number of Tregs located in the long-term allogeneic islet grafts. Tregs were critical not only for the induction, but also maintenance of tolerance. 
Depletion of Tregs with an antibody to CD25 early post-transplantation (day 14) or after long-term tolerance had been established (day 100) resulted in rejection of islet grafts in both groups of mice. The exact mechanisms by which Tregs are generated by SA-FasL and if they are thymic or induced are yet to be elucidated. SA-FasL may shift the balance of Teffs/Tregs in favor of Tregs by selectively inducing apoptosis in Teffs. Consistent with this notion, studies demonstrating that Tregs are more resistant to Fas/FasL mediated apoptosis due to their increased expression of $\mathrm{c}-\mathrm{FLIP}^{36}$ and SA-FasL-engineered Tregs have better regulatory function than the unmanipulated cells in preventing T1D and graft-vshost diseases in preclinical models ${ }^{37,38}$.

\section{Rapamycin in transplantation}

Another pathway to increase Tregs is through TGF- $\beta$ and rapamycin. In vitro, it has been shown that a combination of TGF- $\beta$ and rapamycin converts conventional T cells into Tregs ${ }^{39}$. These converted Tregs are known as induced Tregs (iTregs) if developed in vitro or peripheral Tregs (pTregs) if developed in vivo. Such peripherally generated Tregs are necessary to control autoimmunity, as not all $T$ cells that are able to respond to self-antigen are deleted in the thymus. iTregs have suppressive activity and can be identified by the lack of Helios or Nrp-1 ${ }^{40}$.

Rapamycin also increases the Treg to Teff ratio through suppressing the

growth of effector $\mathrm{T}$ cells, and expanding Tregs ${ }^{41}$. Rapamycin functions by 
inhibiting mammalian target of rapamycin $(\mathrm{mTOR})^{42}$. Deletion of mTOR in mice $\mathrm{T}$ cells causes them to spontaneously become iTregs ${ }^{43}$. Rapamycin is currently in use as an immunosuppressive drug in the Edmonton Protocol, one of the leading protocols on islet transplantation ${ }^{44}$. However, in current use, it must be administered long-term in order to stave off rejection. During such long-term use, rapamycin is toxic to $\beta$-cells, reducing their insulin secretion, mass, and proliferation, while increasing their autophagy and apoptosis ${ }^{45,46}$. Therefore, the time of rapamycin administration must be shortened drastically or eliminated in order for a favorable outcome in the cure of diabetes.

Other methods of increasing the Treg:Teff cell ratio include IFN- $Y$ and indoleamine 2,3-dioxygenase (IDO) ${ }^{47}$. Despite the fact that it is thought of as an inflammatory cytokine, sustained IFN- $\gamma$ activity can be tolerogenic. IFN- $\gamma$ has been shown to activate IDO production in $\mathrm{DCs}^{48}$. IDO is an enzyme that catalyzes the degradation of tryptophan, and as such may starve $T$ cells and prevent their activation and proliferation. IDO also has been shown to induce $\mathrm{CD}^{+} \mathrm{T}$ cells to become regulatory $\mathrm{T}$ cells. The observed synergy between SAFasL and rapamycin may operate through DC expression of IDO in response to rapamycin and IDO initiating a forward regulatory loop resulting in the generation of Tregs ${ }^{47}$. Rapamycin has also been shown to work in conjunction with another anti-inflammitory cytokine, $\mathrm{IL}-10^{49}$. This combination of treatment induces $\mathrm{T}$ regulatory type one (Tr1) cells which have proven to aid in tolerance in islet transplantation $^{49}$. 
Rapamycin also affects $B$ cell proliferation ${ }^{50}$. It blocks entry into the $S$ phase of cell growth in B cells, and inhibits differentiation into plasma cells ${ }^{50}$. As a result, less anti-donor antibodies are generated. This three pronged tolerance induction through inhibition of $B$ and $T$ cell responses and the increase in Treg responses make rapamycin an ideal immunomodulatory drug.

\section{Fas-mediated activation induced cell death (AICD) as a means of immunomodulation}

Fas is expressed in the thymus, heart, and liver ${ }^{51}$, and notably on the surface of activated $B$ and T cells. FasL is found on the surface of activated T cells and NK cells, as well as in immune privilege sites such as testis and eye ${ }^{52}$. The interaction of Fas with FasL is a critical mechanism of immune homeostasis and self-tolerance through activation-induced cell death (AICD). Mutations in affecting the function of Fas or FasL result in hyper proliferation of lymphocytes and autoimmunity, suggesting that the Fas pathway has a non-redundant function vital to immunoregulation ${ }^{53,54}$. Fas pathway was also shown to be important to immune privilege status of various organs, such as eyes and testicular tissues ${ }^{55}$. Fas/FasL-interaction was also demonstrated to be involved in acquired tolerance to tumors. Many tumors express FasL as a mechanism of immune evasion by inducing apoptosis in T effector cells responding to tumor associated antigens ${ }^{56}$. As such, the Fas pathway has great potential to regulate immune response and has been the subject of intense research. 
In addition to naïve $\mathrm{T}$ cells becoming activated in response to encounters with donor cells, humans and nonhuman primates have preexisting memory $\mathrm{T}$ cells from previous infections which can also cross-react with transplants, known as heterologous immunity ${ }^{57,58}$. These memory cells in humans and nonhuman primates express $\mathrm{Fas}^{59,60}$. In addition, both $\mathrm{CD}^{+}$and $\mathrm{CD}^{+}$memory cells are sensitive to Fas/FasL mediated apoptosis ${ }^{61,62}$.

In researching just how fundamental apoptosis is to inducing peripheral tolerance, $\mathrm{Li}$ et al. found that blocking apoptosis with cyclosporin A inhibits allograft tolerance even with costimulatory blockade ${ }^{63}$. However, attempts to harness the power of Fas/FasL in order to cause apoptosis of donor reactive $T$ cells have met with mixed results. Use of an agonistic Fas antibody in mice induced apoptosis, but had the side effects of liver toxicity and death, presumably because of the expression of Fas on liver tissue ${ }^{64}$.

In utilizing gene therapy to manipulate apoptosis of donor reactive T cells, FasL overexpression on heart grafts surprisingly accelerated rejection with a massive increase in neutrophil infiltration into the graft ${ }^{65}$. Upon further study, it was found that FasL is cleaved from the membrane through matrix metalloproteinases ${ }^{66,67}$, and that chemotaxis of neutrophils is activated by the soluble form of FasL, and not the membrane bound form ${ }^{68,69}$. In addition, membrane bound FasL is effective at inducing apoptosis, but soluble FasL actually blocks apoptosis in T cells ${ }^{70}$. Therefore, the use of FasL as an effective immune regulatory will require separation of its apoptotic function from 
chemotactic and anti-apoptotic functions. See Figure 2 for a schematic diagram of Fas/FasL induced apoptosis.

\section{SA-FasL as a novel form of FasL}

In order to combat these problems in inducing tolerance to transplants, Yolcu et al. generated a novel form of FasL which lacks the cleavage site and is fused with streptavidin to form a chimeric protein $(S A-F a s L)^{71}$. This novel molecule has two important features; i) forms oligomers owing to the structural features of streptavidin and ii) binds to biotinylated biologic and non-biologic surfaces for transient display (Figure 3). Several studies have shown the feasibility of attaching SA-FasL to biotinylated islets, cardiac tissue, or splenocytes ${ }^{72-74}$. Importantly, immunomodulation with SA-FasL-engineered cells and tissues resulted in apoptosis of alloreactive T cells and induction of tolerance without detectable chemotactic function for neutrophils ${ }^{74}$.

In the context of islet transplantation as a cure for type 1 diabetes, we showed that rapamycin as an mTOR inhibitor works in synergy with SA-FasL to induce robust tolerance as all SA-FasL-engineered islet grafts survived in chemically diabetic allogeneic recipients for 500 days $(n=45)^{74}$. This compelling observation lead us to investigate the underlying mechanism(s) of the long term survival of islet grafts. Since rapamycin administration is stopped 14 days after transplant in this protocol, and SA-FasL is almost completely absent from the surface of cultured islets 11 days after engineering, the long term survival must rely on a third regulatory mechanism. 


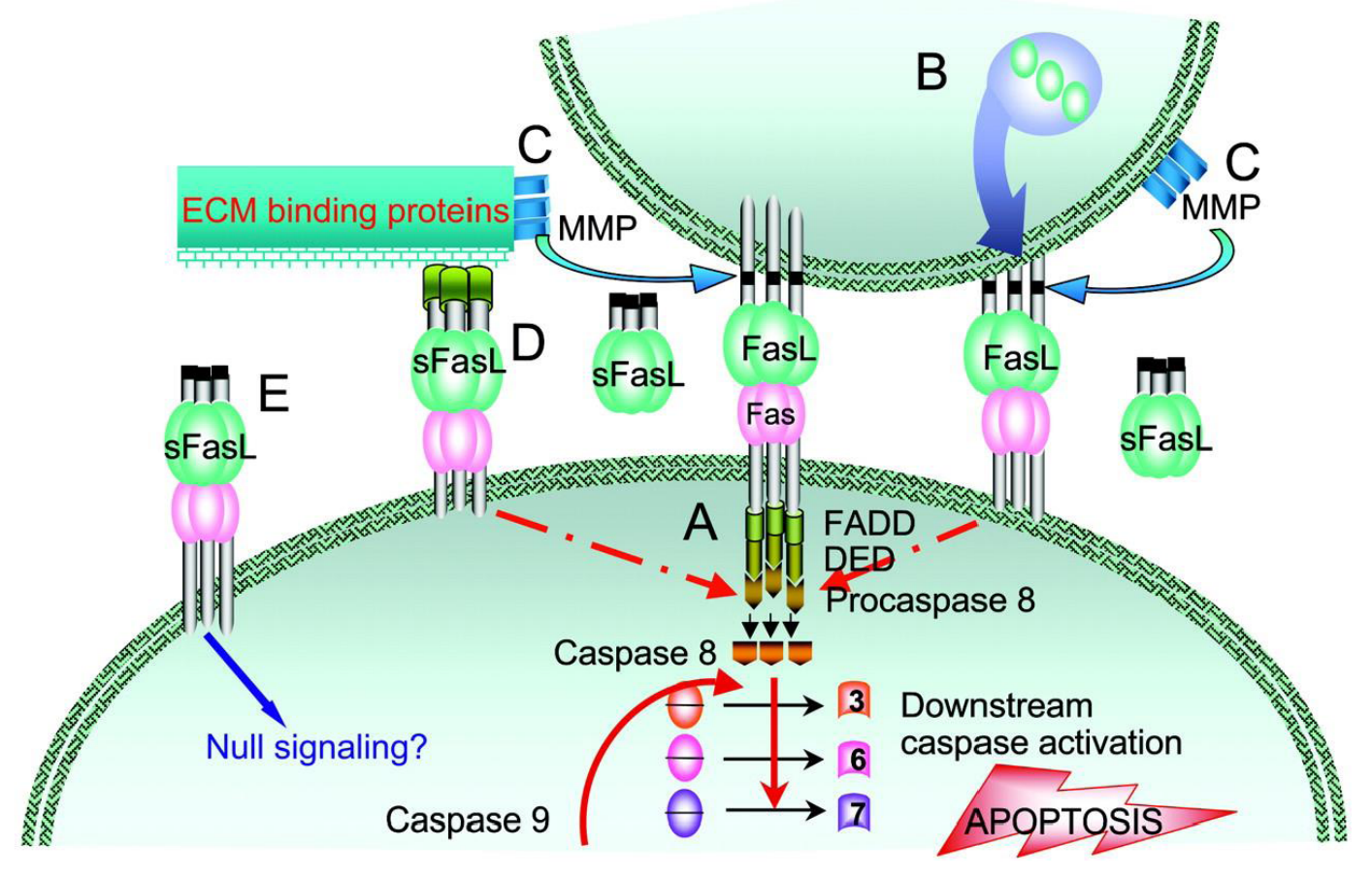

Figure 2 Schematic diagram of Fas/FasL pathway of apoptosis. (A) Trimeric binding of FasL and Fas at the cell membrane recruits Fas-associated protein with death domain (FADD) and procaspasae-8. Procaspase-8 is then autocatalyzed and converts procaspases- $3,-6$, and -7 into their active states. (B) FasL is synthesized in vesicles and stored until excreted. (C) Matrix metalloproteinases (MMPs) cleave FasL from the cell membrane resulting in soluble FasL (sFasL). (D) sFasL may transiently induce signaling while interacting with extracellular matrix proteins. (E) sFasL blocks membrane bound FasL from binding Fas and is ineffective at inducing signaling. (Askenasy et al. Blood 2005;105:1396-1404.) 


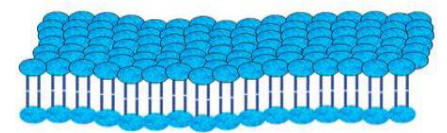

Cell membrane

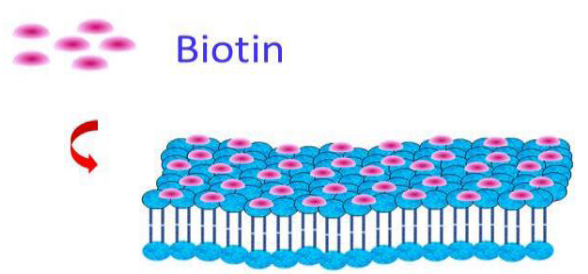

Biotinylated cell membrane

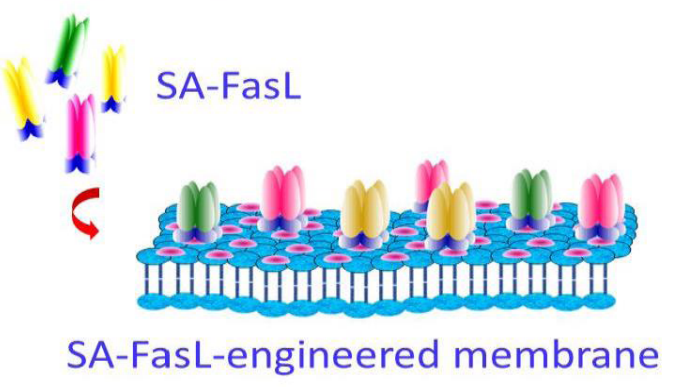

Figure 3: Engineering cell membranes with SA-FasL. Cell membranes bind to biotin when incubated together. Biotinylated membranes bind tightly to SA-FasL allowing the display of SA-FasL on their surface. (Schabowsky et al. Exp Mol Pathol. 2009;86:198-207.) 


\section{Islet transplant sites}

Infusion of islets through portal vein into the liver is the only site being practiced in the clinic. Intraportal transplants are effective in creating an environment in which islets can sense blood glucose and secrete insulin with appropriate response levels. Intraportal injection of islets also obviates the need for surgery, as islets are directly injected into the portal vein. In addition, intraportal transplant protocols may be the most well studied in humans. However, intraportal transplants may not yield the best environment for islets, mainly due to the instant blood-mediated inflammatory reaction, which causes the death of many islets soon after transplantation ${ }^{17}$. Another downside is the higher concentration of toxic immunosuppressive drugs in the liver.

Therefore, other locations have been explored in clinical transplantations including intramuscular ${ }^{75}$, intraperitonea ${ }^{76}$, and intrabone ${ }^{77}$ injections of islets. As of yet these are still experimental procedures, but they are an important step towards discovering the optimal transplantation site which minimizes instant blood mediated inflammatory reaction and toxicity of immunosuppressive drugs. In the context of the recent developments using biomaterials as delivery vehicles and for encapsulation of islets or immunomodulation, liver is not a suitable transplant site. As such, there is a great need for the development of transplant sites as alternatives to intraportal transplantation that will be clinically applicable and lack the complications of transplantation into the liver. 


\section{Hydrogel cotransplantation with islets}

Hydrogels are cross-linked polymer networks that are highly hydrated. There are various types of hydrogels with different chemical content or polymerization features suitable to the targeted applications. Hydrogels allow incorporation of various bioactive functionalities at specific concentrations in order to affect the environment. For example, hydrogels incorporated with vascular endothelial growth factor (VEGF) slowly released the protein over several days and stimulated cells in culture ${ }^{78}$.

Among various hydrogels, polyethylene glycol (PEG) has great potential for use in transplantation due to its safety for in vivo use and low inflammationcausing profiles $^{79}$. One PEG hydrogel in particular, maleimide-terminated 4-arm poly(ethylene) glycol (PEG-4MAL), was generated to take advantage of these attributes in an islet transplantation setting ${ }^{80}$. As the name suggests, PEG-4MAL is formed from a 4-arm macromer of PEG-MAL. This is then incubated with an RGD peptide with a c-terminal cysteine, allowing for cell adhesion. PEG-4MAL was then conjugated with VEGF and cross-linked into a hydrogel ${ }^{81}$. VEGF was tested for its ability to induce angiogenisis, which is necessary for islets to get the maximum level of engraftment and function. Encapsulation of islets in VEGF conjugated PEG-4MAL hydrogels and delivery into small bowel mesentery in rats resulted in engraftment, vascularization, and insulin production over the course of four weeks ${ }^{81}$. PEG-VEGF has also been shown to be effective at modifying vascularization and reducing inflammatory leukocyte recruitment at the graft 
when transplanted with a single donor set of islets in the epididymal fat pad in mice and improved survival of the graft ${ }^{82}$.

Hydrogels provide a flexible and desired platform to deliver SA-FasL to the target tissues for immunomodulation. The advantages of this approach are twofold; i) safety due to localized immunomodulation and ii) efficacy since SA-FasL is presented at the target tissue for a robust response. To explore this potential, our lab in collaboration with Andres Garcia lab at Georgia Institute of Technology investigated the efficacy of PEG gels engineered with SA-FasL in inducing tolerance to islet allografts. Garcia lab generated PEG-4MAL macromers with biotin-PEG-thiol to create microgels which are covalently tethered to biotin. These PEG-4MAL biotinylated microgels were shown to bind SA-FasL in a dosedependent manner, release the molecule over the course of weeks in vivo, induce apoptosis in Fas expressing cells in vitro and induce tolerance to unmanipulated allogeneic islets when co-transplanted with SA-FasL-engineered PEGs under the kidney capsule.

\section{Utilizing scaffolds for alternative transplant sites}

As PEG hydrogels cannot be infused into the liver and are not biodegradable, we also collaborated with Lonnie Shea lab at the University of Michigan to use biodegradable and compatible microporous poly (lacto-coglycolide) (PLG) scaffolds developed by this group. The Shea lab previously demonstrated the validity of using PLG scaffolds to transplant islets in abdominal 
adipose tissue ${ }^{83}$. Islets are loaded on this nonencapsulated platform that allows islets to better integrate into the host microenvironment ${ }^{84}$. These scaffolds loaded with syngeneic islet transplants were penetrated by host cells, and islets were revascularized when transplanted in the epidymal fat pad ${ }^{84}$. Importantly, these scaffolds are able to adsorb fundamental extracellular matrix components before transplant, such as collagen and fibronectin, which then aid in a quick restoration of euglycemia in mice ${ }^{85}$.

When used in combination with SA-FasL engineering of islets, PLG scaffolds may synergistically improve islet engraftment and survival in animal models of diabetes. This may work through causing apoptosis of effector T cells, inducing immune privilege at the site of engraftment through mechanisms promoting Treg generation, and avoiding the instant blood-mediated inflammatory reaction through extrahepatic transplantation. We have demonstrated the efficacy of PLG scaffolds to induce tolerance to allogeneic islets using two different platforms; i) PLG scaffolds were modified with biotin and engineered with SA-FasL and loaded with unmodified islets, or ii) unmodified scaffolds loaded with SA-FasL-engineered allogeneic islets. PLG scaffold-based islet transplantation and immunomodulation, therefore, provide a clinically practical approach as it obviates the need for islet engineering and intraportal transplantation. 


\section{CHAPTER 2: SA-FASL-ENGINEERED ISLETS INDUCE A BIPHASIC SPATIOTEMPORAL ALLOTOLERANCE REQUIRING A PHAGOCYTE/TGF- B/TREG AXIS}

\section{Introduction}

Type 1 diabetes is an autoimmune disease caused by the destruction of insulin-producing beta cells in the pancreas, resulting in long term hyperglycemia. Transplantation of allogeneic pancreatic islets was shown to be effective in reversing hyperglycemia in patients with type 1 diabetes ${ }^{86}$. However, allogeneic islet grafts are subject to rejection initiated and perpetuated by Teff cells $^{87,88}$. Therefore, approaches that specifically target Teff cells for physical and/or functional elimination have potential to protect allogeneic islet grafts as a curative therapy for type 1 diabetes.

T effector (Teff) cells upregulate Fas receptor (CD95/Apo-1) on their surface following activation and become sensitive to FasL (CD178)-mediated apoptosis, defined as activation-induced cell death (AICD) ${ }^{89-91}$. AICD is critical for the establishment of immune homeostasis and tolerance to self-antigens ${ }^{89}$. The pivotal role of Fas/FasL pathway in regulating $T$ cell responses is emphasized by the emergence of autoimmunity in cases of Fas or FasL deficiencies $^{54,90}$. The Fas pathway, therefore, has significant potential for the development of therapeutic approaches to treat autoimmune diseases and 
transplant rejection. However, the pursuit of tissue-targeted expression of FasL for immunomodulation in settings of autoimmunity and transplantation has produced conflicting observations ${ }^{92-95}$ that potentially arise from the complex nature of FasL expression, the existence of two different isoforms, and the pleiotropic and opposing functions performed by each isoform. FasL is expressed as a type II membrane-bound protein, which can be cleaved by matrix metalloproteinases into soluble form in response to environmental cues ${ }^{66}$. The membrane-bound form was reported to have apoptotic activity, while the soluble form lacks such activity and serves as a chemotactic factor for neutrophils ${ }^{69,96}$. These initial observations were further confirmed in transgenic mice expressing either a soluble or membrane-bound form of $\mathrm{FasL}^{97}$. The membrane-bound form was shown to be apoptotic and essential for controlling autoimmunity, while the soluble form promoted autoimmunity and tumorigenesis via non-apoptotic functions. Therefore, the therapeutic application of FasL as an immunomodulator may require a form that primarily has apoptotic function.

We have previously reported ${ }^{71}$ the generation a novel form of FasL chimeric with a modified form of core streptavidin (SA-FasL). This molecule forms spontaneous oligomers in solution and has robust apoptotic activity on Fas-expressing lymphocytes. Importantly, SA-FasL can be transiently displayed on the surface of biotinylated cells, tissues, or organs for systemic or localized immunomodulation $^{72,74,98,99}$. Systemic immunomodulation with donor SA-FasLengineered splenocytes resulted in tolerance to cardiac allografts in rodents ${ }^{99}$, and facilitated the engraftment and survival of hematopoietic stem cells in 
allogeneic hosts ${ }^{100}$. Localized immunomodulation using SA-FasL-engineered islet allografts resulted in indefinite graft acceptance in a chemically diabetic BALB/c-to-C57BL/6 mouse model ${ }^{74}$.

We herein investigated the mechanistic basis of tolerance achieved by SA-FasL-engineered allogeneic islets and report that tolerance is initiated by a regulatory loop consisting of apoptosis, phagocytes, and TGF- $\beta$. Importantly, tolerance at the induction phase is donor-specific and systemic, and evolves into graft site-restricted immune privilege requiring Treg presence at the maintenance phase.

\section{Materials and Methods}

\section{Mice and Recombinant Proteins}

C57BL/6, B6.Cg-Foxp3 ${ }^{\text {tm2(EGFP)Tch } / J, ~ B A L B / c, ~ a n d ~ C 3 H ~ m i c e ~ w e r e ~ o b t a i n e d ~ f r o m ~}$ Jackson Laboratories). C57BL/6.SJL and TCR transgenic OT-I and OT-II mice on Rag $^{-/}$background were purchased from Taconic Farms. BALB/c.RIP-OVA mice were a gift from Dr. S. Webb, Scripps Research Institute, La Jolla, CA. Animal were kept in our specific pathogen-free animal housing facility at the University of Louisville using protocols approved by the Institutional Animal Care and Use Committee. Recombinant SA and SA-FasL proteins were produced in our laboratory using the Drosophila DES expression system (Invitrogen) as previously described ${ }^{71}$.

\section{Pancreatic Islet Isolation, Engineering, and Transplantation}


Pancreatic islets were harvested from 8 to 12 -week-old donors under anesthesia using a standard protocol ${ }^{71}$. Islets were engineered with SA-FasL or SA control proteins as described ${ }^{74}$ and $\sim 500$ islets were transplanted under kidney capsule of streptozotocin chemically induced diabetic mice (confirmed by BG $\geq 300 \mathrm{mg} / \mathrm{dl}$ for two consecutive days). Selected groups of mice were given i.p. injections of rapamycin $(0.2 \mathrm{mg} / \mathrm{kg})$ starting on the day of transplantation daily for 15 days. Animals were monitored for blood glucose levels and those with two consecutive daily measurements of $\geq 250 \mathrm{mg} / \mathrm{dl}$ were considered diabetic and rejecting the graft.

\section{Skin and Heart Transplantation}

Donor tail skin was harvested from euthanized mice, cut into $2 \mathrm{~cm}$ square, and grafted on dorsal area of recipients under anesthesia. Animals were bandaged and bandage was removed 7 days post-transplant. Animals were monitored daily and skin was considered rejected at $90 \%$ necrosis. Heterotopic heart transplantation and graft monitoring were performed as described ${ }^{99}$.

\section{In Vivo Proliferation Assays}

OVA CD8 ${ }^{+} \mathrm{T}$ cells were isolated from spleen and mesenteric LNs of OT-I transgenic C57BL/6 mice, labeled with CFSE as described ${ }^{101}$, and $15 \times 10^{6}$ cells/animal were transferred by tail vein injection into C57BL/B6.SJL congenic mice. One day later, these mice were transplanted with SA- or SA-FasLengineered pancreatic islets isolated from RIP-mOVA transgenic BALB/c mice 
expressing a membranous from of OVA in pancreatic beta cells under the control of rat insulin promoter ${ }^{102}$. Lymphocytes were harvested from kidney-draining LNs, mesenteric LNs, and spleens 5 days after islet transplantation and stained with antibodies against CD8-PerCp, V $\beta-5-P E$, and CD45.2-APC. Proliferation of OT-I cells were determined by gating on $\mathrm{V} \beta-5^{+} \mathrm{CD} 8^{+} \mathrm{CD} 45.2^{+} \mathrm{T}$ cells.

Splenocytes were isolated from C57BL/6 mice with long-term syngeneic and allogeneic graft acceptors and rejectors, labeled with CFSE, and injected by tail vein into naive $\mathrm{F} 1$ (C57BL/6 $\times \mathrm{BALB} / \mathrm{c}, \mathrm{H}-2^{\mathrm{b} / \mathrm{d}}$ ) or $\left(\mathrm{C} 57 \mathrm{BL} / 6 \times \mathrm{C} 3 \mathrm{H}, \mathrm{H}-2^{\mathrm{b} / \mathrm{k}}\right.$ ) mice as donor and third party antigenic controls, respectively. After $72 \mathrm{~h}$, lymphocytes were harvested from the spleen and stained with antibodies against $\mathrm{H}-2 \mathrm{~K}^{\mathrm{b}}-\mathrm{PE}$ and $\mathrm{H}-2 \mathrm{~K}^{\mathrm{d}}-\mathrm{APC}$ or $\mathrm{H}-2 \mathrm{~K}^{\mathrm{k}}-\mathrm{PE}$ to differentiate between donor and recipient cells. The cells were run on the FACSCalibur and the data was analyzed using FlowJo software.

\section{Phagocyte Depletion and Treatment with Anti-TGF- $\beta$ Antibody}

Selected groups of mice were injected intravenously with dichloromethylenediphosphonic acid (DMDP, Clodronate) or PBS loaded liposomes (Enca Encapsula NanoSciences) one day prior to islet transplantation. Depletion of macrophages and immature DCs in peripheral blood were assessed using antibodies against F4/80, CD11b, and CD11C at various times posttreatment.

For blocking TGF- $\beta$ in vivo, mice were treated either with $300 \mu \mathrm{g} /$ mouse monoclonal antibody (1D11) to TGF- $\beta 1,2$, and 3 on days $-1,+1,+3$, and +5 
post-transplantation $(n=2)$ or $1 \mathrm{mg} /$ mouse on days $-1,+1,+3,+5$, and +6 posttransplantation $(n=3)$, or $0.5 \mathrm{mg} /$ mouse on days $100,102.104,106$ posttransplantation $(n=4)$. A blocking antibody (JES5-2A5) to IL-10 was used at 1 $\mathrm{mg} /$ mouse on days $-1,+1,3,5$, and 6 post-transplantation $(n=5)$.

\section{Analysis of TGF- $\beta$ production by $T$ cells undergoing apoptosis and macrophages engulfing apoptotic bodies}

CFSE labeled OT-II T splenocytes were activated with OVA for $72 \mathrm{hrs}$ and live cells were isolated by Lympholyte density separation and incubated with SAFasL or SA protein (equal molarity to SA-FasL) as control for 16-18 hrs. Cells were washed extensively, labeled with Annexin V, 7AAD, and CD4 and analyzed using multiparameter flow cytometry.

Peritoneal macrophages were cultured in 24-well plates at $2 \times 10^{6}$ cells/well and incubated for 1 hour in serum free medium at $37^{\circ} \mathrm{C}$ in a $5 \% \mathrm{CO}_{2}$ incubator. Non-adherent cells were washed out and adherent macrophages were cocultured with apoptotic OT-II cells at $1: 3$ ratio in serum free media for $18 \mathrm{hrs}$. To remove non-engulfed apoptotic cells, wells were washed extensively with PBS and fixed with $4 \%$ of paraformaldehyde for 20 minutes at room temperature. After Fcyll/III receptor blockade and permeabilization, cells were stained with a mouse anti-TGF- $\beta$ antibody (R\&D systems) for 45 minutes at $37^{\circ} \mathrm{C}$ and the binding was visualized using Alexa 546-labeled anti-mouse IgG antibody (Invitrogen). Macrophages were identified by Alexa 647-labeled anti-F4/80 
antibody (Caltag Laboratory). Cells were analyzed using confocal microscopy for the uptake of apoptotic bodies (green) and production of TGF- $\beta$ (blue).

\section{Immunohistochemical analyses}

The kidney harboring islet graft was snap-frozen in Tissue-Tek O.C.T. compound (Sakura FineTek), cut into 5-8 $\mu \mathrm{m}$ thick sections using a Bright OTF5000 cryomicrotome (Rose Scientific Ltd.). For TGF- $\beta$ staining, primary and secondary Ab complexes were first prepared by mixing 1:1000 dilution of antiTGF- $\beta$ Ab (clone 1D11) or mouse IgG1 isotype control in PBS with equal volume of 1:300 dilution of Alexa 546-labeled goat anti-mouse Ab followed by rotating for

$18 \mathrm{hrs}$ at $4^{\circ} \mathrm{C}$. Antibody complexes were then blocked with heat-inactivated mouse serum $(0.1 \% \mathrm{v} / \mathrm{v})$ by incubating on rotator at $4^{\circ} \mathrm{C}$ for $2 \mathrm{hrs.} \mathrm{Tissue}$ sections were then fixed in 1:1 ice cold acetone-methanol for 10 minutes at room temperature (RT), washed, and incubated in $2 \%$ paraformaldehyde for 10 minutes at RT. Tissue sections were then incubated in a blocking solution (1\% BSA, 5\% goat serum and 1:400 Fcyll/III receptor block) for 30 minutes at RT followed by staining first with Alexa647-conjugated rat anti-mouse F4/80 Ab (1:100 dilution, Caltag laboratories) in $1 \% \mathrm{BSA}$ for 1 hour at $37^{\circ} \mathrm{C}$. After washing twice with PBS, tissue sections were then stained with anti-TGF- $\beta$ or isotype Ab complexes by incubation for $4 \mathrm{hrs}$ at room temperature. Hoechst (Molecular Probes) was used to stain DNA in the tissue. Fluorescent images were obtained using a Leica TCS SP5 confocal microscope under 20X magnification. 


\section{Statistical Analyses}

The Welch's $t$-test was used to determine difference between two groups except in the supplemental data which used an unpaired two-tailed $t$-test. Graft survival statistical difference was assessed using the log-rank test. Data are expressed as mean $\pm \mathrm{SD}$. $P$ values of $<0.05$ were considered significant. Statistical analysis and graph creation was performed using GraphPad Prism software.

\section{$\underline{\text { Results }}$}

\section{Reduced frequency of proliferating alloreactive $T$ cells in lymph nodes draining FasL-engineered islet grafts}

We have previously shown that pancreatic islets engineered to display SA-FasL protein on their surface overcame rejection in chemically diabetic allogeneic hosts ${ }^{74}$. Graft survival was associated with apoptotic depletion of Teff cells within islet grafts ${ }^{74}$. To assess if the depletion of alloreactive $T$ cells is systemic, CFSE-labeled OT-I CD8 ${ }^{+} \mathrm{T}$ cells (CD45.2) recognizing a dominant epitope of ovalbumin (OVA) were adoptively transferred into congenic C57BL/6.SJL mice (CD45.1) one day before sub-renal capsule transplantation of islets from OVA transgenic BALB/c (RIP-OVA) donors. We observed a marked increase in the percentage of proliferating OT-I cells ( 54\%) in the kidney draining lymph nodes of recipients transplanted with control streptavidin (SA)engineered islets (Figure 4A). OT-I cells also showed significant, but less robust proliferation in the lymphoid tissues distant from the graft, such as mesenteric lymph nodes ( 15\%) and the spleen ( 24\%). In marked contrast, significantly 

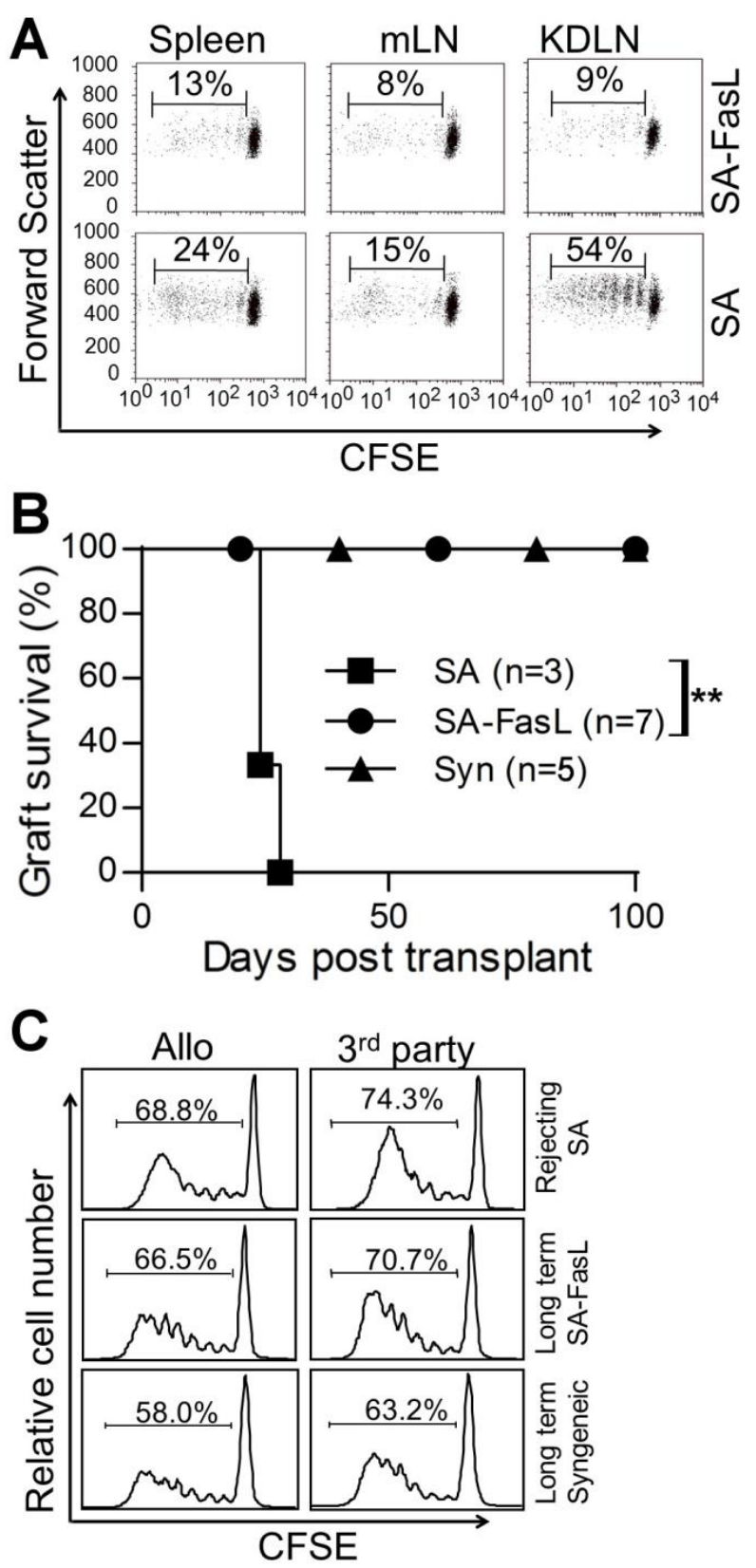

Figure 4: Graft milieu-localized modulation of alloreactive $T$ cell responses as the prominent feature of tolerance established by SA-FasL-engineered allogeneic islets. (A) Presence of proliferating CFSE-labeled OT-I CD8 ${ }^{+} \mathrm{T}$ cells (CD45.2) adoptively transferred into C57BL/6.SJL mice (CD45.1) one day prior to transplantation of BALB/c RIP-OVA islet graft engineered with SA-FasL or control 
SA proteins. The indicated lymphoid tissues were harvested 5 days post islet transplantation, and single cell suspensions were analyzed using flow cytometry and gating on the OT-I cell population. (B) Survival of allogeneic islet grafts. BALB/c allogeneic islets were engineered with SA-FasL $(n=7)$ or $S A(n=5)$ control proteins. Syngeneic islets engineered with $S A-F a s L$ used as controls $(n=3)$. All graft recipients were treated with a short course of rapamycin $(0.2 \mathrm{mg} / \mathrm{kg}$ daily for 15 doses starting on the day of transplantation). Survival compared with log-rank test $\left({ }^{\star *} p<0.01\right)$. (C) In vivo proliferation assay. Splenocytes were harvested from recipients of allogeneic SA-engineered islet grafts at rejection and syngeneic or SA-FasL-engineered allogeneic islet grafts after 100 days post-transplantation. Cells were labeled with CFSE and injected i.v. into F1 (C57BL/6 x BALB/c, H$\left.2^{\mathrm{b} / \mathrm{d}}\right)$ or $\left(\mathrm{C} 57 \mathrm{BL} / 6 \times \mathrm{C} 3 \mathrm{H}, \mathrm{H}-2^{\mathrm{b} / \mathrm{k}}\right)$ mice to test their proliferative response against donor and third party antigens, respectively. 
lower percentages of proliferating OT-I cells were detected in the same three tissues of recipients transplanted with SA-FasL-engineered BALB/C RIP-OVA islet grafts, with the decrease being more pronounced ( $>5$-fold) in graft draining LNs. These observations are consistent with the reported critical role of graftdraining lymph nodes in regulating alloreactive immunity ${ }^{87}$. Furthermore, these results show that the impact of SA-FasL on alloreactive $T$ cells is not systemic, but rather primarily localized to the graft ${ }^{74}$ and graft draining lymph nodes as shown here.

\section{Systemic donor-reactive responses persist despite long-term islet graft acceptance}

The reduced proliferative response of donor-reactive $T$ cells in SA-FasLengineered islet graft recipients (Figure $4 A$ ) in the early phase of tolerance induction may evolve into two different outcomes at the maintenance phase; establishment of generalized tolerance and consequent unresponsiveness to donor antigens or localized immune privilege in spite of persistent donor-reactive

responses. We first confirmed our previous observations ${ }^{74}$ by demonstrating that transplantation of SA-FasL-engineered BALB/C islets into chemically diabetic C57BL/6 mice under transient cover of rapamycin (15 daily doses) results in long-term graft survival (Figure 4B). This tolerogenic effect was dictated by SAFasL as islet grafts engineered with streptavidin as control protein transplanted using the same rapamycin regimen were acutely rejected ( $n=3$; MST 24 \pm 2.3 ). We next tested if tolerant graft recipients generate a systemic donor-reactive 
response. An in vivo proliferation assay was used to assess the status of donorspecific immune responses in acceptors of SA-FasL-engineered islet grafts. T cells harvested from the spleen of long-term (> 100 days) SA-FasL-islet graft recipients generated a strong in vivo proliferative response against both donor $(\mathrm{BALB} / \mathrm{c})$ and third party $(\mathrm{C} 3 \mathrm{H})$ antigens (Figure $4 \mathrm{C})$. The donor-reactive response was of similar magnitude to those generated by $T$ cells from long-term syngeneic or rejecting control SA-engineered allograft recipients. An intact systemic T cell response to the donor antigens in long-term SA-FasL-engineered islet allograft survivors is consistent with the demonstrated role of FasL in physiological immune privilege ${ }^{103,104}$.

\section{Phagocytes are required for tolerance induction}

Apoptotic lymphocytes were shown to have immunomodulatory features involving phagocytes and TGF- $\beta^{105,106}$. We, therefore, next investigated the role of phagocytes in the induction of tolerance in our model. Depletion of macrophages and immature DCs using clodronate loaded liposomes (Figure 5) one day before transplantation resulted in acute rejection of SA-FasL-engineered islet grafts in all recipients (Figure $6 A ; n=7, \mathrm{MST}=24 \pm 9.6$ days). In marked contrast, all the mice treated with empty liposome (no clodronate) showed graft survival over an observation period of 100 days ( $n=5$, MST $>100$ days), supporting a critical role of these cells in the induction of tolerance.

Immunohistochemical analysis revealed more $\mathrm{F} 4 / 80^{+}$macrophages localized in the periphery of SA-FasL engineered islets early post-transplantation 


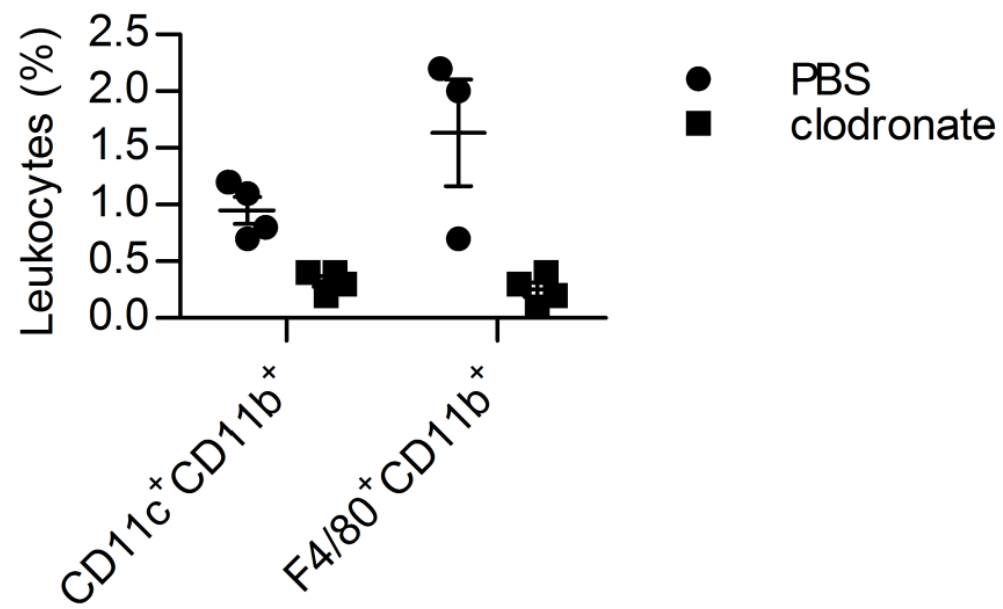

Figure 5: Liposome encapsulated clodronate depletes both macrophages and immature dendritic cells in mice. C57BL/6 mice were treated intravenously with clodronate or PBS-loaded liposomes $(0.1 \mathrm{ml} / 10 \mathrm{gr}$ of body weight) one day prior to islet transplantation. The depletion of macrophages and immature DCs in peripheral blood lymphocytes was assessed $24 \mathrm{hrs}$ after clodronate treatment using antibodies against F4/80, CD11b, and CD11c in flow cytometry $(n=3)$. Data is shown as percentage of lymphoid/myeloid population double positive for $\mathrm{CD} 11 \mathrm{C} / \mathrm{CD} 11 \mathrm{~b}$ or $\mathrm{F} 4 / 80 / \mathrm{CD} 11 \mathrm{~b}$. Statistics were calculated using an unpaired two-tailed t-test. 


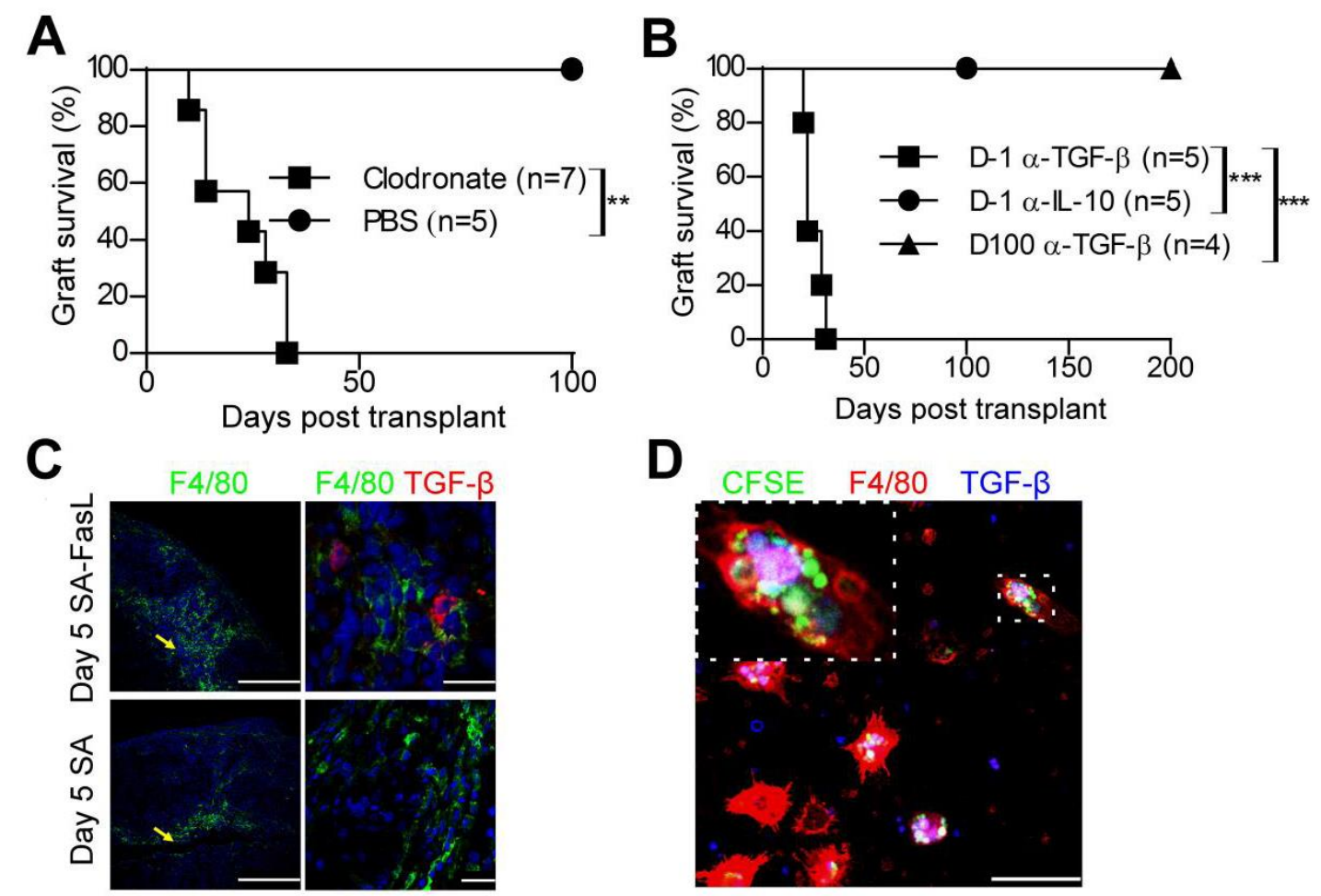

Figure 6: Depletion of phagocytes or blockade of TGF- $\beta$ at the induction phase of SA-FasL-mediated tolerance results in prompt islet graft rejection.

(A) Survival of SA-FasL-engineered BALB/C islets in allogeneic C57BL/6 mice treated with liposomes encapsulated with PBS or clodronate injected intravenously $(0.1 \mathrm{ml} / 10 \mathrm{~g}$ body weight $)$ one day before islet transplantation (clodronate MST $24 \pm 9.6$; log-rank $P=0.0014$ ). (B) Survival of SA-FasLengineered $\mathrm{BALB} / \mathrm{c}$ islets in allogeneic C57BL/6 mice treated with TGF- $\beta$ or IL-10 antibodies. Graft recipients were treated intravenously with blocking antibodies to TGF- $\beta$ (squares) or IL-10 (circles) starting one day prior to SA-FasLengineered allogeneic islet transplantation for 4-5 doses or starting on day 100 post-transplantation. Treatment with anti-TGF- $\beta$ antibody at the induction, but not maintenance, phase of tolerance results in islet graft rejection (MST $=25.5 \pm$ 4.8 days for TGF- $\beta$ D-1 vs $>100$ days for IL-10 D-1; log-rank $P=0.0006$ ). 
Representative confocal images of macrophages and TGF- $\beta$ positive cells in SAFasL- or SA-engineered allogeneic islet grafts 5 days post-transplantation under the cover of rapamycin. Nuclear staining is shown in blue. Arrow heads indicate grafted islets. Scale bars, $250 \mu \mathrm{m}$ (left panels) and $25 \mu \mathrm{m}$ (right panels). (D) Production of TGF- $\beta$ by macrophages digesting apoptotic bodies. OT-II T cells were activated with ovalbumin and treated with SA-FasL for the induction of apoptosis. Apoptotic $T$ cells were then cocultured with macrophages and analyzed using confocal microscopy for the uptake of apoptotic bodies (green) and production of TGF- $\beta$ (blue). Mostly, macrophages engulfing apoptotic bodies produce cytoplasmic TGF- $\beta$ (pink) scale bar $50 \mu \mathrm{m}$. 
(day 5) as compared with SA-engineered control islet grafts (Figure 6C). SAFasL-engineered islets scored positive for TGF- $\beta$, while this cytokine was undetectable in SA-engineered control islets (Figure $6 C$ ). Consistent with these in vivo observations, we demonstrated using in vitro cultures that both $\mathrm{T}$ cells undergoing SA-FasL-mediated apoptosis (data not shown) and macrophages engulfing apoptotic bodies from T cells produce TGF- $\beta$ (Figure 6D). However, it remains to be investigated if TGF- $\beta$ secreted by macrophages contributes to tolerance seen in this model. Taken together, these results demonstrate the critical role of phagocytes in the induction phase of tolerance attained by SAFasL-engineered allogeneic islet grafts.

\section{TGF- $\beta$ is required for the induction, but not the maintenance of tolerance}

IL-10 and TGF- $\beta$ are immunoregulatory cytokines, and in particular TGF- $\beta$ has been implicated in tolerance involving $T$ cell apoptosis in various models ${ }^{105-}$ 107. We, therefore, tested the role of these cytokines in the induction and maintenance of tolerance. Recipients of SA-FasL-engineered allogeneic islets were treated intravenously with a blocking antibody to TGF- $\beta$ and IL-10. Neutralization of TGF- $\beta$ at the induction phase of tolerance resulted in acute rejection of all SA-FasL engineered islet grafts (Figure $6 B ; n=5$, MST $=22 \pm 4.9$ days), whereas antibody treatment at the maintenance phase of tolerance (100 days post-transplantation) had no impact on graft survival ( $n=4$ MST $>60$ days post injection). In marked contrast, treatment with a blocking antibody against IL10 as another regulatory cytokine at the induction phase did not affect long-term 
acceptance of SA-FasL-engineered islet grafts (Figure $6 B ; n=5$, MST $>100$ days). These results demonstrate the critical role of TGF- $\beta$ in the induction, but not maintenance, phase of tolerance.

\section{Tolerance is systemic at the induction phase and shows both donor and tissue specificity}

We have previously shown that long-term tolerance achieved by SA-FasLengineered islet grafts is localized to the graft and requires Treg cells for maintenance ${ }^{74}$. Treg cells were shown to traffic to allogeneic pancreatic islets immediately post-transplantation in response to inflammatory cues, where they manifest their immunoregulatory function within the graft microenvironment ${ }^{87,108}$. Therefore, we assessed if the SA-FasL-mediated long-term, localized tolerance is systemic at the induction phase using a simultaneous two-islet graft model. C57BL/6 mice were transplanted with BALB/C SA-FasL-engineered islets under the right kidney capsule and unmanipulated islets from BALB/C or $\mathrm{C} 3 \mathrm{H}$ third party donors under the left kidney capsule. These animals were also subjected to a short course of rapamycin $(0.2 \mathrm{mg} / \mathrm{kg})$ administered daily for 15 days starting the day of transplantation. Surgical removal of the kidney harboring SA-FasLengineered islet graft 60 days post-transplantation did not result in hyperglycemia in recipients transplanted with donor-matched, unmodified islet grafts, demonstrating the survival and function of unmodified donor grafts (Figure $7 A ; n$ $=4$ MST $>100$ days). Importantly, tolerance in this group was maintained by Treg cells as their depletion using an antibody to CD25 resulted in rejection of 

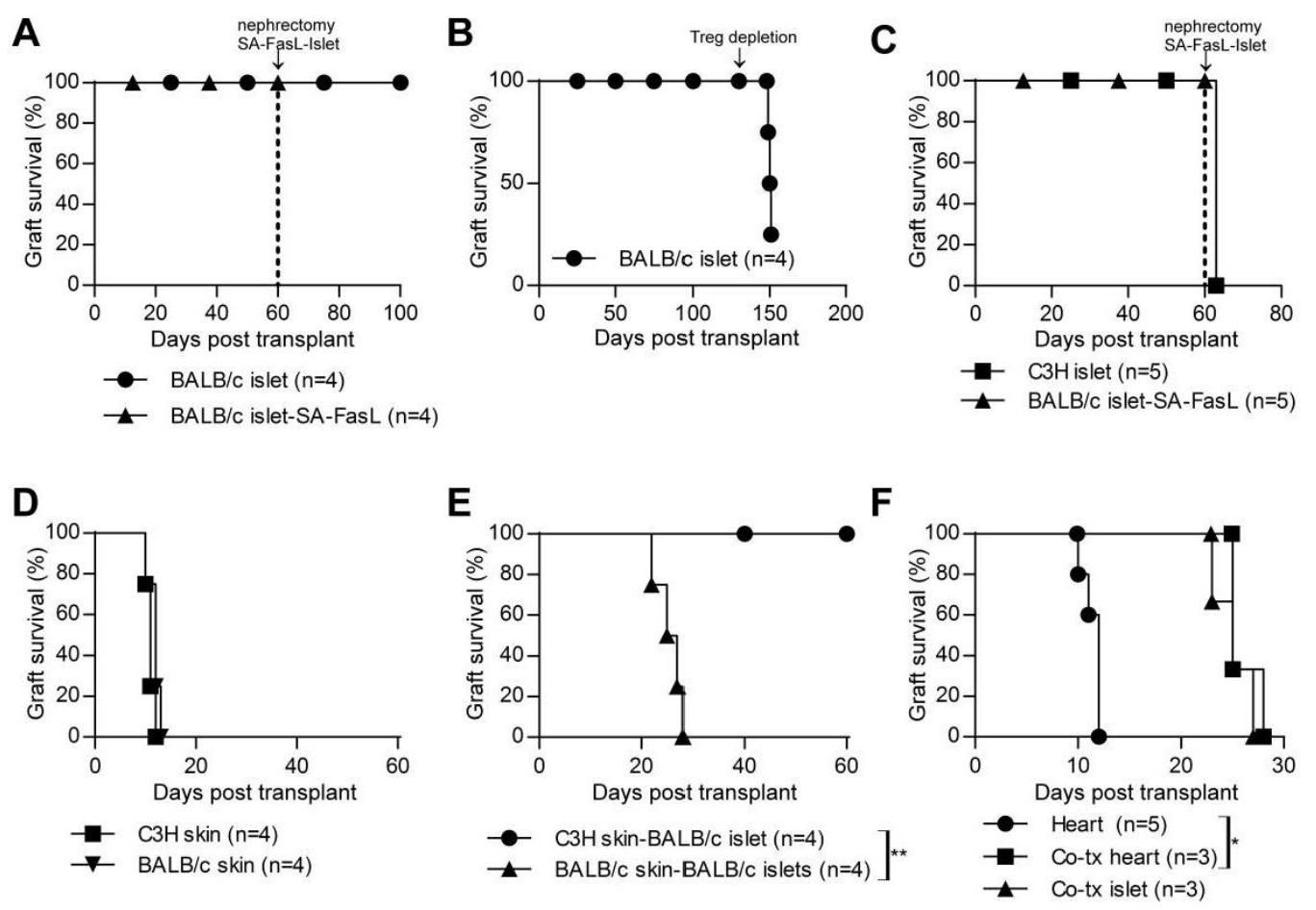

Figure 7: Tolerance to SA-FasL-engineered islet grafts is donor-specific and systemic at the induction phase. SA-FasL-engineered BALB/c islets were transplanted under the kidney capsule of streptozotocin diabetic C57BL/6 recipients. These recipients were also transplanted with (A) unmodified BALB/C (allo) or (C) $\mathrm{C} 3 \mathrm{H}$ (3rd party) islet grafts under the contralateral kidney capsule and subjected to a short course of rapamycin treatment $(0.2 \mathrm{mg} / \mathrm{kg}$ daily for 15 doses starting the day of transplantation). (A) Surgical removal of the kidney harboring SA-FasL-engineered BALB/c islet graft 60 days post-transplantation (arrow) did not result in hyperglycemia, demonstrating the survival and function of unmodified donor-matched islets. (B) Ablation of Treg cells in mice shown in panel A (after surgical removal of the kidney harboring the SA-FasL-engineered islets) using an antibody to CD25 (PC.61) on day 130 post-transplantation (arrow) resulted in rejection of 3 out of 4 grafts, demonstrating the role of Treg 
cells in maintaining survival of the unmodified islet graft. (C) Surgical removal of SA-FasL-engineered BALB/c islet graft (arrow) results in prompt hyperglycemia in the cohort harboring unmodified $\mathrm{C} 3 \mathrm{H}$ third party islet graft under the contralateral kidney capsule, demonstrating rejection. (D) Survival of BALB/C donor and $\mathrm{C} 3 \mathrm{H}$ third party skin grafts in $\mathrm{C} 57 \mathrm{BL} / 6$ recipients simultaneously transplanted with (E) BALB/c SA-FasL-engineered islet grafts. Rejection of $\mathrm{BALB} / \mathrm{c}$, but not third party $\mathrm{C} 3 \mathrm{H}$, skin results in prompt rejection of SA-FasLengineered islets (MST = $26 \pm 2.6$ days, log-rank comparison of islet survival $\mathrm{P}=$ 0.0067). (F) SA-FasL-engineered islets do not induce tolerance when cotransplanted with donor-matched heart grafts. Chemically diabetic C57BL/6 were transplanted with SA-FasL-engineered islets under the kidney capsule and donor-matched heart graft in the abdomen. A separate group was transplanted with heart only under a brief course of rapamycin to serve as control. Both graft types are rejected with heart graft showing prolonged survival as compared with the control (MST $25 \pm 1.7$ vs $12 \pm 0.9$ days, log-rank comparison of heart survival $P=0.0074)$. 
$3 / 4$ grafts within 22 days (Figure $7 B$ ). The mouse that did not reject the graft had minimal depletion of Treg cells (Figure 8). This is concordant with previous results demonstrating the rejection of SA-FasL-engineered grafts after Treg depletion $^{74}$. In marked contrast, surgical removal of the SA-FasL-engineered BALB/C islet graft resulted in prompt hyperglycemia in recipients transplanted with the unmodified $\mathrm{C} 3 \mathrm{H}$ third party islet graft, thus demonstrating that tolerance requires antigen-specificity (Figure $7 C, n=5$ ).

We next used the simultaneous two-graft model to determine the tissuespecific nature of tolerance at the induction phase. C57BL/6 mice were transplanted with BALB/c SA-FasL-engineered islets and donor-matched or $\mathrm{C} 3 \mathrm{H}$ third party skin grafts under the transient cover of rapamycin. Both donor and third party skin grafts were acutely rejected (Figure 7D). Rejection of BALB/C skin also triggered rejection of SA-FasL-engineered BALB/C islets, causing development of hyperglycemia within 30 days (Figure 7E; $n=4$, MST $26 \pm 2.6$ days). In marked contrast, the rejection of $\mathrm{C} 3 \mathrm{H}$ skin did not interfere with longterm acceptance of BALB/C SA-FasL-engineered islets as all mice remained euglycemic for an observation period of 60 days (Figure 7E; $n=4$, MST $>60$ days). Because skin grafts elicit vigorous allogeneic immune responses, we next assessed the survival of heart allografts. Similar to skin grafts, BALB/c heart grafts transplanted simultaneously with SA-FasL-engineered islets were rejected, albeit in a delayed tempo as compared with control heart allografts alone (Figure $7 F ; \mathrm{MST}=25 \pm 1.7$ vs $12 \pm 0.9$ days for controls, $P=0.0169$ ). Heart graft rejection also caused hyperglycemia, an indication of SA-FasL- 

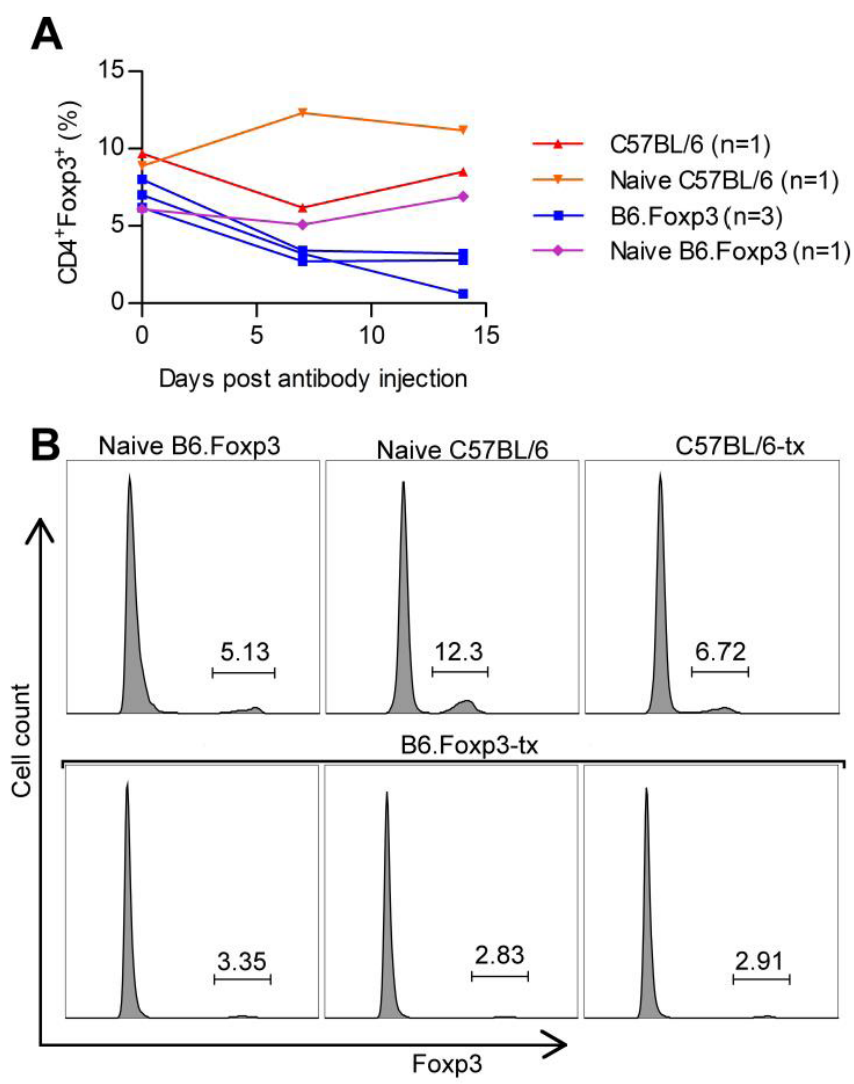

Figure 8: Treg depletion in long-term islet-graft recipients. (A) Mice in Figure 7 B were injected with CD25 depleting antibody (PC.61) and tested for FoxP3+ cells gated on CD4+ cells from peripheral blood on various days post injection. One of islet recipient was regular $\mathrm{C} 57 \mathrm{BL} / 6$, while the other 3 were C57BL6.FoxP3. All mice injected with PC.61 were analyzed here. The C57BL/6 animal had minimal depletion of Treg cells and did not reject the islet graft, whereas all the other 3 mice had Treg depleted significantly and rejected islet grafts. Treg levels in naïve C57BL/6 and C57BL6.FoxP3 are shown as control. (B) Flow cytometry histograms showing data from (A) on day 7 post antibody injection. 
engineered islet graft rejection (Figure $7 F ; n=3$, MST $=25 \pm 2.0$ days). Taken together, these results demonstrate that localized immunomodulation with SAFasL-engineered islets evolves into systemic tolerance at the induction phase that is both donor- and tissue-specific.

\section{SA-FasL-engineered islets establish a donor-specific immune privilege site that requires the graft for maintenance}

Although FasL has been implicated in physiological immune privilege ${ }^{103,}$ ${ }^{104}$, the direct evidence for such a role in induced immune privilege remains to be provided. To assess if the SA-FasL-engineered islet graft induces an immune privileged site, long-term ( $>60$ days) recipients were treated with streptozotocin to destroy the graft. A group of mice were transplanted with a second set of unmodified donor-matched or $\mathrm{C} 3 \mathrm{H}$ third party islet grafts into the same site of the primary graft 4 days after the confirmation of hyperglycemia. The second set of BALB/c islet grafts restored euglycemia in all recipients for an observation period exceeding 70 days (Figure $9 B ; n=5$ ). In marked contrast, third party islet allografts established euglycemia only for 20 days, demonstrating acute graft rejection (Figure $9 B ; n=5, \mathrm{MST}=19 \pm 2.7$ days).

To test whether alloantigens expressed by the graft are the driving force for the maintenance of induced immune privilege, a second set of long-term (>60 days) graft recipients were injected with streptozotocin and maintained for 20 days with exogenous insulin, a period considered to be sufficient for clearance of the injured graft. Transplantation of unmodified donor-matched second set of 
A

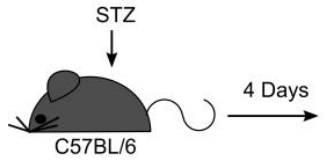

B

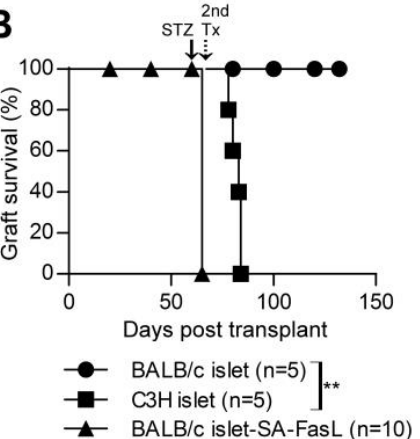

SA-FasL-BALB/c-islet
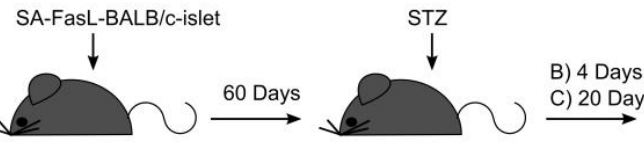

$\mathrm{C} 3 \mathrm{H}$ or $\mathrm{BALB} / \mathrm{c}$ islet

C

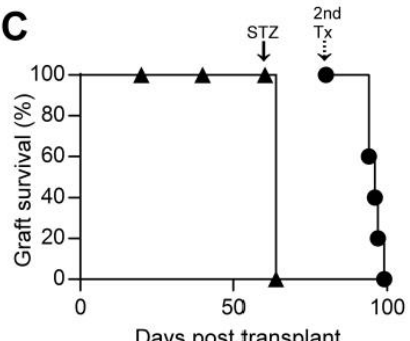

2nd Tx nephrectomy

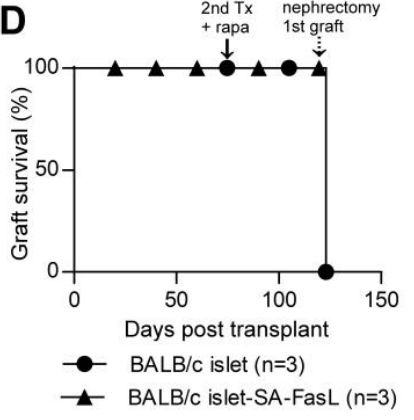

Figure 9: Tolerance induced by SA-FasL-engineered islet grafts evolves into donor-specific immune privilege at the maintenance phase sustained by the presence of graft and Treg cells. (A) A model showing C57BL/6 mice treated with STZ and transplanted with SA-FasL-engineered BALB/C islets were treated with streptozotocin again 60 days post-transplantation (arrow) to destroy the graft (B and $C)$. (B) After confirmation of hyperglycemia (4 days), a cohort of mice were re-transplanted immediately with a second set of unmodified donormatched and another with third party $\mathrm{C} 3 \mathrm{H}$ islet grafts under the same kidney capsule harboring the original graft (dotted arrow). $\mathrm{C} 3 \mathrm{H}$ third party, but not $\mathrm{BALB} / \mathrm{c}$ donor-matched, islet grafts were rejected acutely (MST $=19 \pm 2.7$ days; log-rank $P=0.0027)$. (C) Delayed re-transplantation of a second set of donormatched unmodified islets (dotted arrow) 20 days post streptozotocin treatment (arrow) results in acute islet rejection (MST $=16 \pm 2.1$ days), demonstrating that the induced graft site-immune privilege requires the presence of alloantigens (graft) for maintenance. (D) Rapamycin treatment does not confer protection to a second set of islet graft transplanted at a distant site. Long-term (80 days) 
C57BL/6 recipients of BALB/C SA-FasL-engineered islet grafts were transplanted with a second set, donor-matched unmanipulated islet graft under the contralateral kidney capsule (arrow), and treated with rapamycin $(0.2 \mathrm{mg} / \mathrm{kg}$ daily for 15 days starting the day of second islet transplantation). Surgical removal of the kidney harboring the original islet graft on day 120 post-transplantation (dotted arrow) resulted in prompt hyperglycemia, demonstrating that treatment with rapamycin does not extend the immune privilege status of the primary SAFasL-engineered islets to a second set unmodified graft. 
islet grafts under the same kidney capsule that harbored the primary graft resulted in temporary euglycemia and rejection of all grafts in an acute fashion (Figure $9 C ; n=5$, MST $=16 \pm 2.1$ days). These data demonstrate a requirement for the continued presence of islet alloantigens for the maintenance of induced immune privilege site.

\section{Immune privilege cannot be extended to a second set of unmanipulated islet grafts transplanted to a distant site under the cover of rapamycin}

The two-islet graft model showed that peripheral tolerance is systemic at the induction phase and requires a short course of rapamycin. This agent works in synergy with Fas-mediated apoptosis to eliminate Teff cells ${ }^{63,109}$ and also has

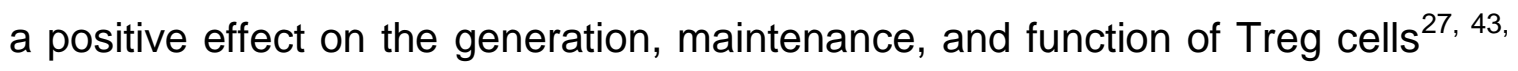
110. Inasmuch as the localized tolerance in our model was maintained by Treg cells (Figure $7 B$ ), we tested if rapamycin can expand and/or mobilize Treg cells from long-term surviving primary grafts into the second set of donor graft transplanted at a distant site. Long-term (80 days) acceptors of SA-FasLengineered BALB/C islets were transplanted with a second set of unmodified, donor-matched islet grafts under the contralateral kidney capsule under the same rapamycin regimen used for the induction of tolerance. Surgical removal of the primary graft 40 days after transplantation of the secondary graft resulted in prompt hyperglycemia within 3 days (Figure $9 D, n=3$ ). These data confirm our previously published studies demonstrating that tolerance at maintenance phase 
is localized ${ }^{74}$, and further show that rapamycin at this phase cannot mobilize/extend tolerance to a secondary graft placed in a distant site. 
CHAPTER 3: LOCAL IMMUNOMODULATION WITH SA-FASL-ENGINEERED BIOMATERIALS ACHIEVES ALLOGENEIC ISLET GRAFT ACCEPTANCE

\section{Introduction-}

Current clinical treatments for type 1 diabetes rely on direct injection into the portal vein, exposing the graft to the blood, which leads to the death of 50 $80 \%$ of transplanted islets through instant blood-mediated inflammatory reactions $(\text { IBMIR })^{111,112}$. Other sites for transplant have been explored, including kidney, spleen, and omentum ${ }^{113}$, or the murine version of omentum, epididymal fat pad $(E F P)^{114}$. These extrahepatic sites for transplant have varying degrees of vascularization and inflammatory responses to islet transplants, which leads to different levels of engraftment and islet survival.

As such, type 1 diabetes patients might greatly benefit from alternative site transplantation where IBMIR and inflammatory responses are reduced, yet islets are sufficiently vascularized. This may be achievable through transplantation in conjunction with biomaterials such as maleimide-terminated 4-arm poly(ethylene) glycol (PEG-4MAL) and poly (lacto-co-glycolide) (PLG). PEG-4MAL with VEGF tethered to the hydrogel network and slowly released through proteolytic degradation was shown to increase vascularization of islets transplanted at the epididymal fat pad in mice ${ }^{82}$. 
These hydrogels may also be used in conjunction with SA-FasL to control the immune response to engrafted islets. Integrating biotin into the PEG-4MAL gels and then engineering with SA-FasL could allow for the slow release of SAFasL as the gels degrade, allowing for continuous immunosuppression in the area of the graft.

PLG scaffolds also show promise for enabling clinical islet transplants at extrahepatic sites. Islets can be seeded into the pores of the scaffold, which then allows for integration with the host tissue. PLG scaffolds transplanted with islet grafts in the EFP of mice allow for islet vascularization and nutrient diffusion due to their high porosity ${ }^{115,116}$. Further experimentation showed that decorating PLG scaffolds with collagen IV, which is important in extracellular matrix structure, resulted in an increase in function of the transplanted islets ${ }^{115,117}$.

In this chapter, we study the ability of PLG scaffolds and PEG-4MAL hydrogels in combination with SA-FasL and a short course of rapamycin to induce long-term tolerance to allogeneic islets in a chemically induced mouse model of BALB/c-to-C57BL/6. We also engineer biomaterials with SA-FasL alongside islet engineering with SA-FasL to induce tolerance to islets without additional immunosuppression in the same allogeneic model.

\section{Materials and Methods}

Islet transplantation. BALB/c pancreatic islets were isolated using Liberase TL as a digestive enzyme (Roche Life Science) and purified by a Ficoll density gradient as previously published ${ }^{118}$. To biotinylate islets, overnight cultured islets were incubated in $5 \mu \mathrm{M}$ EZ-Link Sulfo-NHS-LC-Biotin (Thermo Scientific) for 30 
min at room temperature, washed extensively with PBS to remove unbound biotin solution. Biotinylated islets and microgels were engineered with SA-FasL ( $150 \mathrm{ng} / 500$ islets and 1-10 $\mu \mathrm{g} / 1000$ microgels). In select groups, unengineered islets or microgels or both were used in place of SA-FasL engineered islets or microgels. Approximately 500 islets were co-transplanted with 1000 microgels into streptozotocin diabetic (> $250 \mathrm{mg} / \mathrm{dL}$ ) C57BL/6 or $\mathrm{B} 6.129(\mathrm{Cg})$ Foxp3 $^{\text {tm3(DTR/GFP)Ayr } / J}\left(\mathrm{C} 57 \mathrm{BL} / 6\right.$.FoxP3 $\left.{ }^{\text {EGFP/DTR }}\right)$ recipients, where indicated. For Treg depletion, islet graft recipients were injected i.p. with diphtheria toxin (50 $\mu \mathrm{g} / \mathrm{kg}$ body weight) and depletion was confirmed 3 days later in peripheral blood lymphocytes using flow cytometry. Selected groups were also treated i.p. with rapamycin at $0.2 \mathrm{mg} / \mathrm{kg}$ daily for 15 doses starting the day of transplantation. In select groups of mice, islets were loaded onto PLG scaffolds (2/mouse). Diabetic mice were given anesthesia and a small incision was made on the abdomen to allow scaffolds to be placed on epididymal fat pads. Adipose tissue was wrapped around scaffolds before being returned to the abdomen. Mice were then sutured. Select biotin-PLG scaffolds were engineered by placing scaffolds to a round bottom tube and adding SA-FasL ( 0.5 or $2.5 \mu \mathrm{g} /$ scaffold) diluted in PBS and incubating at $20^{\circ} \mathrm{C}$ for 30 minutes while rotating and shaking the tube every 10 minutes. Scaffolds were washed twice before being loaded with islets. Unmodified BALB/c islets co-transplanted with unmodified PEG gels or loaded onto unmodified PLG scaffolds were used as controls. Animals were monitored for blood glucose and $\geq 250 \mathrm{mg} / \mathrm{dL}$ blood glucose levels for two consecutive daily measurements were considered rejected. Data was graphed using GraphPad 
Prism and log-rank test was used to determine significance between groups, $p<$ 0.05 was considered significant.

\section{Intraperitoneal Glucose Tolerance Test}

Mice were put in clean cages without food and allowed to fast for 6 hours. After fasting, mice were injected with $25 \%$ glucose solution $(2 \mathrm{gm} / \mathrm{kg}$ body weight). Mice were monitored for blood glucose levels before injection and at 10, $20,30,60,90$, and 120 minutes post glucose injection.

Immune monitoring. Spleen, kidney, and kidney draining lymph nodes were harvested from rejecting and long-term mice (> 200 days). Single cells were prepared from the spleen and lymph nodes by gentle mechanical dispersion and from islet harboring kidney by collagenase digestion. Cells were stained using antibodies to cell surface markers (Alexa 700-CD4 Ab, APC-Cy7-CD8 Ab, PECy7-CD25 Ab from Pharmingen, BD, and eFlour 450-CD44 Ab and PerCPCy5.5-CD62L Ab from eBioscience). Intracellular FoxP3 staining was carried out on fixed/permeablized cells using FoxP3 Transcription Factor Staining Buffer set (eBioscience). For mixed lymphocyte reaction, splenocytes were panned and labelled with CFSE. Stimulator cells were prepared from either naïve BALB/c (donor) or $\mathrm{C} 3 \mathrm{H}\left(3^{\text {rd }}\right.$ party) mice, irradiated with 200 cGy, and cocultured with equal numbers of responder cells in 96 -well plates $\left(0.1 \times 10^{6}\right.$ cells/well). Cells were cultured in $200 \mu \mathrm{l}$ DMEM supplemented with HEPES buffer, sodium pyruvate, penicillin/streptomycin, L-Glutamine (ThermoFisher Scientific), FBS, L- 
Arginine HCL, folic acid, L-Asparagine, 2-Mercaptoethanol (Sigma), and responder serum. Cells were harvested after four days of culture at $37^{\circ} \mathrm{C}$ and stained with Alexa 700-CD4 Ab, APC-Cy7-CD8 Ab, and 7AAD to separate dead cells (BD Pharmingen). Data was collected using BD LSR II and analyzed using Diva software. Data was graphed using GraphPad Prism and Welch's t test was used to determine significance between groups, $\mathrm{p}<0.05$ was considered significant.

Proliferation assay. Splenocytes harvested from selected group of transplant recipients were labeled with CFSE and used as responders to irradiated (2000 cGy) splenocytes from donor or third party $\mathrm{C} 3 \mathrm{H}$ mice in a standard in vitro proliferation assay ${ }^{74}$. After 4 days in culture, cells were stained with 7AAD and fluorescence-conjugated Abs against CD4 and CD8, and analyzed for CFSE dilution by gating on live cells using BD LSR II. Data was analyzed using Diva software. Data was graphed using GraphPad Prism and Welch's $t$ test was used to determine significance between groups, $p<0.05$ was considered significant.

Confocal Microscopy. After the observation period of 200 days, long-term islet bearing kidneys were snap frozen in OCT compound (Sakura Tissue-Tek) by submerging in methyl butane (Sigma) on dry ice. Tissues were cut in $10 \mu \mathrm{m}$-thick slices using a Bright OTF5000 cryomicrotome (Rose Scientific) and put on frosted slides for staining. Slides were fixed in $4 \%$ paraformaldehyde, incubated in $0.5 \%$ Triton $\mathrm{X}-100$, and blocked in $0.1 \%$ bovine serum albumin, $5 \%$ goat 
serum, and rat anti-mouse CD16/CD32 (BD Pharmingen). Staining was performed using rabbit anti-glucagon mAb (Cell Signaling) and guinea pig antiinsulin polyclonal antibody (Dako) as primary antibodies, followed by washing and staining with AlexaFluor-647-conjuaged goat anti-rabbit antibody (Life Technologies) and AlexaFluor-555-conjugated anti-guinea pig antibody (Invitrogen). Hoechst 33342 (Molecular Probes) was used to stain DNA. Fluorescent images were obtained using a Leica TCS SP5 confocal microscopy under 10X magnification.

\section{Statistical analysis}

Flow data was tested for significance using a two tailed Welch's t-test. Graft survival was tested for significance using the log-rank test. $P$ values of $<0.05$ were considered significant. Survival curves, IPGTT, and flow graphs were created and analyzed using GraphPad Prism software.

\section{Results}

\section{SA-FasL-engineered microgels induce apoptosis}

Herein, we engineered a novel biomaterial for the sustained presentation of SA-FasL within the islet graft microenvironment. This approach eliminates the need for islet modification and establishes a translatable, effective immunomodulatory strategy that does not require chronic immunosuppression. Hydrogel microparticles (microgels) were synthesized from maleimide-terminated 4-arm poly(ethylene) glycol (PEG-4MAL) macromers using microfluidics 
polymerization ${ }^{119}$. The PEG-4MAL platform enables stoichiometric, covalent incorporation of thiol-containing molecules, and provides improved crosslinking efficiency for formation of structurally defined hydrogels ${ }^{80}$. PEG-4MAL exhibits minimal toxicity in vivo, and it is rapidly excreted in the urine ${ }^{79}$, important considerations for clinical applications. Biotinylated microgels were produced by reacting biotin-PEG-thiol with PEG-4MAL macromer, and generating $150 \mu \mathrm{m}$ diameter microgels crosslinked with dithiothreitol (DTT) via microfluidics polymerization (Figure 10A). The resulting microgels displayed covalentlytethered biotin capable of capturing SA with high affinity (Figure 10B). These results show that SA-FasL can be tethered to biotinylated microgels.

\section{Long-term islet allograft survival induced by SA-FasL-engineered microgels}

The immunomodulatory efficacy of microgels presenting SA-FasL was tested in an allogeneic islet transplantation setting. Unmodified allogeneic $(B A L B / c)$ islets were mixed with microgels, and the resulting mixture was transplanted under the kidney capsule of streptozotocin-diabetic C57BL/6 mice. Mice receiving unmodified islets and control biotinylated microgels acutely rejected all grafts [median survival time $(\mathrm{MST})=14.6 \pm 1.7$ days; Figure $11 \mathrm{~A}$ ] Islets co-transplanted with SA-FasL-engineered microgels had significantly prolonged survival $(\mathrm{MST}=37.6 \pm 9.0$ days). The presentation of SA-FasL on both microgels and biotinylated islets further delayed rejection with four grafts rejecting within 59 days and one graft surviving for the 200-day observation 


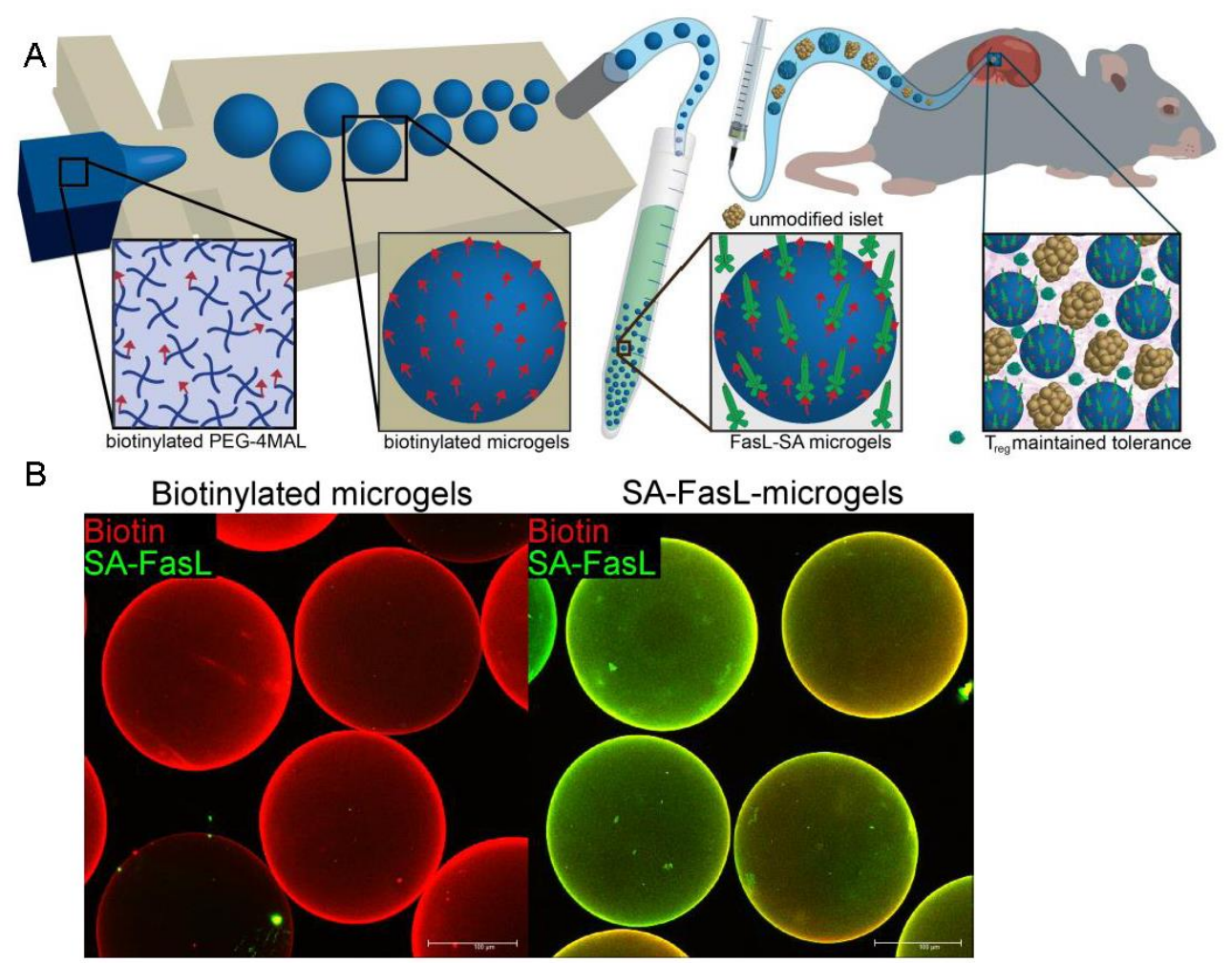

Figure 10: Microgels for controlled presentation of immunomodulatory proteins. (A) Flow focusing microfluidics were used to generate biotinylated microgels from biotin-functionalized PEG-4MAL macromers. SA-FasL was immobilized on microgels and these immunomodulatory microgels were cotransplanted with islets under the kidney capsule of diabetic mice, inducing graft acceptance. (B) Biotinylated microgels capture and display SA. Biotinylated microgels (left) or SA-FasL-engineered microgels (right) stained to show both free biotin (red) and SA-FasL (green). Scale bar $100 \mu \mathrm{m}$. 
period. The improved performance of this group suggests a dose-dependent immunomodulatory effect for SA-FasL. This was confirmed in mice receiving microgels engineered with 10 times more SA-FasL protein which further improved graft survival as 2/5 unmodified islet grafts did not show signs of rejection by the 200-day experimental end-point (Figure 11A, B). Notably, all grafts $(n=5)$ functioned and survived for the entire 200-day observation window in mice co-transplanted with unmodified islets and SA-FasL-presenting microgels when subjects were treated with a short course of rapamycin $(0.2 \mathrm{mg} / \mathrm{kg}$ daily initiated on day 0 post-transplantation for 15 doses; Figure $11 \mathrm{~A}, 12)$. Intraperitoneal glucose tolerance tests demonstrated equivalent function of these long-term grafts compared with naïve mice (Figure 11C). In marked contrast, the same protocol with rapamycin injections but without SA-FasL-engineered microgels resulted in acute rejection (MST $=20.6 \pm 3.9$ days) (Figure $11 \mathrm{~A}$ ). Taken together, these results show that simple co-transplantation of allogeneic islets and SA-FasL-engineered microgels restores long-term glycemic control without the use of chronic immunosuppression or islet modification.

\section{Tregs required for long-term survival of islets in mice treated with SA-FasL- engineered microgels}

Because of the localized nature of immunomodulation, we assessed the systemic response of graft recipients to donor antigens in an in vitro proliferation assay. Both $\mathrm{CD}^{+}$and $\mathrm{CD}^{+} \mathrm{T}$ cells from long-term (> 200 days) islet graft recipients treated with SA-FasL-engineered microgels showed proliferative 
a

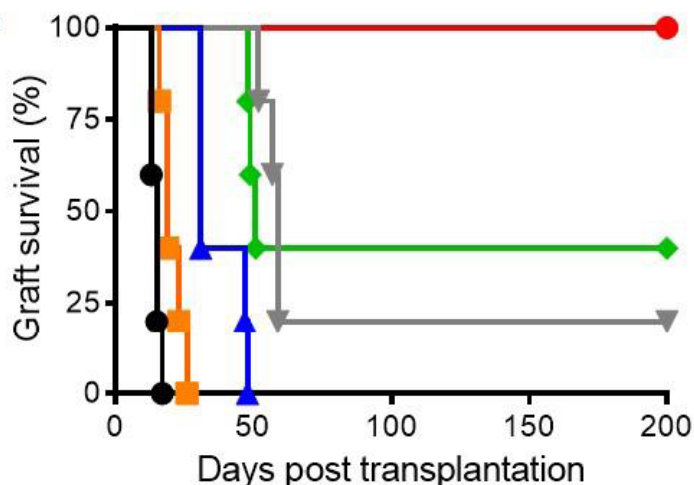

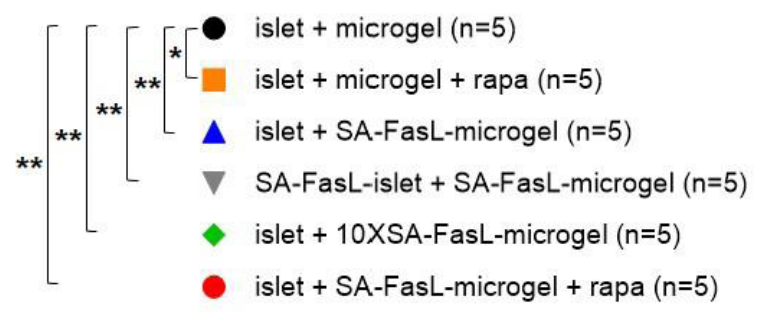

b

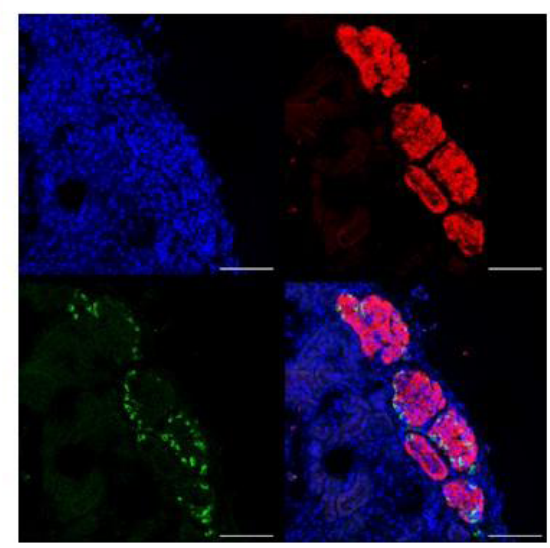

c - naive $(n=3)$

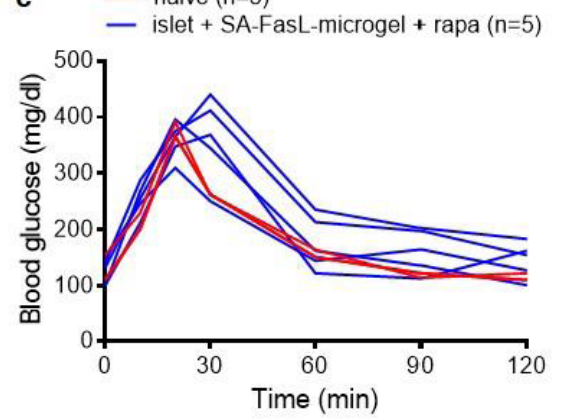

Figure 11: Survival of allogeneic islet grafts co-transplanted with SA-FasLpresenting microgels. (A) Islet graft survival. Biotinylated microgels were engineered with SA-FasL ( $1 \mu \mathrm{g}$ protein/1000 microgels, unless otherwise noted) and co-transplanted with unmodified or SA-FasL-engineered BALB/c islets (500/transplant) under the kidney capsule of chemically diabetic C57BL/6 recipients. Rapamycin was used at $0.2 \mathrm{mg} / \mathrm{kg}$ daily i.p. injection for 15 doses starting the day of transplantation in the indicated groups. Animals were monitored for blood glucose levels and two consecutive daily readings of $\geq 250$ $\mathrm{mg} / \mathrm{dL}$ were considered to be diabetic (rejection) $\left({ }^{*} \mathrm{p}<0.05,{ }^{* *} \mathrm{p}<0.01\right)$. (B) Immunostaining of a long-term graft ( $>200$ days) from recipient receiving microgels engineered with $10 \mu \mathrm{g}$ of SA-FasL showing insulin (red) and glucagon (green) positive cells as well as DNA (blue). (C) Intraperitoneal glucose tolerance 
test on day 200 showing long-term islet grafts with normal function. 


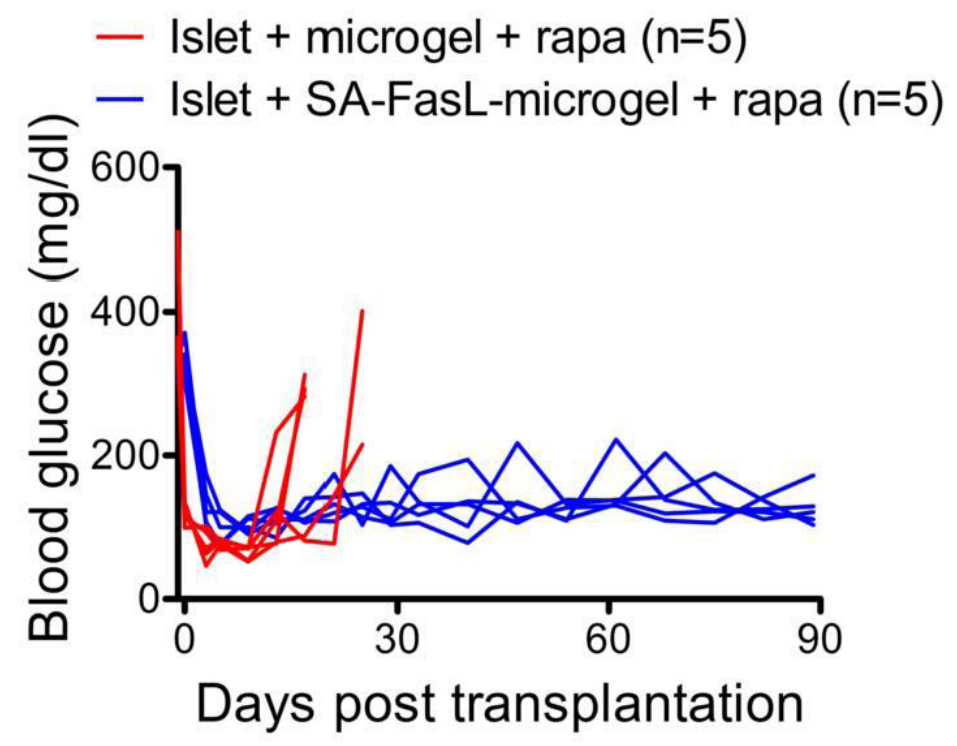

Figure 12: Blood glucose levels. Readings were taken on chemically diabetic C57BL/6 mice transplanted with microgels presenting SA-FasL $(1 \mu \mathrm{g}$ protein/1000 microgels) and naïve BALB/c islet grafts (500) under a short cover of rapamycin (administered i.p. daily at $0.2 \mathrm{mg} / \mathrm{kg}$ for 15 doses). Controls included mice subjected to the same regimen, except receiving microgels without SA-FasL protein. 
responses to donor as well as third party antigens (Figure 13A). The observed responses were at similar magnitudes to those obtained using $T$ cells from rejecting mice receiving unmodified microgels plus rapamycin. This result indicates that mice receiving SA-FasL-engineered microgels maintain systemic immune competence, and that the protection afforded by SA-FasL-engineered microgels remains localized to the graft, as reported previously in two transplant settings using FasL as an immunomodulatory molecule ${ }^{74,120}$.

To further elucidate the mechanism of graft acceptance, immune cell populations harvested from the spleen, graft draining lymph nodes (LNs), and the graft were analyzed using flow cytometry in a time-course study, with particular focus on Teff and T-regulatory (Treg) cells as targets of FasL-mediated immunomodulation. We observed a trend towards an increased ratio of Treg to $\mathrm{CD}^{+}$and CD8 ${ }^{+}$Teff cells in the graft $\left(p<0.05\right.$ for Treg:CD8 ${ }^{+}$Teff $)$and Treg to $\mathrm{CD}^{+}$and Teff cells in graft draining LNs $\left(p<0.05\right.$ for Treg:CD4 ${ }^{+}$Teff population) in groups receiving SA-FasL-engineered microgels and rapamycin compared to control groups receiving unmodified microgels alone or in combination with rapamycin (Figure 13B). Treg cells, similar to Teff cells, follow the inflammatory cues and infiltrate into rejecting grafts without a functional consequence ${ }^{121,122}$. As such, we conducted a depletion study to directly assess the role of Treg cells in the observed graft acceptance in our model. For these studies, BALB/c allogeneic islets were transplanted into transgenic C57BL/6 mice expressing human diphtheria toxin (DT) receptor under the control of Foxp3. Chemically diabetic transgenic mice transplanted with allogeneic islets and SA-FasL- 

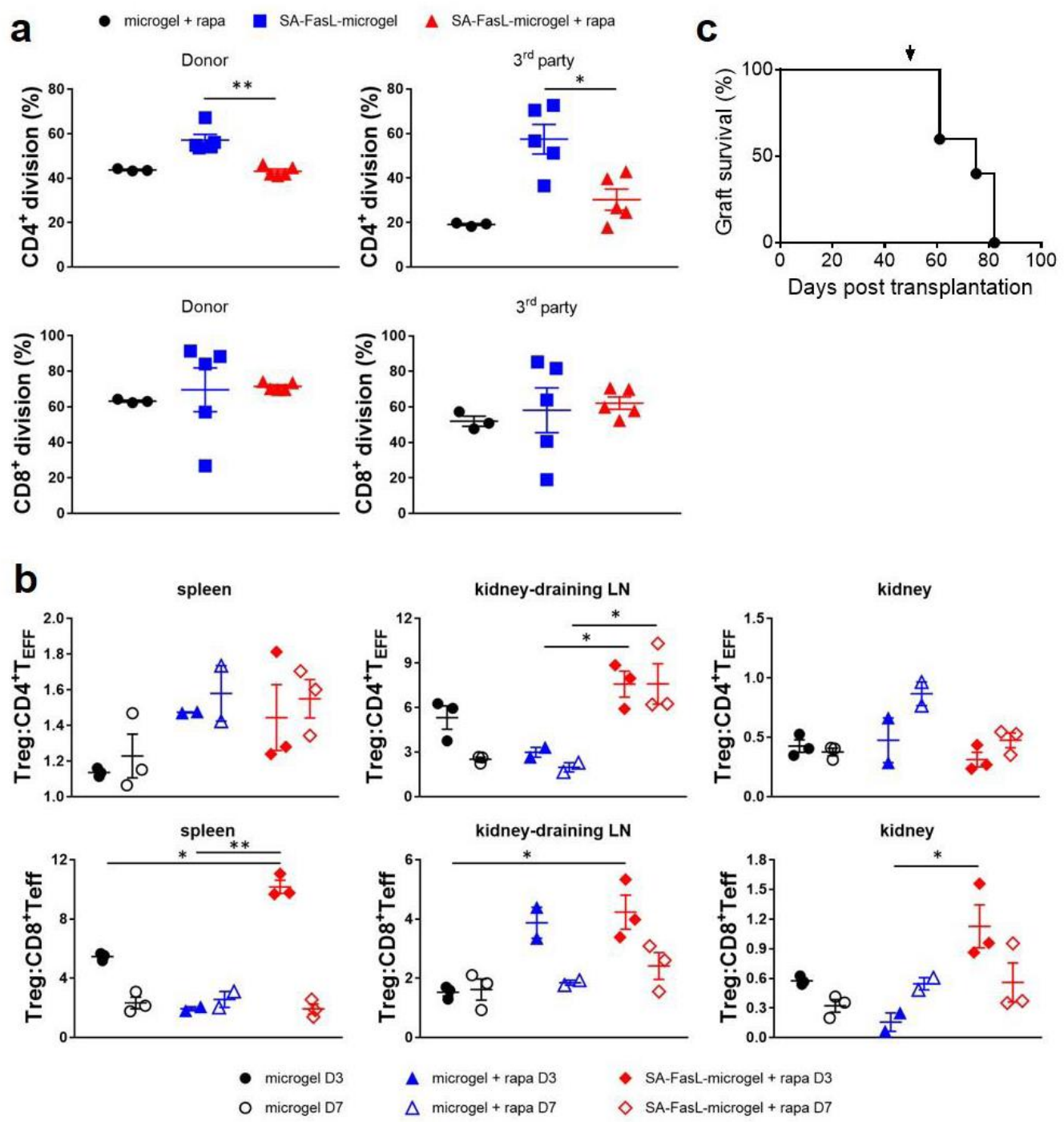

Figure 13: Immune monitoring and the role of CD4+CD25+FoxP3+ Treg cells in islet graft acceptance. (A) Systemic response of long-term graft survivors to donor antigens. Splenocytes from the indicated groups were labeled with carboxyfluorescein succinimidyl ester (CFSE) and used as responders to irradiated $\mathrm{BALB} / \mathrm{c}$ donor and $\mathrm{C} 3 \mathrm{H}$ third party stimulators in an ex vivo mixed lymphocyte reaction assay. The dilution of CFSE dye in CD4+ and CD8+ T cells was assessed using antibodies to CD4 and CD8 molecules in flow cytometry and 
plotted as percent division for each cell population. (B) Time course analysis of immune cell types. Single cells prepared from the spleen, kidney, and kidneydraining lymph nodes of the indicated groups on day 3 and 7 post-islet transplantation were stained with fluorescence-labelled antibodies to cell surface molecules that define CD4+ Teff (CD4+CD44hiCD62Llo), CD8+ Teff (CD8+CD44hiCD62Llo), and Treg (CD4+CD25+FoxP3+) populations and analyzed using flow cytometry. The ratios of Treg to CD4+ Teff and CD8+ Teff are plotted (mean \pm SEM, ${ }^{*} p<0.05,{ }^{* *} p<0.005$ ). (C) Depletion of Treg cells results in acute rejection of established islet grafts. C57BL/6.FoxP3EGFP/DTR mice $(n=5)$ were transplanted with BALB/c islet grafts and SA-FasL presenting microgels under transient cover of rapamycin (administered i.p. daily at 0.2 $\mathrm{mg} / \mathrm{kg}$ for 15 doses). These mice were then injected i.p. with $50 \mu \mathrm{g} / \mathrm{kg}$ diphtheria toxin on day 50 post transplantation (arrow) to deplete Treg cells. 
engineered microgels under the transient cover of rapamycin established graft acceptance, as seen previously in $\mathrm{C} 57 \mathrm{BL} / 6$ recipients, with all mice maintaining graft function at day 50 post-transplantation. Depletion of Treg cells by administration of DT on day 50 resulted in rejection of all grafts by day 82 (Figure $13 \mathrm{C}$; MST $=72.2 \pm 10.2$ days), demonstrating the dominant role of this cell type in graft acceptance.

\section{Transplantation of SA-FasL modified islets on microporous scaffolds}

We investigated the transplantation of SA-FasL modified islets on microporous scaffolds implanted into the epididymal fat pad (Figure 14A). Initial studies employed syngeneic islets transplanted into streptozotocin-induced diabetic mice to determine the impact of the scaffolds and short term rapamycin on the engraftment and function of the islets. Transplantation of the syngeneic islets led to the establishment of euglycemia within 10 days for all animals, and the animals maintained euglycemia for the duration of the study (100 days) (Figure 14B). Subsequently, allogeneic islets modified with SA-FasL were transplanted on microporous scaffolds. Unmodified islets transplanted on scaffolds with transient rapamycin had rejection of the grafts, as indicated by increased blood glucose levels, by day 30 (Figure 14B). Mice transplanted with allogeneic islets modified with SA-FasL and receiving transient rapamycin had normalized blood glucose levels that were sustained for 200 days (Figure 14B),

similar to the results with syngeneic islets. Rapamycin has been previously reported to synergize with FasL presentation to prolong graft survival ${ }^{74}$, as either 
A
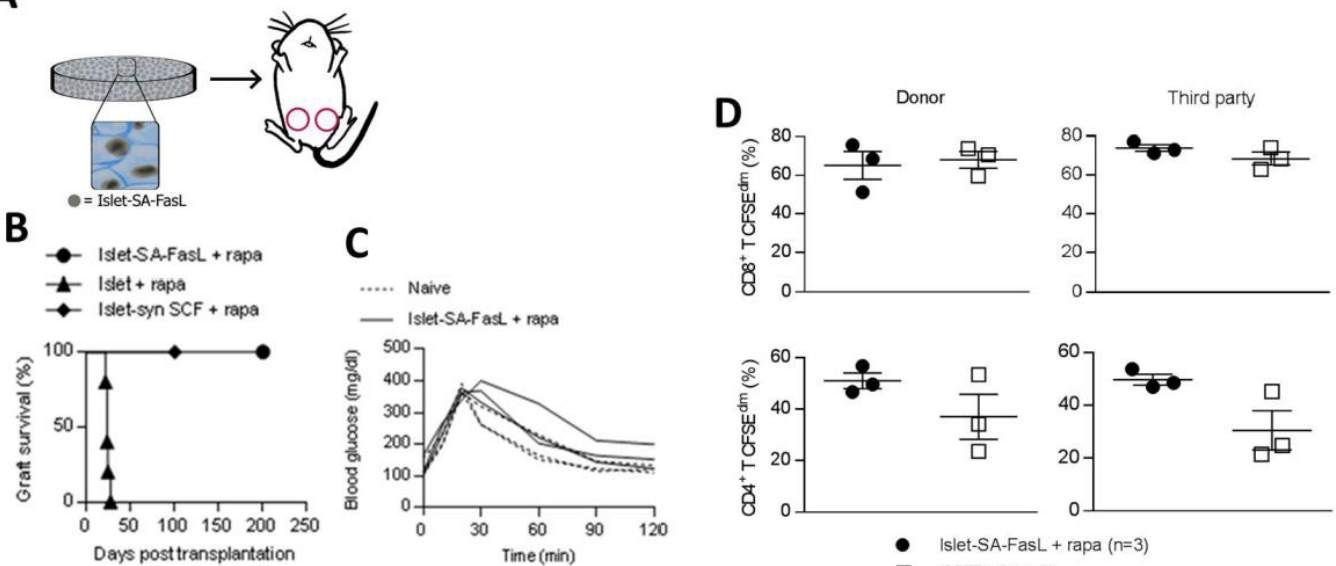

Figure 14: SA-FasL engineered islets establish allogeneic tolerance when

transplanted on PLGA scaffolds. (A) Schematic showing biotinylated allogeneic islets functionalized with SA-FasL are loaded on microporous PLGA scaffolds and planted in the epididymal fat pad of mice. (B) Kaplan Meier analysis of allogeneic BALB/C islets transplanted under the short cover of rapamycin on unmodified PLGA scaffolds in C57BL/6 recipients. Conditions include SA-FasL-engineered islets $(\mathrm{n}=5$, MST $>200$ days, $\mathrm{P}=0.0018$ vs. rapamycin alone, $P=0.0308$ ), naïve islets $(n=5, M S T=23 \pm 2.19$ days), and unmodified syngeneic islets ( $n=3$, MST > 100 days). (C) Intraperitoneal glucose tolerance test of long-term islet grafts compared to naïve C57BL/6 mice after fasting for 6 hours, followed by i.p. glucose injection. Blood glucose of mice was taken starting just before injection and at the indicated time points. (D) T cell proliferative response from recipients of long-term (> 200 days) BALB/c SA-FasLengineered islets mounted on unmodified PLGA scaffolds plus rapamycin $(n=3)$ and naïve C57BL/6 as controls $(n=3)$. Responders were labeled with CFSE and used against $\mathrm{BALB} / \mathrm{C}$ donor and third party $\mathrm{C} 3 \mathrm{H}$ stimulators in a standard ex vivo 
mixed lymphocyte reaction. After 4 days of culture, cells were stained with antibodies against CD4 and CD8 molecules and incubated with 7AAD to gate out dead cells before flow cytometry analysis. Bars represent mean and SEM. Asterisks represent level of significance $\left({ }^{*} p<0.05,{ }^{* *} p<0.01\right)$ found by using a two-tailed Welch's t-test. 
factor alone results in only short-term graft function. An intraperitoneal glucose tolerance test (IPGTT) study demonstrated that the normalization of blood glucose levels by the transplanted islets was similar to that observed with naïve mice (i.e., non-diabetic) (Figure 14C), which is consistent with previous reports of islets transplanted on scaffolds ${ }^{116,123}$.

T cell proliferative responses were analyzed from the spleens. The collected cells were labeled with CFSE and used against BALB/c donor and third party $\mathrm{C} 3 \mathrm{H}$ stimulators in a standard ex vivo mixed lymphocyte reaction. After 4 days of culture, the responses from CD8 T cells indicated similar proliferative responses for the SA-FasL islets, the unmodified islets, and an age-matched C57BL/6 control, with responses similar to both the donor and third party stimulators (Figure 14D). Interestingly, CD4 T cell responses were greater for the SA-FasL modified islets relative to either the unmodified islets or age-matched control. This response was similar for both the donor and third party stimulators. These results demonstrate that $\mathrm{CD} 4$ and $\mathrm{CD} 8$ responsiveness is maintained outside the graft. Collectively, these studies demonstrate that the microporous scaffolds for transplantation of FasL modified islets to an extrahepatic, extra-renal site provides for engraftment of the islets and protection from the immune response similar to previous reports performed with transplantation into the kidney capsule or liver ${ }^{74,124}$. 


\section{FasL scaffolds support allogeneic graft function without sustained immunosuppression}

We subsequently investigated whether SA-FasL modified scaffolds could prevent allogeneic islet rejection similar to the SA-FasL modified islets, while also supporting engraftment and long-term function to maintain normoglycemia. Scaffolds decorated with SA-FasL were loaded with islets from BALB/c donors and transplanted into the epididymal fat pad of diabetic C57BL/6 mice. Naïve islets mounted on SA-FasL-engineered PLG scaffolds along with transient rapamycin demonstrated graft survival for more than 200 days in more than $80 \%$ of the animals (Figure 15A), with one animal rejecting at day 30. Rapamycin without FasL had a mean graft survival time of $23.6 \pm 2.2$ days (Figure 15A, B). Interestingly, when both islets and scaffolds were conjugated with FasL but did not receive the short course rapamycin treatment, one third of the mice established long-term tolerance while the rest rejected by day 50 . For the transplantation of islets on SA-FasL modified scaffolds, normoglycemia was established within days of transplantation (Figure 15B). The blood glucose dynamics were similar between the SA-FasL-modified scaffolds and the unmodified scaffolds (with rapamycin) through day 20 , at which point, the blood glucose levels began to rise for the unmodified scaffolds likely due to rejection of the islets. An IPGTT performed at day 200 demonstrated restoration of normoglycemia at a rate that was similar to naïve animals (Figure 15C). 

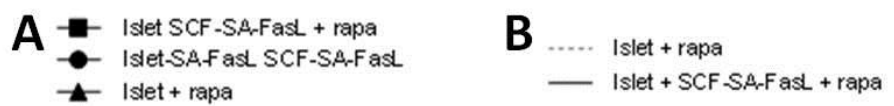

C N..... Naive
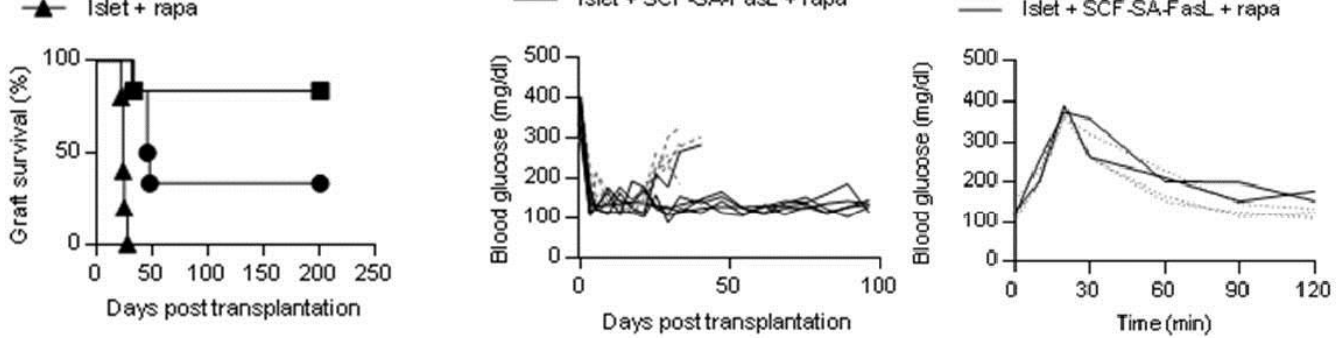

Figure 15: Islets on scaffolds conjugated with SA-FasL demonstrate robust

long-term tolerance. (A) Survival of allogeneic BALB/c islets mounted on PLGA scaffolds and transplanted in the epididymal fat pad of chemically diabetic C57BL/6 recipients. Groups included naïve islets mounted on SA-FasLengineered PLGA scaffolds plus rapamycin $(n=6$, MST $>200$ days, $P=0.0007$ vs rapamycin alone), SA-FasL-engineered islets mounted on SA-FasLengineered PLGA scaffolds $(n=6, M S T=46$ days, $P=0.0007$ vs rapamycin alone), and naïve islets transplanted under a short cover of rapamycin $(n=5$, MST $=23 \pm 2.19$ days). All mice received islets loaded on 2 PLGA scaffolds. PLGA scaffolds were engineered with $2.5 \mu \mathrm{g} / \mathrm{scaffold}$, except 3 mice in the isletFasL + PLGA-SA-FasL that were transplanted with PLGA scaffolds engineered with $0.5 \mu \mathrm{g} / \mathrm{scaffold}$ and all 3 animals rejected their grafts. Rapamycin was given to the indicated groups through i.p. injection at $0.2 \mathrm{mg} / \mathrm{kg}$ daily for 15 days starting on the day of transplantation. Mice were monitored twice weekly for blood glucose levels. Those with $>250 \mathrm{mg} / \mathrm{dL}$ for two consecutive readings 24 hours apart were considered diabetic and rejecting the graft. Analysis done using log-rank test, ${ }^{* *} P<0.01,{ }^{* * *} P<0.001$. (B) Blood glucose readings of two groups of 
mice from (A). (C) Intraperitoneal glucose tolerance test (IPGTT) of long-term islet grafts compared to naïve C57BL/6 mice after fasting for 6 hours, followed by i.p. glucose injection. Blood glucose of mice was taken starting just before injection and at the indicated time points. 


\section{CHAPTER 4: DISCUSSION}

The studies done in chapter 2 show that SA-FasL-engineered pancreatic islets induce a biphasic, spatiotemporal tolerance to allografts. This tolerance begins as systemic during the early induction phase, and becomes localized during the maintenance phase. Despite extensive searching of the literature, we have not found this biphasic, spatiotemporal tolerance induced in other models. We also showed the noted ability of FasL to induce immune privilege at the site of the graft. This immune privilege relied on phagocytes and the tolerogenic cytokine TGF- $\beta$ and required the graft and Tregs to maintain it.

FasL has been shown to give similar tolerogenic effects when used for immunomodulation in other studies $25,36,55,92,103,125$. However, other studies have shown the inability FasL to induce tolerance to allografts ${ }^{65,93,94}$. The conflicting results may be explained by the difference in function of membrane and soluble forms, reverse signaling, and its continuous expression when upregulated through gene therapy ${ }^{68,92-94,97,126-129}$. Complications can arise especially when FasL is cleaved from the cell membrane by matrix metalloproteinases and is converted to its soluble form, as the soluble form causes chemotaxis in neutrophils, competes for binding with membrane-bound FasL, thereby blocking apoptosis. ${ }^{70,96,97}$. 
In comparison, SA-FasL does not notably increase chemotaxis of neutrophils, has removed the cleavage site, induces apoptosis in T cells, and is only transiently displayed on the surface of islets, all of which may lead to the more consistent results in these studies ${ }^{72,74,118}$. For example, islet grafts ectopically expressing wild type FasL were shown to undergo acute rejection mediated by neutrophils ${ }^{68,94}$. On top of this, sustained expression may cause excessive apoptosis which has been shown to result in necroptosis resulting in inflammatory responses ${ }^{130}$. Lastly, overexpression of the soluble form of FasL in tissues rich in metalloproteinases may program an anti-apoptotic and proinflammatory cascade that results in destructive, rather than protective immune responses against allografts ${ }^{129}$. All in all, the apoptotic SA-FasL engineered on islet grafts temporarily for localized immunomodulation overcomes various shortcomings of the wild type FasL.

Induction of tolerance in our model required phagocytes and TGF- $\beta$, as depleting phagocytes or blocking TGF- $\beta$ resulted in graft rejection. We hypothesize that Teff cells respond to the islet graft and undergo apoptosis due to the SA-FasL on the graft. Phagocytes then bind to the apoptotic cells, which causes them to secrete anti-inflammatory cytokines, including TGF- $\beta$, which, in conjunction with rapamycin, leads to the expansion or conversion of Tregs. In support of this hypothesis, confocal microscopy revealed a higher number of macrophages infiltrating SA-FasL-engineered islet grafts compared to SA-engineered control grafts soon after transplantation. Some of these macrophages colocalized with TGF- $\beta$ in the SA-FasL engineered grafts. TGF- $\beta$ secreted by macrophages or 
other phagocytes binding apoptotic bodies may contribute to the generation and suppressor function of Treg cells as well as the suppression of $T$ cells within the

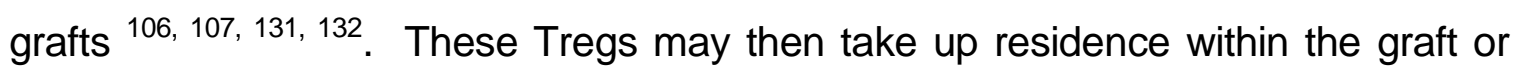
home to other sources of inflammation such as a second set of unengineered islets to establish immune privilege at both sites. Although we demonstrate the direct role of phagocytes and TGF- $\beta$ in the induction phase of tolerance, the exact reasons for the necessity of phagocytes and the source of TGF- $\beta$ remain to be elucidated and will be the subject of future studies.

Despite tolerance being systemic during the induction phase, during the maintenance phase it is localized to the graft and requires Tregs present and graft tissue to maintain the immune privilege. Although FasL has been implicated in acquired immune privilege ${ }^{92,103,104}$, to our knowledge this is the first study to provide direct evidence for such a role by demonstrating that a second set of unmanipulated islet grafts survive rejection following transplantation into the same site supporting the long-term survival of SA-FasL-engineered islets. The immune privilege in our model was antigen-specific and could not be extended to an unmanipulated islet graft transplanted at a distant site, even in the presence of rapamycin with the potential to expand and mobilize Treg cells, which are required for immune privilege in our model. The established immune privilege required the persistence of alloantigens in the form of the graft, as delayed (4 vs 20 days) transplantation of the second set of unmanipulated islet graft following the destruction of original graft with streptozotocin resulted in acute rejection. These observations are consistent with previous studies on FasL in physiological 
immune privileged sites ${ }^{104,133}$. FasL in the eye contained herpes simplex virusinduced inflammation by eliminating activated $T$ cells ${ }^{104}$. Corneal grafts expressing FasL under normal physiological conditions from wild type, but not mutant mice lacking this molecule, showed long-term survival in allogeneic recipients ${ }^{103}$. Our findings are also consistent with studies using tissues with increased expression of FasL. Syngeneic myoblasts transfected to express FasL protected unmodified allogenic islets from rejection when co-transplanted under the same kidney capsule ${ }^{92}$.

Tolerance was antigen and tissue specific, as SA-FasL-engineered islets failed to protect third party islet and donor-matched skin and heart grafts. These observations are consistent with previous studies showing tolerance specificity of tissue-specific antigens ${ }^{134}$. However, rejection of donor heart and skin, but not the third party skin, also resulted in the rejection of SA-FasL-engineered islet grafts. This may be described by the nature of the immune response to different tissues. The immune response to skin and heart allografts may elicit a systemic response which is stronger than the response to islets. SA-FasL-engineered islets exhibited some tolerance when combined with heart transplantation, as heart grafts were somewhat prolonged when compared to heart grafts alone. Skin grafts were not prolonged in the same fashion, which is consistent with previous studies showing their immunogenicity ${ }^{63}$. We have previously shown that transfer of SA-FasL-engineered splenocytes induces tolerance to cardiac allografts in rats ${ }^{99}$. This study shows that SA-FasL induced tolerance depends on the nature of the tissue engineered with SA-FasL, treatment dose, and 
setting. In the case of SA-FasL-engineered splenocyte treatment, several systemic injections of cells were required ${ }^{99}$.

The transient display of immunomodulatory ligands on the surface of grafts has the potential to induce permanent graft acceptance in the absence of chronic immunosuppression. The advantage of a tolerance inducing treatment using SAFasL is antigen specificity that is localized to the graft, which would allow a competent immune system to fight off infections while leaving the graft as an immune privileged site.

Immune privilege generated by SA-FasL to islets transplanted with PEG microgels in chapter 3 also involved Tregs and was localized to the graft. This was demonstrated by the ability of splenocytes in long-term tolerant mice to respond normally to donor antigens. These results are consistent with the established role of FasL in immune privileged tissues, such as the eye and the testes $^{55,104,135}$. This is also consistent with a study demonstrating that primary myoblasts transfected to express FasL conferred immune privilege to cotransplanted allogeneic islet grafts ${ }^{92}$.

SA-FasL engineering of microgels have several advantages over gene therapy, including controlled loading, presentation, and retention of SA-FasL in the graft microenvironment. This is in contrast to gene therapy, which utilizes uncontrolled, continuous expression of FasL, which possesses multiple functions and different modes of expression that may be regulated differentially by the target tissues in membrane bound or soluble form. SA-FasL presented on microgels induces localized tolerance without causing major toxicity as compared 
to agonistic Fas antibodies which have been shown to cause toxicity ${ }^{64}$. Finally, SA-FasL-engineered microgels can be prepared and mixed with islets when the transplantation is to take place, avoiding the multiple manipulations and washing of islets required by some tolerance protocols. Additional studies in large animal or humanized mouse models will be necessary for further proof-of-efficacy and translation to the clinic.

Chapter 3 also showed the use of biomaterial scaffolds in combination with SA-FasL in order to transplant islets with long-term survival at a site outside the liver and kidney capsule. This protocol proved to be effective as SA-FasLengineered islet allografts were tolerated and regulated blood glucose for more than 200 days under a transient cover of rapamycin when transplanted on PLG scaffolds into an extrahepatic site with translational potential ${ }^{114}$.

Similar to engineering microgels, engineering SA-FasL on PLG scaffolds allows for minimal manipulation of islets prior to transplantation. This would lessen the damage islets during engineering and washing steps, and as such may result in better clinical outcomes. As a potential off-the-shelf product, further studies will be needed to test long-term storage of SA-FasL pre-engineered scaffolds. Scaffolds were able to be loaded with protein in an enhanced manner when compared to particles. This is probably due to the higher surface area of scaffolds. Protein loading and efficiency were similar to other techniques like carbodiimide coupling to PLG particles ${ }^{136,137 .}$

Both particles and scaffolds engineered to display SA-FasL were able to induce apoptosis. Interestingly, for concentrations between 40 and $400 \mathrm{ng} / \mathrm{mg}$, 
the extent of binding was highly consistent within experiments, yet considerable variation in apoptosis was observed between experiments, suggesting a sensitivity to the protein loading or presentation within this range. Previous studies using surface anchored polymer chains with covalently linked agonistic Fas antibodies were only able to induce up to $34 \%$ apoptosis in cells expressing Fas, while the SA-FasL engineering of biomaterials in our studies was able to induce $92 \%$ apoptosis $^{138}$. This result may be due to the far greater surface density of protein (up to $150 \mathrm{ng} / \mathrm{cm}^{2}$ vs $1.6 \mathrm{ng} / \mathrm{cm}^{2}$ ) and the differences in SAFasL compared to Fas antibody.

Importantly, microporous scaffolds engineered with SA-FasL supported engraftment and function of the transplanted unmodified allogeneic islets that maintained normoglycemia for more than 200 days, while islets transplanted on unmodified PLG scaffolds promptly rejected within 30 days, consistent with our previous results in subrenal islet transplantation ${ }^{74}$. As in the other models, this is likely due to Tregs in the graft microenvironment. When rapamycin was not included in the treatment protocol, SA-FasL was able to prolong the graft, which was also consistent with our findings in the subrenal transplant model ${ }^{74}$.

In conclusion, engineering allogeneic islets with SA-FasL induces systemic tolerance during the induction phase, and sustains immune privilege at the graft site during the maintenance phase. The induction of this immune privilege requires TGF- $\beta$ and phagocytes, while maintenance requires Tregs and the graft. SA-FasL-engineered islets are also able to induce tolerance in when transplanted in conjunction with PEG microgels or PLG scaffolds. Engineering of both microgels 
and scaffolds also induces tolerance to islet allografts. Utilizing these biomaterials to lessen the damage to islets and transplant them in new locations may be helpful in translating SA-FasL based tolerance into the clinic.

\section{Summary, implications, and future directions}

In chapter 2, we showed that SA-FasL and rapamycin require TGF- $\beta$, Tregs, and phagocytes to induce tolerance to allogeneic islets. This induction of tolerance is systemic, as evidenced by protection of a simultaneously transplanted unmodified allogeneic islet graft under the contralateral kidney capsule. It is antigen specific, as skin, heart, or third party islet grafts were rejected.

In chapter 3 we showed that SA-FasL-engineered PEG-4MAL microgels in conjunction with a short course of rapamycin were effective at inducing long-term tolerance to cotransplanted allogeneic islets in a BALB/c-to-C57BL/6 mouse model of diabetes. Long-term tolerance was not achieved without rapamycin, although rejection was significantly delayed when microgels and islets were both engineered with SA-FasL in the same model. This tolerance also required Tregs as their depletion by diphtheria toxin resulted in prompt graft rejection. We also showed the effectiveness of microporous PLG scaffolds loaded with SA-FasL-islets and transplanted in the EFP to induce long-term tolerance in this model when accompanied with a short course of rapamycin administration. SA-FasL-engineered scaffolds and rapamycin were also effective at inducing long-term tolerance to 
loaded islets. Engineering both the scaffolds and loaded islets induced long-term tolerance in one third of the mice in the absence of rapamycin.

In all of these studies, maintenance of tolerance was localized to the graft, as splenic T cells from long-term tolerant mice proliferated in a manner similar to control splenocytes when stimulated with allogeneic splenocytes. This indicates that, if translated into the clinic, a treatment using SA-FasL-engineered islets or biomaterials would have little effect on graft recipients' overall immune system, reducing their risk of infections and malignancies compared to graft recipients on chronic immunosuppressive drugs. In addition, such a treatment would reduce the damage to kidney, liver, and islets present in current clinical transplant recipients due to the toxicity of immunosuppressives.

As a substitute for the murine epididymal fat pad, the omentum could be used in future clinical trials. Indeed, islet transplants have been done on the omentum utilizing scaffolds in nonhuman primates and humans ${ }^{139,140}$. Before clinical trials can commence utilizing SA-FasL-engineered PLG scaffolds loaded with islets, we may first test the viability using a humanized mouse model. Additionally, since SA-FasL is derived from rat FasL, we will first start by creating chimeric human SA-FasL and testing it in humanized mouse models of islet transplantation.

Additionally, we must also consider the difference in mouse versus human immunity in other aspects. As humans come in contact with more organisms which can generate inflammation in transplant recipients, and also because of higher 
levels of preexisting memory T cells (heterologous immunity) ${ }^{57,58}$ as compared to clean laboratory mice, more stringent tolerance protocols must be utilized for clinical trials. Such protocols could simply include additional immunosuppressive drugs currently used for intraportal transplants, daclizumab and tacrolimus. However, there may not be a need to use them long-term if SA-FasL is effective at inducing apoptosis of graft specific T cells and inducing Tregs which take up residence within the graft as seen in the mouse transplant model.

Further studies will investigate injection of soluble SA-FasL. While soluble FasL was shown to cause chemotaxis of neutrophils and inflammation ${ }^{68}$, SA-FasL forms tetramers and oligomers, and can cause apoptosis in vitro. Soluble SA-FasL injection is a simple addition to our protocol as it does not require incubation steps. Indeed, if soluble SA-FasL were used in place of engineering, less islets would be lost due to washing and time spent in media. On top of this, soluble SA-FasL would be easy to modify dosage timing and amounts. However, soluble SA-FasL would likely influence the systemic immune system.

Finally, we will explore other chimeric proteins with potential for influencing tolerance, such as SA-IL-2 or SA-TGF- $\beta$. These two may specifically attract or generate Tregs at the site of the transplant. In addition to its ability to generate Tregs, membrane bound TGF- $\beta$ on Tregs was shown to be protective against diabetes in NOD mice ${ }^{141}$. Therefore, we may look into Treg therapies using SATGF- $\beta$. 


\section{REFERENCES}

1 Prevention CfDCa: Diabetes Report Card 2014. In, Atlanta, GA: Centers for Disease Control and Prevention, US Dept of Health and Human Services, 2014.

2 Skowera A, Ellis RJ, Varela-Calvino R, Arif S, Huang GC, Van-Krinks C, Zaremba A, Rackham C, Allen JS, Tree TI, Zhao M, Dayan CM, Sewell AK, Unger WW, Drijfhout JW, Ossendorp F, Roep BO, Peakman M: CTLs are targeted to kill beta cells in patients with type 1 diabetes through recognition of a glucose-regulated preproinsulin epitope. J Clin Invest 2008;118:3390-3402.

3 Steck AK, Rewers MJ: Genetics of type 1 diabetes. Clin Chem 2011;57:176-185.

4 Kaprio J, Tuomilehto J, Koskenvuo M, Romanov K, Reunanen A, Eriksson $\mathrm{J}$, Stengard J, Kesaniemi YA: Concordance for type 1 (insulin-dependent) and type 2 (non-insulin-dependent) diabetes mellitus in a populationbased cohort of twins in Finland. Diabetologia 1992;35:1060-1067.

5 Redondo MJ, Jeffrey J, Fain PR, Eisenbarth GS, Orban T: Concordance for islet autoimmunity among monozygotic twins. N Engl J Med 2008;359:2849-2850.

6 Flodstrom M, Maday A, Balakrishna D, Cleary MM, Yoshimura A, Sarvetnick N: Target cell defense prevents the development of diabetes after viral infection. Nat Immunol 2002;3:373-382.

$7 \quad$ von Herrath M: Can we learn from viruses how to prevent type 1 diabetes?: the role of viral infections in the pathogenesis of type 1 diabetes and the development of novel combination therapies. Diabetes 2009;58:2-11.

8 Willcox A, Richardson SJ, Bone AJ, Foulis AK, Morgan NG: Analysis of islet inflammation in human type 1 diabetes. Clin Exp Immunol 2009;155:173-181. 
9 Makhlouf L, Grey ST, Dong V, Csizmadia E, Arvelo MB, Auchincloss H, Jr., Ferran C, Sayegh MH: Depleting anti-CD4 monoclonal antibody cures new-onset diabetes, prevents recurrent autoimmune diabetes, and delays allograft rejection in nonobese diabetic mice. Transplantation 2004;77:990-997.

10 Nakayama M, Abiru N, Moriyama H, Babaya N, Liu E, Miao D, Yu L, Wegmann DR, Hutton JC, Elliott JF, Eisenbarth GS: Prime role for an insulin epitope in the development of type 1 diabetes in NOD mice. Nature 2005;435:220-223.

11 Wong FS, Karttunen J, Dumont C, Wen L, Visintin I, Pilip IM, Shastri N, Pamer EG, Janeway CA, Jr.: Identification of an MHC class I-restricted autoantigen in type 1 diabetes by screening an organ-specific cDNA library. Nature medicine 1999;5:1026-1031.

12 Kimpimäki T, Kupila A, Hämäläinen A-M, Kukko M, Kulmala $P$, Savola K, Simell T, Keskinen P, llonen J, Simell O, Knip M: The First Signs of $\beta$-Cell Autoimmunity Appear in Infancy in Genetically Susceptible Children from the General Population: The Finnish Type 1 Diabetes Prediction and Prevention Study. The Journal of Clinical Endocrinology \& Metabolism $2001 ; 86: 4782-4788$.

13 Wherrett DK, Bundy B, Becker DJ, DiMeglio LA, Gitelman SE, Goland R, Gottlieb PA, Greenbaum CJ, Herold KC, Marks JB, Monzavi R, Moran A, Orban T, Palmer JP, Raskin P, Rodriguez H, Schatz D, Wilson DM, Krischer JP, Skyler JS: Antigen-based therapy with glutamic acid decarboxylase (GAD) vaccine in patients with recent-onset type 1 diabetes: a randomised double-blind trial. Lancet 2011;378:319-327.

14 Ludvigsson J, Krisky D, Casas R, Battelino T, Castano L, Greening J, Kordonouri O, Otonkoski T, Pozzilli P, Robert JJ, Veeze HJ, Palmer J, Samuelsson U, Elding Larsson H, Aman J, Kardell G, Neiderud Helsingborg J, Lundstrom G, Albinsson E, Carlsson A, Nordvall M, Fors H, Arvidsson CG, Edvardson S, Hanas R, Larsson K, Rathsman B, Forsgren H, Desaix H, Forsander G, Nilsson NO, Akesson CG, Keskinen P, Veijola R, Talvitie T, Raile K, Kapellen T, Burger W, Neu A, Engelsberger I, Heidtmann B, Bechtold S, Leslie D, Chiarelli F, Cicognani A, Chiumello G, Cerutti F, Zuccotti GV, Gomez Gila A, Rica I, Barrio R, Clemente M, Lopez Garcia MJ, Rodriguez M, Gonzalez I, Lopez JP, Oyarzabal M, Reeser HM, Nuboer R, Stouthart P, Bratina N, Bratanic N, de Kerdanet M, Weill J, Ser N, Barat P, Bertrand AM, Carel JC, Reynaud R, Coutant R, Baron S: GAD65 antigen therapy in recently diagnosed type 1 diabetes mellitus. $N$ Engl J Med 2012;366:433-442. 
15 Shapiro AM, Ricordi C, Hering BJ, Auchincloss H, Lindblad R, Robertson RP, Secchi A, Brendel MD, Berney T, Brennan DC, Cagliero E, Alejandro R, Ryan EA, DiMercurio B, Morel P, Polonsky KS, Reems JA, Bretzel RG, Bertuzzi F, Froud T, Kandaswamy R, Sutherland DE, Eisenbarth G, Segal M, Preiksaitis J, Korbutt GS, Barton FB, Viviano L, Seyfert-Margolis V, Bluestone J, Lakey JR: International trial of the Edmonton protocol for islet transplantation. N Engl J Med 2006;355:1318-1330.

16 Zinger A, Leibowitz G: Islet transplantation in type 1 diabetes: hype, hope and reality - a clinician's perspective. Diabetes Metab Res Rev 2014;30:83-87.

17 Bennet W, Groth CG, Larsson R, Nilsson B, Korsgren O: Isolated human islets trigger an instant blood mediated inflammatory reaction: implications for intraportal islet transplantation as a treatment for patients with type 1 diabetes. Upsala journal of medical sciences 2000;105:125-133.

18 Ozmen L, Ekdahl KN, Elgue G, Larsson R, Korsgren O, Nilsson B: Inhibition of thrombin abrogates the instant blood-mediated inflammatory reaction triggered by isolated human islets: possible application of the thrombin inhibitor melagatran in clinical islet transplantation. Diabetes 2002;51:1779-1784.

19 Shapiro AMJ: Strategies Towards Single-Donor Islets of Langerhans Transplantation. Curr Opin Organ Tran 2011;16:627-631.

20 Barlow AD, Nicholson ML, Herbert TP: Evidence for Rapamycin Toxicity in Pancreatic $\beta$-Cells and a Review of the Underlying Molecular Mechanisms. Diabetes 2013;62:2674-2682.

21 Drachenberg CB, Klassen DK, Weir MR, Wiland A, Fink JC, Bartlett ST, Cangro CB, Blahut S, Papadimitriou JC: Islet cell damage associated with tacrolimus and cyclosporine: morphological features in pancreas allograft biopsies and clinical correlation. Transplantation 1999;68:396-402.

22 Hinterberger M, Aichinger M, Prazeres da Costa O, Voehringer D, Hoffmann R, Klein L: Autonomous role of medullary thymic epithelial cells in central CD4(+) T cell tolerance. Nat Immunol 2010;11:512-519.

23 Posselt AM, Barker CF, Tomaszewski JE, Markmann JF, Choti MA, Naji A: Induction of donor-specific unresponsiveness by intrathymic islet transplantation. Science 1990;249:1293-1295.

24 Tomita Y, Khan A, Sykes M: Role of intrathymic clonal deletion and peripheral anergy in transplantation tolerance induced by bone marrow 
transplantation in mice conditioned with a nonmyeloablative regimen. $J$ Immunol 1994;153:1087-1098.

25 George JF, Sweeney SD, Kirklin JK, Simpson EM, Goldstein DR, Thomas $\mathrm{JM}$ : An essential role for Fas ligand in transplantation tolerance induced by donor bone marrow. Nature medicine 1998;4:333-335.

26 Li XC, Strom TB, Turka LA, Wells AD: T cell death and transplantation tolerance. Immunity 2001;14:407-416.

27 Battaglia M, Stabilini A, Roncarolo MG: Rapamycin selectively expands CD4+CD25+FoxP3+ regulatory T cells. Blood 2005;105:4743-4748.

28 Sakaguchi S, Ono M, Setoguchi R, Yagi H, Hori S, Fehervari Z, Shimizu J, Takahashi T, Nomura T: Foxp3+ CD25+CD4+ natural regulatory T cells in dominant self-tolerance and autoimmune disease. Immunol Rev 2006;212:8-27.

29 Bacchetta R, Passerini L, Gambineri E, Dai M, Allan SE, Perroni L, Dagna-Bricarelli F, Sartirana C, Matthes-Martin S, Lawitschka A, Azzari C, Ziegler SF, Levings MK, Roncarolo MG: Defective regulatory and effector T cell functions in patients with FOXP3 mutations. J Clin Invest 2006;116:1713-1722.

30 Chapman NM, Chi H: mTOR signaling, Tregs and immune modulation. Immunotherapy 2014;6:1295-1311.

31 Sakaguchi S, Vignali DA, Rudensky AY, Niec RE, Waldmann H: The plasticity and stability of regulatory T cells. Nat Rev Immunol 2013;13:461467.

32 Feuerer M, Shen Y, Littman DR, Benoist C, Mathis D: How punctual ablation of regulatory $T$ cells unleashes an autoimmune lesion within the pancreatic islets. Immunity 2009;31:654-664.

33 Lindley S, Dayan CM, Bishop A, Roep BO, Peakman M, Tree TI: Defective suppressor function in CD4(+)CD25(+) T-cells from patients with type 1 diabetes. Diabetes 2005;54:92-99.

34 Bluestone JA, Buckner JH, Fitch M, Gitelman SE, Gupta S, Hellerstein MK, Herold KC, Lares A, Lee MR, Li K, Liu W, Long SA, Masiello LM, Nguyen V, Putnam AL, Rieck M, Sayre PH, Tang Q: Type 1 diabetes immunotherapy using polyclonal regulatory $T$ cells. Science translational medicine 2015;7:315ra189. 
35 Safinia N, Vaikunthanathan T, Fraser H, Thirkell S, Lowe K, Blackmore L, Whitehouse G, Martinez-Llordella M, Jassem W, Sanchez-Fueyo A, Lechler RI, Lombardi G: Successful expansion of functional and stable regulatory $\mathrm{T}$ cells for immunotherapy in liver transplantation. Oncotarget 2016;7:7563-7577.

36 Motz GT, Santoro SP, Wang LP, Garrabrant T, Lastra RR, Hagemann IS, Lal P, Feldman MD, Benencia F, Coukos G: Tumor endothelium FasL establishes a selective immune barrier promoting tolerance in tumors. Nature medicine 2014;20:607-615.

37 Kaminitz A, Yolcu ES, Stein J, Yaniv I, Shirwan H, Askenasy N: Killer Treg restore immune homeostasis and suppress autoimmune diabetes in prediabetic NOD mice. J Autoimmun 2011;37:39-47.

38 Yolcu ES, Kaminitz A, Mizrahi K, Ash S, Yaniv I, Stein J, Shirwan H, Askenasy N: Immunomodulation with donor regulatory T cells armed with Fas-ligand alleviates graft-versus-host disease. Experimental hematology 2013;41:903-911.

39 Kawamoto K, Pahuja A, Hering BJ, Bansal-Pakala P: Transforming growth factor beta 1 (TGF-beta1) and rapamycin synergize to effectively suppress human $\mathrm{T}$ cell responses via upregulation of FoxP3+ Tregs. Transpl Immunol 2010;23:28-33.

40 Yadav M, Stephan S, Bluestone JA: Peripherally induced tregs - role in immune homeostasis and autoimmunity. Front Immunol 2013;4:232.

41 Battaglia M, Stabilini A, Migliavacca B, Horejs-Hoeck J, Kaupper T, Roncarolo MG: Rapamycin promotes expansion of functional CD4(+)CD25(+)FOXP3(+) regulatory T cells of both healthy subjects and type 1 diabetic patients. J Immunol 2006;177:8338-8347.

42 Abraham RT, Wiederrecht GJ: Immunopharmacology of rapamycin. Annual review of immunology 1996;14:483-510.

43 Delgoffe GM, Kole TP, Zheng Y, Zarek PE, Matthews KL, Xiao B, Worley PF, Kozma SC, Powell JD: The mTOR kinase differentially regulates effector and regulatory T cell lineage commitment. Immunity 2009;30:832844.

44 Shapiro AM, Lakey JR, Ryan EA, Korbutt GS, Toth E, Warnock GL, Kneteman NM, Rajotte RV: Islet transplantation in seven patients with type 1 diabetes mellitus using a glucocorticoid-free immunosuppressive regimen. N Engl J Med 2000;343:230-238. 
45 Barlow AD, Nicholson ML, Herbert TP: Evidence for rapamycin toxicity in pancreatic beta-cells and a review of the underlying molecular mechanisms. Diabetes 2013;62:2674-2682.

46 Barlow AD, Xie J, Moore CE, Campbell SC, Shaw JA, Nicholson ML, Herbert TP: Rapamycin toxicity in MIN6 cells and rat and human islets is mediated by the inhibition of mTOR complex 2 (mTORC2). Diabetologia 2012;55:1355-1365.

47 Wang Z, Hong J, Sun W, Xu G, Li N, Chen X, Liu A, Xu L, Sun B, Zhang JZ: Role of IFN-gamma in induction of Foxp3 and conversion of CD4+ CD25- T cells to CD4+ Tregs. J Clin Invest 2006;116:2434-2441.

48 Jurgens B, Hainz U, Fuchs D, Felzmann T, Heitger A: Interferon-gammatriggered indoleamine 2,3-dioxygenase competence in human monocytederived dendritic cells induces regulatory activity in allogeneic $T$ cells. Blood 2009;114:3235-3243.

49 Battaglia M, Stabilini A, Draghici E, Gregori S, Mocchetti C, Bonifacio E, Roncarolo MG: Rapamycin and interleukin-10 treatment induces T regulatory type 1 cells that mediate antigen-specific transplantation tolerance. Diabetes 2006;55:40-49.

50 Aagaard-Tillery KM, Jelinek DF: Inhibition of human B lymphocyte cell cycle progression and differentiation by rapamycin. Cellular immunology 1994;156:493-507.

51 Watanabe-Fukunaga R, Brannan Cl, Itoh N, Yonehara S, Copeland NG, Jenkins NA, Nagata S: The cDNA structure, expression, and chromosomal assignment of the mouse Fas antigen. $\mathrm{J}$ Immunol 1992;148:1274-1279.

52 Nagata S: Apoptosis by death factor. Cell 1997;88:355-365.

53 Takahashi T, Tanaka M, Brannan Cl, Jenkins NA, Copeland NG, Suda T, Nagata S: Generalized lymphoproliferative disease in mice, caused by a point mutation in the Fas ligand. Cell 1994;76:969-976.

54 Rieux-Laucat F, Le Deist F, Hivroz C, Roberts IA, Debatin KM, Fischer A, de Villartay JP: Mutations in Fas associated with human lymphoproliferative syndrome and autoimmunity. Science 1995;268:13471349.

55 Takeda Y, Gotoh M, Dono K, Nishihara M, Grochowiecki T, Kimura F, Yoshida T, Ohta Y, Ota H, Ohzato H, Umeshita K, Takeda T, Matsuura N, Sakon M, Kayagaki N, Yagita H, Okumura K, Miyasaka M, Monden M: 
Protection of islet allografts transplanted together with Fas ligand expressing testicular allografts. Diabetologia 1998;41:315-321.

56 Igney $\mathrm{FH}$, Behrens $\mathrm{CK}$, Krammer $\mathrm{PH}$ : Tumor counterattack--concept and reality. Eur J Immunol 2000;30:725-731.

57 Adams AB, Pearson TC, Larsen CP: Heterologous immunity: an overlooked barrier to tolerance. Immunol Rev 2003;196:147-160.

58 Adams AB, Williams MA, Jones TR, Shirasugi N, Durham MM, Kaech SM, Wherry EJ, Onami T, Lanier JG, Kokko KE, Pearson TC, Ahmed R, Larsen CP: Heterologous immunity provides a potent barrier to transplantation tolerance. J Clin Invest 2003;111:1887-1895.

59 Gattinoni L, Lugli E, Ji Y, Pos Z, Paulos CM, Quigley MF, Almeida JR, Gostick E, Yu Z, Carpenito C, Wang E, Douek DC, Price DA, June CH, Marincola FM, Roederer M, Restifo NP: A human memory T cell subset with stem cell-like properties. Nature medicine 2011;17:1290-1297.

60 Lugli E, Dominguez MH, Gattinoni L, Chattopadhyay PK, Bolton DL, Song K, Klatt NR, Brenchley JM, Vaccari M, Gostick E, Price DA, Waldmann TA, Restifo NP, Franchini G, Roederer M: Superior T memory stem cell persistence supports long-lived T cell memory. J Clin Invest 2013;123:594-599.

61 Hamann D, Baars PA, Rep MH, Hooibrink B, Kerkhof-Garde SR, Klein MR, van Lier RA: Phenotypic and functional separation of memory and effector human CD8+ T cells. The Journal of experimental medicine 1997;186:1407-1418.

62 Ramaswamy M, Cruz AC, Cleland SY, Deng M, Price S, Rao VK, Siegel RM: Specific elimination of effector memory CD4(+) T cells due to enhanced Fas signaling complex formation and association with lipid raft microdomains. Cell Death Differ 2011;18:712-720.

63 Zhang HG, Su X, Liu D, Liu W, Yang P, Wang Z, Edwards CK, Bluethmann H, Mountz JD, Zhou T: Induction of specific T cell tolerance by Fas ligand-expressing antigen-presenting cells. J Immunol 1999;162:1423-1430.

64 Ogasawara J, Watanabe-Fukunaga R, Adachi M, Matsuzawa A, Kasugai T, Kitamura Y, Itoh N, Suda T, Nagata S: Lethal effect of the anti-Fas antibody in mice. Nature 1993;364:806-809. 
65 Takeuchi T, Ueki T, Nishimatsu H, Kajiwara T, Ishida T, Jishage K, Ueda $\mathrm{O}$, Suzuki H, Li B, Moriyama N, Kitamura T: Accelerated rejection of Fas ligand-expressing heart grafts. J Immunol 1999;162:518-522.

66 Tanaka M, Itai T, Adachi M, Nagata S: Downregulation of Fas ligand by shedding. Nature medicine 1998;4:31-36.

67 Askenasy N, Yolcu ES, Yaniv I, Shirwan H: Induction of tolerance using Fas ligand: a double-edged immunomodulator. Blood 2005;105:13961404.

68 Ottonello L, Tortolina G, Amelotti M, Dallegri F: Soluble Fas ligand is chemotactic for human neutrophilic polymorphonuclear leukocytes. $J$ Immunol 1999;162:3601-3606.

69 Seino K, Iwabuchi K, Kayagaki N, Miyata R, Nagaoka I, Matsuzawa A, Fukao K, Yagita H, Okumura K: Chemotactic activity of soluble Fas ligand against phagocytes. J Immunol 1998;161:4484-4488.

70 Suda T, Hashimoto H, Tanaka M, Ochi T, Nagata S: Membrane Fas ligand kills human peripheral blood T lymphocytes, and soluble Fas ligand blocks the killing. The Journal of experimental medicine 1997;186:20452050.

71 Yolcu ES, Askenasy N, Singh NP, Cherradi SEL, Shirwan H: Cell membrane modification for rapid display of proteins as a novel means of immunomodulation: FasL-decorated cells prevent islet graft rejection. Immunity 2002;17:795-808.

72 Askenasy N, Yolcu ES, Wang Z, Shirwan H: Display of Fas Ligand protein on cardiac vasculature as a novel means of regulating allograft rejection. Circulation 2003;107:41-47.

73 Yolcu ES, Askenasy N, Singh NP, Shirwan H: Prevention of islet allograft rejection with splenocytes displaying a novel form of FasL. Faseb $\mathrm{J}$ 2003;17:C278-C279.

74 Yolcu ES, Zhao H, Bandura-Morgan L, Lacelle C, Woodward KB, Askenasy N, Shirwan H: Pancreatic islets engineered with SA-FasL protein establish robust localized tolerance by inducing regulatory $T$ cells in mice. J Immunol 2011;187:5901-5909.

75 Rafael E, Tibell A, Ryden M, Lundgren T, Savendahl L, Borgstrom B, Arnelo U, Isaksson B, Nilsson B, Korsgren O, Permert J: Intramuscular autotransplantation of pancreatic islets in a 7-year-old child: a 2-year follow-up. Am J Transplant 2008;8:458-462. 
76 Basta G, Montanucci P, Luca G, Boselli C, Noya G, Barbaro B, Qi M, Kinzer KP, Oberholzer J, Calafiore R: Long-term metabolic and immunological follow-up of nonimmunosuppressed patients with type 1 diabetes treated with microencapsulated islet allografts: four cases. Diabetes Care 2011;34:2406-2409.

77 Maffi P, Balzano G, Ponzoni M, Nano R, Sordi V, Melzi R, Mercalli A, Scavini M, Esposito A, Peccatori J, Cantarelli E, Messina C, Bernardi M, Del Maschio A, Staudacher C, Doglioni C, Ciceri F, Secchi A, Piemonti L: Autologous pancreatic islet transplantation in human bone marrow. Diabetes 2013;62:3523-3531.

78 Zieris A, Prokoph S, Levental KR, Welzel PB, Grimmer M, Freudenberg U, Werner C: FGF-2 and VEGF functionalization of starPEG-heparin hydrogels to modulate biomolecular and physical cues of angiogenesis. Biomaterials 2010;31:7985-7994.

79 Phelps EA, Headen DM, Taylor WR, Thule PM, Garcia AJ: Vasculogenic bio-synthetic hydrogel for enhancement of pancreatic islet engraftment and function in type 1 diabetes. Biomaterials 2013;34:4602-4611.

80 Phelps EA, Enemchukwu NO, Fiore VF, Sy JC, Murthy N, Sulchek TA, Barker TH, Garcia AJ: Maleimide cross-linked bioactive PEG hydrogel exhibits improved reaction kinetics and cross-linking for cell encapsulation and in situ delivery. Advanced materials (Deerfield Beach, Fla) 2012;24:64-70, 62.

81 Phelps EA, Templeman KL, Thulé PM, García AJ: Engineered VEGFreleasing PEG-MAL hydrogel for pancreatic islet vascularization. Drug delivery and translational research 2015;5:125-136.

82 Weaver JD, Headen DM, Aquart J, Johnson CT, Shea LD, Shirwan H, García AJ: Vasculogenic hydrogel enhances islet survival, engraftment, and function in leading extrahepatic sites. Science Advances 2017;3:e1700184.

83 Graham JG, Zhang X, Goodman A, Pothoven K, Houlihan J, Wang S, Gower RM, Luo X, Shea LD: PLG Scaffold Delivered Antigen-Specific Regulatory T Cells Induce Systemic Tolerance in Autoimmune Diabetes. Tissue Engineering Part A 2013;19:1465-1475.

84 Gibly RF, Zhang X, Graham ML, Hering BJ, Kaufman DB, Lowe WL, Shea LD: Extrahepatic islet transplantation with microporous polymer scaffolds in syngeneic mouse and allogeneic porcine models. Biomaterials 2011;32:9677-9684. 
85 Salvay DM, Rives CB, Zhang X, Chen F, Kaufman DB, Lowe WL, Shea LD: Extracellular Matrix Protein-Coated Scaffolds Promote the Reversal of Diabetes After Extrahepatic Islet Transplantation. Transplantation 2008;85:1456-1464.

86 Hering BJ, Clarke WR, Bridges ND, Eggerman TL, Alejandro R, Bellin MD, Chaloner K, Czarniecki CW, Goldstein JS, Hunsicker LG, Kaufman DB, Korsgren O, Larsen CP, Luo X, Markmann JF, Naji A, Oberholzer J, Posselt AM, Rickels MR, Ricordi C, Robien MA, Senior PA, Shapiro AM, Stock PG, Turgeon NA, Clinical Islet Transplantation C: Phase 3 Trial of Transplantation of Human Islets in Type 1 Diabetes Complicated by Severe Hypoglycemia. Diabetes Care 2016;39:1230-1240.

87 Fan ZG, Spencer JA, Lu Y, Pitsillides CM, Singh G, Kim P, Yun SH, Toxavidis V, Strom TB, Lin CP, Koulmanda M: In vivo tracking of 'colorcoded' effector, natural and induced regulatory T cells in the allograft response. Nature medicine 2010;16:718-U125.

88 Gill RG, Rosenberg AS, Lafferty KJ, Singer A: Characterization of primary T cell subsets mediating rejection of pancreatic islet grafts. J Immunol 1989;143:2176-2178.

89 Ju S-T, Panka DJ, Cul H, Ettinger R, El-Khatib M, Sherr DH, Stanger BZ, Marshak-Rothstein A: Fas(CD95) FasL interactions required for programmed cell-death after T-cell activation. Nature 1996;373:444-448.

90 Watanabe-Fukunaga R, Brannan Cl, Copeland NG, Jenkins NA, Nagata $S$ : Lymphoproliferation disorder in mice explained by defects in Fas antigen that mediates apoptosis. Nature 1992;356:314-317.

91 Dhein J, Walczak H, Baumler C, Debatin KM, Krammer PH: Autocrine TCell Suicide Mediated by Apo-1/(Fas/Cd95). Nature 1995;373:438-441.

92 Lau HT, Yu M, Fontana A, Stoeckert CJ, Jr.: Prevention of islet allograft rejection with engineered myoblasts expressing FasL in mice. Science 1996;273:109-112.

93 Allison J, Georgiou HM, Strasser A, Vaux DL: Transgenic expression of CD95 ligand on islet beta cells induces a granulocytic infiltration but does not confer immune privilege upon islet allografts. Proc Natl Acad Sci U S A 1997;94:3943-3947.

94 Kang SM, Schneider DB, Lin Z, Hanahan D, Dichek DA, Stock PG, Baekkeskov S: Fas ligand expression in islets of Langerhans does not confer immune privilege and instead targets them for rapid destruction. Nature medicine 1997;3:738-743. 
95 Zhang $H$, Yang $Y$, Horton JL, Samoilova EB, Judge TA, Turka LA, Wilson $\mathrm{JM}$, Chen Y: Amelioration of collagen-induced arthritis by CD95 (Apo1/Fas)-ligand gene transfer. J Clin Invest 1997;100:1951-1957.

96 Schneider P, Holler N, Bodmer JL, Hahne M, Frei K, Fontana A, Tschopp $\mathrm{J}$ : Conversion of membrane-bound Fas(CD95) ligand to its soluble form is associated with downregulation of its proapoptotic activity and loss of liver toxicity. Journal of Experimental Medicine 1998;187:1205-1213.

97 O' Reilly LA, Tai L, Lee L, Kruse EA, Grabow S, Fairlie WD, Haynes NM, Tarlinton DM, Zhang JG, Belz GT, Smyth MJ, Bouillet P, Robb L, Strasser A: Membrane-bound Fas ligand only is essential for Fas-induced apoptosis. Nature 2009;461:659-663.

98 Yolcu ES, Askenasy N, Singh NP, Cherradi SL, Shirwan H: Cell membrane modification for rapid display of proteins as a novel means of immunomodulation: FasL-decorated cells prevent islet graft rejection. Immunity 2002;17:795-808.

99 Yolcu ES, Gu X, Lacelle C, Zhao H, Bandura-Morgan L, Askenasy N, Shirwan $\mathrm{H}$ : Induction of Tolerance to Cardiac Allografts Using Donor Splenocytes Engineered to Display on Their Surface an Exogenous FasL Protein. J Immunol 2008;181:931-939.

100 Askenasy N, Pearl-Yafe M, Mizrahi K, Yolcu E, Stein J, Shirwan H, Yaniv I: FAS-ligand enhances hematopoietic cell engraftment through abrogation of alloimmune responses and non-immunogenic interactions. Experimental hematology 2007;35:49-50.

101 Elpek KG, Yolcu ES, Franke DDH, Lacelle C, Schabowsky RH, Shirwan $\mathrm{H}$ : Ex vivo expansion of CD4(+)CD25(+)FoxP3(+) T regulatory cells based on synergy between IL-2 and 4-1BB signaling. J Immunol 2007;179:72957304.

102 Kurts C, Heath WR, Carbone FR, Allison J, Miller JF, Kosaka H: Constitutive class I-restricted exogenous presentation of self antigens in vivo. The Journal of experimental medicine 1996;184:923-930.

103 Stuart PM, Griffith TS, Usui N, Pepose J, Yu XH, Ferguson TA: CD95 ligand (FasL)-induced apoptosis is necessary for corneal allograft survival. J Clin Invest 1997;99:396-402.

104 Griffith TS, Brunner T, Fletcher SM, Green DR, Ferguson TA: Fas LigandInduced Apoptosis as a Mechanism of Immune Privilege. Science 1995;270:1189-1192. 
105 Perruche S, Zhang P, Liu Y, Saas P, Bluestone JA, Chen W: CD3-specific antibody-induced immune tolerance involves transforming growth factorbeta from phagocytes digesting apoptotic T cells. Nature medicine 2008;14:528-535.

106 Chen W, Frank ME, Jin W, Wahl SM: TGF-beta released by apoptotic T cells contributes to an immunosuppressive milieu. Immunity 2001;14:715725.

107 Fadok VA, Bratton DL, Konowal A, Freed PW, Westcott JY, Henson PM: Macrophages that have ingested apoptotic cells in vitro inhibit proinflammatory cytokine production through autocrine/paracrine mechanisms involving TGF-beta, PGE2, and PAF. J Clin Invest 1998;101:890-898.

108 Zhang N, Schroppel B, Lal G, Jakubzick C, Mao X, Chen D, Yin N, Jessberger R, Ochando JC, Ding Y, Bromberg JS: Regulatory T cells sequentially migrate from inflamed tissues to draining lymph nodes to suppress the alloimmune response. Immunity 2009;30:458-469.

109 Algeciras-Schimnich A, Griffith TS, Lynch DH, Paya CV: Cell cycledependent regulation of FLIP levels and susceptibility to Fas-mediated apoptosis. J Immunol 1999;162:5205-5211.

110 de la Rosa M, Rutz S, Dorninger H, Scheffold A: Interleukin-2 is essential for CD4+CD25+ regulatory T cell function. Eur J Immunol 2004;34:24802488.

111 Korsgren O, Nilsson B, Berne C, Felldin M, Foss A, Kallen R, Lundgren T, Salmela K, Tibell A, Tufveson G: Current status of clinical islet transplantation. Transplantation 2005;79:1289-1293.

112 Bennet W, Sundberg B, Lundgren T, Tibell A, Groth CG, Richards A, White DJ, Elgue G, Larsson R, Nilsson B, Korsgren O: Damage to porcine islets of Langerhans after exposure to human blood in vitro, or after intraportal transplantation to cynomologus monkeys: protective effects of sCR1 and heparin. Transplantation 2000;69:711-719.

113 Merani S, Toso C, Emamaullee J, Shapiro AM: Optimal implantation site for pancreatic islet transplantation. The British journal of surgery 2008;95:1449-1461.

114 Chen X, Zhang X, Larson C, Chen F, Kissler H, Kaufman DB: The epididymal fat pad as a transplant site for minimal islet mass.

Transplantation 2007;84:122-125. 
115 Salvay DM, Rives CB, Zhang X, Chen F, Kaufman DB, Lowe WL, Jr., Shea LD: Extracellular matrix protein-coated scaffolds promote the reversal of diabetes after extrahepatic islet transplantation. Transplantation 2008;85:1456-1464.

116 Blomeier H, Zhang X, Rives C, Brissova M, Hughes E, Baker M, Powers AC, Kaufman DB, Shea LD, Lowe WL, Jr.: Polymer scaffolds as synthetic microenvironments for extrahepatic islet transplantation. Transplantation 2006;82:452-459.

117 Gibly RF, Zhang X, Lowe WL, Jr., Shea LD: Porous scaffolds support extrahepatic human islet transplantation, engraftment, and function in mice. Cell Transplant 2013;22:811-819.

118 Yolcu ES, Askenasy N, Singh NP, Cherradi SE, Shirwan H: Cell membrane modification for rapid display of proteins as a novel means of immunomodulation: FasL-decorated cells prevent islet graft rejection. Immunity 2002;17:795-808.

119 Headen DM, Aubry G, Lu H, García AJ: Microfluidic-Based Generation of Size-Controlled, Biofunctionalized Synthetic Polymer Microgels for Cell Encapsulation. Advanced Materials 2014;26:3003-3008.

120 Lau HT, Yu M, Fontana A, Stoeckert CJ, Jr.: Prevention of islet allograft rejection with engineered myoblasts expressing FasL in mice. Science 1996;273:109-112.

121 Bunnag S, Allanach K, Jhangri GS, Sis B, Einecke G, Mengel M, Mueller TF, Halloran PF: FOXP3 expression in human kidney transplant biopsies is associated with rejection and time post transplant but not with favorable outcomes. Am J Transplant 2008;8:1423-1433.

122 Yapici U, Bemelman FJ, Scheepstra CG, Roelofs JJ, Claessen N, van der Loos C, van Donselaar-van der Pant K, Bouts AH, Idu MM, Rowshani AT, ten Berge IJ, Florquin S: Intragraft FOXP3 protein or mRNA during acute renal allograft rejection correlates with inflammation, fibrosis, and poor renal outcome. Transplantation 2009;87:1377-1380.

123 Hlavaty KA, Gibly RF, Zhang X, Rives CB, Graham JG, Lowe WL, Jr., Luo $X$, Shea LD: Enhancing human islet transplantation by localized release of trophic factors from PLG scaffolds. Am J Transplant 2014;14:1523-1532.

124 Zhao H, Woodward K, Shirwan H, Graham M, Hering B, Yolcu E: Porcine islets engineered to display $S A-F a s L$ protein on their surface induce tolerance in mice following transplantation into the liver or under the kidney capsule [abstract]. Am J Transplant 2016;16. 
125 Matsue $\mathrm{H}$, Matsue K, Walters M, Okumura K, Yagita H, Takashima A: Induction of antigen-specific immunosuppression by CD95L cDNAtransfected 'killer' dendritic cells. Nature medicine 1999;5:930-937.

126 Batteux F, Tourneur L, Trebeden H, Charreire J, Chiocchia G: Gene therapy of experimental autoimmune thyroiditis by in vivo administration of plasmid DNA coding for Fas ligand. J Immunol 1999;162:603-608.

127 Bossi G, Griffiths GM: Degranulation plays an essential part in regulating cell surface expression of Fas ligand in T cells and natural killer cells. Nature medicine 1999;5:90-96.

128 Chen JJ, Sun Y, Nabel GJ: Regulation of the proinflammatory effects of Fas ligand (CD95L). Science 1998;282:1714-1717.

129 Lau HT, Stoeckert CJ: FasL--too much of a good thing? Transplanted grafts of pancreatic islet cells engineered to express Fas ligand are destroyed not protected by the immune system. Nature medicine 1997;3:727-728.

130 Scott RS, McMahon EJ, Pop SM, Reap EA, Caricchio R, Cohen PL, Earp HS, Matsushima GK: Phagocytosis and clearance of apoptotic cells is mediated by MER. Nature $2001 ; 411: 207-211$.

131 Belghith M, Bluestone JA, Barriot S, Megret J, Bach JF, Chatenoud L: TGF-beta-dependent mechanisms mediate restoration of self-tolerance induced by antibodies to CD3 in overt autoimmune diabetes. Nature medicine 2003;9:1202-1208.

132 Chen W, Jin W, Hardegen N, Lei KJ, Li L, Marinos N, McGrady G, Wahl SM: Conversion of peripheral CD4+CD25- naive T cells to CD4+CD25+ regulatory T cells by TGF-beta induction of transcription factor Foxp3. The Journal of experimental medicine 2003;198:1875-1886.

133 Griffith TS, Ferguson TA: The role of FasL-induced apoptosis in immune privilege. Immunol Today 1997;18:240-244.

134 Chan WFN, Razavy H, Luo B, Shapiro AMJ, Anderson CC: Development of either split tolerance or robust tolerance along with humoral tolerance to donor and third-party alloantigens in nonmyeloablative mixed chimeras. $J$ Immunol 2008;180:5177-5186.

135 Stuart PM, Griffith TS, Usui N, Pepose J, Yu X, Ferguson TA: CD95 ligand (FasL)-induced apoptosis is necessary for corneal allograft survival. J Clin Invest 1997;99:396-402. 
136 Yap WT, Song WK, Chauhan N, Scalise PN, Agarwal R, Miller SD, Shea LD: Quantification of particle-conjugated or particle-encapsulated peptides on interfering reagent backgrounds. BioTechniques 2014;57:39-44.

137 Hunter ZN, McCarthy DP, Yap WT, Harp CT, Getts DR, Shea LD, Miller SD: A biodegradable nanoparticle platform for the induction of antigenspecific immune tolerance for treatment of autoimmune disease. ACS Nano 2014;8:2148-2160.

138 Hume PS, Anseth KS: Inducing local T cell apoptosis with anti-Fasfunctionalized polymeric coatings fabricated via surface-initiated photopolymerizations. Biomaterials 2010;31:3166-3174.

139 Berman DM, O'Neil JJ, Coffey LCK, Chaffanjon PCJ, Kenyon NM, Ruiz P, Pileggi A, Ricordi C, Kenyon NS: Long-Term Survival of Nonhuman Primate Islets Implanted in an Omental Pouch on a Biodegradable Scaffold. American Journal of Transplantation 2009;9:91-104.

140 Baidal DA, Ricordi C, Berman DM, Alvarez A, Padilla N, Ciancio G, Linetsky E, Pileggi A, Alejandro R: Bioengineering of an Intraabdominal Endocrine Pancreas. New England Journal of Medicine 2017;376:18871889.

141 Gregg RK, Jain R, Schoenleber SJ, Divekar R, Bell JJ, Lee HH, Yu P, Zaghouani $\mathrm{H}$ : A sudden decline in active membrane-bound TGF-beta impairs both $T$ regulatory cell function and protection against autoimmune diabetes. J Immunol 2004;173:7308-7316. 


\section{CURRICULUM VITA}

Name: Kyle Blake Woodward

\section{Education/Training}

\begin{tabular}{|c|c|c|c|c|}
\hline $\begin{array}{c}\text { Institution \& } \\
\text { Location }\end{array}$ & $\begin{array}{c}\text { Dates } \\
\text { Attended }\end{array}$ & $\begin{array}{c}\text { Degree (if } \\
\text { applicable) }\end{array}$ & $\begin{array}{c}\text { Conferred } \\
(\mathrm{mm} / \mathrm{yyyy})\end{array}$ & Field of \\
\hline $\begin{array}{c}\text { Brigham } \\
\text { Young } \\
\text { University }\end{array}$ & $04 / 2003-$ & BS & $04 / 2009$ & Microbiology \\
\hline University of & $08 / 2010-$ & MS & $12 / 2012$ & Immunology \\
Louisville & $12 / 2012$ & & & \\
\hline University of & $08 / 2010-$ & Ph.D & $08 / 2017$ & Immunology \\
Louisville & $08 / 2017$ & & & \\
\hline
\end{tabular}

Variances from Ordinary Career Progression 
From 2004-2006, I took a break from my undergraduate degree to complete a fulltime proselytizing mission for my church in Taiwan, where I learned to speak Mandarin Chinese.

Between finishing my B.S. in April 2009, and starting work on my Ph.D in August 2010, I worked at two different companies to support my family. I worked on quality control at VM Nutritional. I also worked on the Maintenance team at Ritewood Egg Farm.

\section{Positions/Employment}

\begin{tabular}{|c|c|c|c|}
\hline Dates & Position Title & Organization & Department \\
\hline 08/2007-04/2008 & $\begin{array}{c}\text { Organic Chemistry } \\
\text { Teachers } \\
\text { Assistant }\end{array}$ & $\begin{array}{c}\text { Brigham Young } \\
\text { University }\end{array}$ & Chemistry \\
\hline 04/2008-04/2009 & $\begin{array}{c}\text { Undergraduate } \\
\text { Research } \\
\text { Assistant }\end{array}$ & $\begin{array}{c}\text { Brighman Young } \\
\text { University }\end{array}$ & $\begin{array}{c}\text { Microbiology Lab } \\
\text { of Dr. Robison }\end{array}$ \\
\hline $08 / 2010-08 / 2017$ & $\begin{array}{c}\text { Ph.D } \\
\text { Student/Research } \\
\text { Assistant }\end{array}$ & $\begin{array}{c}\text { University of } \\
\text { Louisville }\end{array}$ & $\begin{array}{c}\text { Microbiology and } \\
\text { Immunology }\end{array}$ \\
\hline
\end{tabular}




\section{Memberships and Honors}

- 2015-2016 Member of Science Policy and Outreach Group (SPOG) of University of Louisville

- 2011-2012 Member of the American Association for the Advancement of Science (AAAS)

\section{Awards}

- Research! Louisville $20133^{\text {rd }}$ place Doctoral Basic Science/Engineering Graduate Students

\section{Publications}

1. Woodward K.B., Wang F., Zhao H., Yolcu E.S., Shirwan H. Novel technologies to engineer graft for tolerance induction. Curr Opin Organ Transplant. 2016 21(1):74-80.

2. Yolcu, E.S. H. Zhao, C. Lacelle, K.B. Woodward, L. Bandura-Morgan, N. Askenasy, and $\mathrm{H}$. Shirwan. Pancreatic islets engineered with SA-FasL protein establish robust localized tolerance by inducing T regulatory cells in mice. J. Immunol. 187:5901-9, 2011

3. H. Zhao, K.B. Woodward, O. Grimany-Nuno, H. Shirwan, and E.S.Yolcu Post-transplant systemic immunomodulation with SA-FasL-engineered donor splenocytes has robust efficacy in preventing cardiac allograft rejection in mice. Transplant Proc, 45.5 (2013): 1805-1807.

4. Woodward, K.B., H. Zhao, L. Bandura-Morgan, N. Askenasy, H. Shirwan, and E.S. Yolcu. SA-FasL-Engineered Islets Induce a Biphasic Spatiotemporal Allotolerance Requiring a Phagocyte/TGF- $\beta /$ Treg Axis. (Manuscript under review)

5. Woodward, K.B., H. Zhao, E.S. Yolcu, B. Hering, and H. Shirwan. SA-FasLengineered pig islets induce long-term xenotolerance in mice. (Manuscript in progress)

6. Woodward, K.B., and H. Shirwan. Immunomodulatory biomaterials induce allogeneic islet acceptance and reversal of diabetes without chronic immunosuppression. (Manuscript in progress) 


\section{Abstracts/Presentations}

1. Woodward, K.B., H. Zhao, S.K. Singh, H. Shirwan, E.S. Yolcu: Engineering islets with immunomodulatory proteins for the induction of tolerance and treatment of type I diabetes. 10th Kentucky Innovation Entrepreneurship Conference, Louisville, KY. September 5, 2014.

2. Woodward, K.B., E.S. Yolcu, H. Zhao, L. Bandura-Morgan, N. Askenasy, H. Shirwan: Pancreatic islets engineered to display on their surface an apoptotic form of SA-FasL induce localized tolerance via phagocytes/TGF- $\beta /$ Treg axes. Immunology 2014, Pittsburgh, PA. May 2-6, 2014.

3. Zhao, H., E.S. Yolcu, K.B. Woodward, N. Ahamad, L. Bandura-Morgan, N. Akenasy: SA-FasL-engineered rat pancreatic islets induces robust localized tolerance through TGF- $\beta / C D 4+C D 25+F o x P 3+$ Treg cells axis in mice. Immunology 2014, Pittsburgh, PA. May 2-6, 2014.

4. Woodward, K.B., Zhao, H., E.S. Yolcu, H. Shirwan. SA-FasL-engineered splenocytes require $B$ cells to induce tolerance to cardiac allografts. Research! Louisville, Louisville, KY. September 24-27, 2013.

5. Zhao, H., E.S. Yolcu, K. B. Woodward, H. Shirwan. Allogeneic pancreatic islets engineered to display on their surface a novel form of FasL protein induces both allo and autotolerance in spontaneously diabetic NOD mouse model. 24th International Congress of The Transplantation Society, Berlin, Germany. July $15-19,2012$

6. Yolcu, E.S., H Zhao, K.B. Woodward, H Shirwan. Pancreatic islets engineered with SA-FasL protein induces localized tolerance that is effective in preventing the rejection of a second set unmanipulated islet grafts transplanted under the contralateral kidney capsule during the induction, but not maintenance phase. 24th International Congress of The Transplantation Society, Berlin, Germany. July 15 - 19, 2012

7. Zhao, H., K. B. Woodward, H. Shirwan, E.S. Yolcu. Systemic immunomodulation with SA-FasL protein-engineered donor splenocytes induces robust tolerance to cardiac allografts in mice. 24th International Congress of The Transplantation Society, Berlin, Germany. July 15 - 19, 2012

8. Zhao, H., E.S. Yolcu, K. B. Woodward, H. Shirwan, Immunomodulation with pancreatic islets engineered to display on their surface a novel form of FasL protein induces auto and allotolerance in spontaneously diabetic NOD mice. The American Diabetes Association's 72nd Scientific Sessions, Philadelphia, PA, .June 8-12, 2012,

9. Yolcu, E.S., K.B. Woodward, H. Zhao, F. Wang, M. Graham, B. Hering, H. Shirwan, CD4+CD25+FoxP3+ Treg cells are critical to tolerance induction by SA-FasL-engineered porcine islets transplanted into mice. Abstracts of the 2016 TTS Congress August 18-23, 2016, Hongkong. Transplantation 2016, 100:S58. 
10. Yolcu, E.S., K.B. Woodward, H. Zhao, H. Shirwan. Dual phases and mechanistic basis of tolerance induced by allogeneic pancreatic islets engineered with SA-FasL protein. Abstracts of the 2016 TTS Congress August 18-23, 2016, Hong Kong. Transplantation 2016, 100:S58.

11. Yolcu, E.S., H. Zhao, K.B. Woodward, M. Graham, B. Hering, H. Shirwan. SA-FasL-engineered porcine islets induce tolerance in mice following intraportal transplantation. Abstracts of the 2016 TTS Congress August 1823, 2016, Hong Kong. Transplantation 2016, 100:S61.

\section{Skills}

- Extensive experience in panel design, staining, and analysis of 15parameter flow cytometry

- Proficient in tissue cutting, immunofluorescent staining, and analysis using confocal microscopy

- Trained and mentored seven people including high school students, rotating graduate students, and postdoctoral fellows

- Experience using Microsoft Office including exhaustive use of Excel in data analysis

- Proficient in mouse handling and treatment procedures

- Adept at preparing and perfecting protocols for new experiments 